Illinois State University

ISU ReD: Research and eData

Theses and Dissertations

6-30-2020

\title{
Applying Psychological Reactance Theory To Intercultural Communication In The Workplace: Dealing With Technological Change And Tolerance For Ambiguity
}

Oumaima Boulhna

Illinois State University, oumaima.boulhna@gmail.com

Follow this and additional works at: https://ir.library.illinoisstate.edu/etd

Part of the Communication Commons

\section{Recommended Citation}

Boulhna, Oumaima, "Applying Psychological Reactance Theory To Intercultural Communication In The Workplace: Dealing With Technological Change And Tolerance For Ambiguity" (2020). Theses and Dissertations. 1277.

https://ir.library.illinoisstate.edu/etd/1277

This Thesis is brought to you for free and open access by ISU ReD: Research and eData. It has been accepted for inclusion in Theses and Dissertations by an authorized administrator of ISU ReD: Research and eData. For more information, please contact ISUReD@ilstu.edu. 


\section{APPLYING PSYCHOLOGICAL REACTANCE THEORY TO INTERCULTURAL COMMUNICATION IN THE WORKPLACE: DEALING WITH \\ TECHNOLOGICAL CHANGE AND TOLERANCE \\ FOR AMBIGUITY}

\section{OUMAIMA BOULHNA}

\section{Pages}

Psychological reactance theory has yet to be applied to intercultural and cross-cultural communication, at least not to a sufficient extent. This study conducted a cross-cultural examination of psychological reactance in intercultural workplace communication situations. Using the theoretical framework of psychological reactance as well as the constructs of intercultural sensitivity and tolerance for ambiguity, this study expanded applications of PRT for technological change messages in the workplace. The present study extended the previous applications of psychological reactance theory and found a significant cross-cultural variation for trait reactance. The results also revealed that tolerance for ambiguity was negatively related to trait reactance, but not related to intercultural sensitivity. Intercultural emotional sensitivity and tolerance for ambiguity both predicted intercultural state reactance. The intercultural and crosscultural lenses of investigation extend PRT's applications to a context of organizational change management, thus merging otherwise disparate lines of inquiry.

KEYWORDS: psychological reactance, intercultural communication, tolerance for ambiguity, intercultural sensitivity, organizational change, cross-cultural communication 
APPLYING PSYCHOLOGICAL REACTANCE THEORY TO INTERCULTURAL COMMUNICATION IN THE WORKPLACE: DEALING WITH

TECHNOLOGICAL CHANGE AND TOLERANCE

FOR AMBIGUITY

OUMAIMA BOULHNA

A Thesis Submitted in Partial
Fulfillment of the Requirements
for the Degree of
MASTER OF SCIENCE
School of Communication
LLINOIS STATE UNIVERSITY

2020 
Copyright 2020 Oumaima Boulhna 


\title{
APPLYING PSYCHOLOGICAL REACTANCE THEORY TO INTERCULTURAL COMMUNICATION IN THE WORKPLACE: DEALING WITH TECHNOLOGICAL CHANGE AND TOLERANCE FOR AMBIGUITY
}

\author{
OUMAIMA BOULHNA
}

COMMITTEE MEMBERS:

Kevin R. Meyer, Chair

John R. Baldwin

Stephen K. Hunt 


\section{ACKNOWLEDGMENTS}

Thank you for considering this research as worthy of your time and to everyone who contributed to this project, directly or indirectly. I would like to express my deepest gratitude to my thesis chair, Dr. Meyer, for his continuous support, valuable advice, and tremendous efforts in making this research possible. Dr. Meyer was especially reliable and motivational, as well as relentlessly provided insightful unwavering directions when needed. His proficiency in academic research best practices, persuasive communication, quantitative methodology, as well as the editorial insights he provided were all instrumental for the successful completion of this project.

I would also like to thank my committee members, Dr. Baldwin and Dr. Hunt, for their interest in this study. Dr. Baldwin's in-depth knowledge about intercultural communication initiated intriguing theoretical and practical discussions complementing the purpose of this project. Thanks to his deliberate involvement, he provided me with useful sources to cite and kept his office door open for questions and feedback. Dr. Hunt's extensive knowledge on the topic of this thesis introduced insightful methodological and practical implications. His encouragement and far-sightedness compelled me to further contemplate the overall value of this work. I also cannot end this journey without recognizing the assistance that I received throughout this program from Patricia Franz with her valuable administrative support and those who volunteered their time to be participants in this study.

Many thanks to all the educators who once crossed my path and to all those who provided me with the tools to critically convert my thoughts into being. Special thanks to my family for always being there and friends for their profound belief in my abilities.

O. B. 


\section{CONTENTS}

Page

ACKNOWLEDGMENTS

TABLES

CHAPTER I: LITERATURE REVIEW

$\begin{array}{ll}\text { Psychological Reactance Theory } & 5\end{array}$

$\begin{array}{ll}\text { Likelihood of Responding } & 7\end{array}$

Size of Reactance as a Magnitude $\quad 9$

Additional Freedom Characteristics in Reactance 11

Behavioral, Cognitive, and Emotional Consequences 14

$\begin{array}{ll}\text { Theoretical Applications } & 16\end{array}$

$\begin{array}{ll}\text { State and Trait Reactance } & 18\end{array}$

$\begin{array}{ll}\text { Boomerang Effect } & 19\end{array}$

Reactance and Language $\quad 21$

Measuring Reactance $\quad 21$

$\begin{array}{ll}\text { Reactance and Technology } & 23\end{array}$

Intercultural and Cross-cultural Communication 25

Implications for Reactance Research $\quad 27$

Intercultural Interaction and Adaptation $\quad 29$

Intercultural Competence and Sensitivity 32

$\begin{array}{ll}\text { Tolerance for Ambiguity } & 37\end{array}$

$\begin{array}{ll}\text { Organizational Culture } & 40\end{array}$

Intercultural Communication in the Workplace $\quad 41$ 
Intercultural Interactions in Organizations

Technology in the Workplace

Research Questions

Conclusion

CHAPTER II: METHODS

Participants

Procedures

Scenario

Measures

Non-Scaled Items

Tolerance for Ambiguity

Trait Reactance

Intercultural Sensitivity

State Reactance

Data Analysis

Conclusion

CHAPTER III: RESULTS

Oneway ANOVAs

Research Question One

Research Question Two

Bivariate Correlations

State Reactance Regression Models

Research Question Five 
$\begin{array}{ll}\text { Hypothesis } & 70\end{array}$

$\begin{array}{ll}\text { Summary } & 73\end{array}$

$\begin{array}{ll}\text { CHAPTER IV: DISCUSSION } & 75\end{array}$

$\begin{array}{ll}\text { Summary of Findings } & 75\end{array}$

$\begin{array}{ll}\text { Research Question One } & 75\end{array}$

$\begin{array}{ll}\text { Research Question Two } & 78\end{array}$

$\begin{array}{ll}\text { Research Question Three } & 80\end{array}$

$\begin{array}{ll}\text { Research Question Four } & 81\end{array}$

Research Question Five $\quad 82$

$\begin{array}{ll}\text { Hypothesis } & 84\end{array}$

$\begin{array}{ll}\text { Implications } & 85\end{array}$

$\begin{array}{ll}\text { Practical Implications } & 85\end{array}$

$\begin{array}{lr}\text { Theoretical Implications } & 89\end{array}$

$\begin{array}{ll}\text { Limitations } & 94\end{array}$

Suggestions for Future Research $\quad 97$

$\begin{array}{ll}\text { Conclusion } & 100\end{array}$

$\begin{array}{ll}\text { REFERENCES } & 102\end{array}$

APPENDIX: SURVEY INSTRUMENT 124 


\section{TABLES}

Table

Page

1. Descriptive Statistics for Demographic Items

2. Factor Loadings for the Intercultural Sensitivity Scale 58

3. Factor Loadings for the Intercultural State Reactance Scale

61

4. Bivariate Correlations among Scales and Subscales for All Variables

5. Beta Weights for State Retaliation Regression Model

69

6. Beta Weights for State Arousal Regression Model

7. Beta Weights for Trait Reactance Predicting Intercultural State Retaliation

8. Beta Weights for Trait Reactance Predicting Intercultural State Arousal 


\section{CHAPTER I: LITERATURE REVIEW}

Humans encounter restrictions over which they might perceive they have little to no control. While culture influences this perception, it can also induce variations as to how people might react to limitations faced in everyday life. This speculation raises significant questions when it comes to the emotional, cognitive, and behavioral similarities and differences that people adopt when considering their various cultural backgrounds. Brehm’s (1966) psychological reactance theory (PRT) established a framework for how people react or do not react when they feel that freedoms are, or might be, taken away from them. However, further testing of the theory is needed to comprehend how intercultural situations may affect applications of PRT. Similar to the idea that people might see reality differently, when in a situation involving intercultural interaction, it is vital not to assume that they share the same perception of reality or assign the same value to what constitutes freedom. Considering the importance of perspective-taking, the present project theorizes that understanding cross-cultural reactions to limitations can be revealing for these human interactions.

Brehm's (1966) theoretical framework made valuable contributions, particularly in the areas of psychology, persuasion, and communication. However, his initial assumption that people inherently — and similarly_value the idea of freedom is one that this study attempts to test through applying his theory to intercultural interactions. Various scholars (e.g., Jonas et al., 2009; Sittenthaler \& Jonas, 2012; Sittenthaler, Jonas, \& Traut-Mattausch, 2016) described reactance as an experience which can occur across cultures. Steindl and Jonas (2012) explored PRT through a cultural lens using "perspective-taking” (p. 1154). Steindl and Jonas' study attempted to understand how to reduce reactance and particularly framed it as a negative and undesirable element of the persuasive communication process. The examination of Austrians and 
Filipinos' reactance classified participants into individualist and collectivist cultures. Their study found that there are variations for how people react depending on their cultural category and that people experience less intense reactance when they consider others' points of view. They found that individualistic cultures are more likely to react to a "self-experienced" (p. 1155) limitation compared to collectivists; however, they are less prone to experience it when the restriction is external. The researchers "consider culture to be a crucial determinant in predicting the amount of reactance" (p. 1153). Brehm's (1966) theoretical framework allowed for testing reactance and this intercultural application (Steindl \& Jonas, 2012) is an indicator of cross-cultural variations in reactance.

Regardless of all the freedoms people can enjoy, humans are complex beings who are full of inadequacies and insufficiencies. We are born into existence without choice of our anatomy, country of birth, parents, social class, and even our very existence. To address these limitations, some individuals may choose and be able to perform plastic surgery, change citizenship, claim new parents, or end their lives. However, it is evident through experience that life can be full of restrictions, some of which are beyond humans' capability to manipulate. From biological to environmental forces, humans are subject to various restrictions which are beyond their control. Moreover, some freedoms can be unattainable for people because of biological or contextual reasons. Biologically, although there are enough similarities between humans for them to belong to the same category of homo sapiens, there could be vital distinctions. There are various genders, heights, pigmentations, and organ structures. Societally, it does not take long for a properly socialized child to understand the rules indicating that they cannot take another child's toy. Similarly, children have experienced or heard from people around them, such as parents, teachers, or peers, that there are potential punitive consequences limiting their desires. Beyond 
physical restrictions, cultures can establish the line between what is permissible and what is not, as well as frame moral principles and ideas of what constitutes freedom. All in all, whether emanating from biological, genetic, or habitual predispositions, humans face limitations.

Cultural determinism (Graves, 1972) suggests that culture is what primarily differentiates societies. When applied to the concept of freedom, this perspective suggests the cultural element of what represents reality and freedom behaviors. While some cultural beliefs frame life events as predetermined, others suggest that people have free will to make their own choices. Sarkissian et al. (2010) examined people's values in the United States, Hong Kong, India, and Columbia, they found that people's intuitions about free will and moral responsibility have some level of cross-cultural convergence. This study's limitation was that it was conducted in the United States and, therefore, considered its findings as more suggestive rather than conclusive. Another publication, by Weinberg, Nichols, and Stich (2001), discussed the differences in perceptions of epistemic intuitions or intuitions that lead to knowledge between American, East Asian, and Indian participants. The authors study suggested that there are cultural variations in terms of cognitive processes, including perception, attention, and memory, which guide individuals' knowledge acquisition. Machery, Mallon, Nichols, and Stich (2004) confirmed the existence of cultural variations between East Asians and Americans regarding their intuitions about thought systems and semantics. This study suggested that Westerners are more prone to express instincts which derive meaning from past experiences, in contrast with meaning-making through language. This raises important speculations regarding the cultural and historical influences on people's meaning-making process. When considering the Western perspective of PRT, “one might suspect" that our intuitions and notions "about free will could show a similar sort of crosscultural variation" (Sarkissian et al., 2010, p. 350). Cultural determinism posits the influence of 
other dimensions on what constitutes a society, like history; however, it also suggests the particularities of each context.

There are various defining forces cross-culturally and numerous elements which illuminate contrast among cultures, and the concept of freedom is one example of these components. For instance, through cross-cultural adaptation (Oberg, 1960; Ruben \& Kealey, 1979; Kim, 2001; Zimmerman, Holman, \& Sparrow, 2003), people can adjust to cultural values of a host culture and this assimilation can occur through day-to-day intercultural communication. This suggests that the transferring of perceptions from culture to another is possible through interaction and exposure. Cultures vary not only in their different historical aspects, but also when it comes to other structures such as religion and political systems. Franck (1997) questioned the origin of the idea of personal freedom and argued for cultural variations in the understanding of cultural freedom. Through visiting various parts of the world, he denoted the significance of factors such as history, religion, and institutional structures in determining whether a culture advocates for or against freedom of conscience. While he analyzed this narrow aspect of freedom in terms of individuals' right to follow a religion or belief system, his study remains a potential indicator of these cultural variations of people's choice. In other words, if there are variations as to how cultures frame religious freedom, we might suspect the existence of such discrepancy on perceptions of freedom more broadly.

People express their resentment towards restrictions differently, and this is where Brehm's (1966) PRT addresses people's psychological states when they face a restriction to their freedom. Considering that not all cultures are the same, Brehm's constructing and testing of the theory through a Western framework raises significant questions as to what happens when people engaged in the restriction are from different cultures. Prominent intercultural scholars 
(c.f., Bennett, Aston, \& Colquhoun, 2000; Gudykunst, 2003; Hall \& Hall, 1989; Hofstede 1997;

Kim, 1988; Lewis, 1999; Ting-Toomey, 1994) established the influence of cross-cultural communication on meaning-making. Understanding people's views of the world and considering their backgrounds allows researchers to have a better understanding of how those people interact together and how this communication influences their experience of reactance (Brehm, 1966).

\section{Psychological Reactance Theory}

Brehm's (1966) PRT explains that, when individuals feel a threat, whether real or perceived, toward their freedom, they experience reactance. This psychological state motivates people to reinstate or restore endangered freedoms. PRT developed from social and clinical psychology and is also applied in communication research today (Rosenberg \& Siegel, 2018). Over half a century ago, Brehm outlined PRT to understand certain human emotions, cognitions, and behaviors. The main presumption of the theory is that individuals value freedom as a significant, useful, and prevalent element in their lives. The value individuals place on their freedoms and choices explains their urge to restore it when endangered (Brehm, 1966).

According to Brehm (1966), psychological reactance entails that a limitation, threat, or restriction of an individual's behavioral freedom would induce a motivational state of arousal. Freedom restriction may trigger an arousal, which leads to reactance. He also explained how reactance theory focuses on specific behavioral freedoms, rather than on freedom in general. He discussed how some behavioral freedoms can be independent from others namely, a person's inability to buy a distinct car brand does not necessarily influence their capacity to purchase another one. In other words, not all freedoms are inevitably interconnected, which entails investigating reactance on a case-to-case basis. Although Brehm stated the logical and psychological relatedness of certain behavioral freedoms, he further suggested considering how 
individuals prioritize them. A behavioral freedom which a person holds dearly does not equate to another which they do not care about. Considering this personal importance, any implied threat or elimination could potentially arouse reactance. Moreover, Brehm's often-discussed reactance theory from the level of individual experience, as opposed to the group or collective aspect. In other words, Brehm often describes reactance as an experience which occurs on the individual level, rather than as a group phenomenon. This theoretical individualization of the experience of reactance denotes the significance of exploring it from the level of social belonging and identity: This arousal would presumably be directed against any further loss of freedom and it would also be directed toward the re-establishment of whatever freedom had already been lost or threatened. Since this hypothetical motivational state is in response to the reduction (or threatened reduction) of one's potential for acting, and conceptually may be considered a counterforce, it will be called "psychological reactance." (p. 2)

To further explain PRT, Brehm and Brehm (1981) used the example of a child who would not eat green vegetables and how psychological reactance works as a persuasion technique to change the child's behavior. In this situation, the child dislikes and refuses to eat a vegetable. When the parents forbid the child from eating it, simultaneously, they are displaying enjoyment from consuming this vegetable in front of the child. This arouses the toddler, which leads the child to behaving as the parents manipulated. This example illustrates humans' tendency to behave counter to perceived imposed limitations. Brehm and Brehm also discussed the elements of freedom and choice as major influencers of what represents threat. For instance, they noted the freedom of an individual buying an item in terms of option availability and the individual's purchasing power and explain that a person who has the potential to buy an unlimited number of cars might not experience the same reactance which another individual might if they realize that 
the production of the only car brand they want is now limited. In this context, the authors explain the significance of social influence and denote how people can impact others' reactions. For example, they noted "that threat to control our freedom has important psychological consequences, and these consequences may be either beneficial or harmful” (p. 3). This explanation of PRT acknowledges its persuasive potential through social influence, as well as the perceptual element of freedom restriction, which can determine the extent of reactance.

\section{Likelihood of Responding}

The two main assumptions of PRT are that people claim ownership of a set of free behaviors they think they can enact and that it is psychologically arousing to them when they perceive their freedom as threatened (Brehm \& Brehm, 1981). In other words, PRT's components revolve around the presence of a perceived freedom which is conceptually possible, the elimination or threat of this freedom, a resulting arousal, and an attempt to restore the initial freedom. In fact, individuals do not think of all behaviors as a given right. Brehm and Brehm justified the definition of freedom with the existence of two circumstances: people's awareness of the freedom and feeling of capability in acting it out. They further explained that it is a perceptual concept, which means that the person subjectively defines it. In other words, freedom exists if people believe they have it and can do it. These underlying characteristics for PRT determine its theoretical framework and applications.

PRT specifies a definition for freedom and ways through which it can be endangered or eradicated, as well as ways through which the subsequent reaction may emerge. Brehm and Brehm (1981) based PRT on the premise that a perceived complete or partial loss of a freedom stimulates the person in question to want to protect and restore that freedom. Beyond behavioral outcomes, PRT denotes a perceptual nature which impacts the extent to which these prospective 
consequences are attractive. Brehm and Brehm provided the example of the commonality of this aspect for romantic couples, in that the desirability of one partner can be influenced by their perceived accessibility. In this context of persuasion, one partner provides an offer and then limits it to induce a perception of attractiveness. These examples illustrate that a reactance response may or may not include a subsequent action, depending on how the concerned person assesses the perceived threat.

Hass and Linder (1972) held experiments on counter-argumentation and the forming of messages. They cited Jones and Brehm (1970) on the significance of awareness or unawareness of loss of freedom to explain the strong relationship between awareness and message structure. The more aware people were of counterarguments, the more persuasion occurred. When twosided communication takes place and considers both parties' freedoms, there is less resistance to the message (Brehm \& Brehm, 1981). For instance, Hass and Linder (1972) described the role of acknowledging the interlocutor's argument early in the process along with providing adequate refutation is less likely to cause a defensive reaction to the persuasive attempt. Jones and Brehm's (1970) study is another example which demonstrated that audiences of a one-sided court trial prosecution communication were less convinced compared to those who were made aware that there are two plausible sides. People's awareness and knowledge about the situation, recognition of counterarguments, and perceived freedom within the communication process can also determine the reactance response.

Aside from the knowledge aspect of reactance, its arousal is dependent on the element of perceptual ability or feasibility. People must believe the freedom and the possibility to enact it exist simultaneously in order to experience reactance (Wicklund \& Brehm, 1968). Moreover, Wicklund and Brehm speculated that, for persuasion practices, expressions establishing 
preference are less likely to lead to reactance, in contrast with rigid statements which represent high-threat messaging. Brehm (1966) hypothesized that perceived ability or competence is dependent on previous experiences and success with these experiences. In other words, when people face a situation and are able to deal with it, they are more confident about it. Moreover, perceived competence stems from their own view of their achievement as well as society's approval of it. This further reinforces the situational element of perceived capability, which infers that people would experience reactance differently with situations they have encountered before, as opposed to ones they have not, or ones they have experienced in the past but failed or succeeded at manifesting their ability with (Brehm \& Brehm, 1981). Previous experiences can develop skills and confidence in a presumed outcome, which influences how they experience reactance.

\section{Size of Reactance as a Magnitude}

Reactance triggers arousal, which reaches its highest level when the restriction also reaches its maximum. In other words, PRT suggests that an absolute limitation on a freedom creates a countereffect of further desirability. Wortman and Brehm (1975) modified the theory to include instances when people willingly give up a freedom stemming from internal or external motivation; in these cases, people do not experience reactance. This makes the imposing of a restriction a significant condition for PRT. An instance of this includes learned helplessness, in which people surrender to a situation when the results are unknown. In this case, the subsequent research on this elimination of one's own freedom frames it as a concession which the individual makes to overcome their unpleasant condition (Wortman \& Brehm, 1975). Sacrificing freedoms, which Brehm and Brehm (1981) assume as inherently desirable, occurs solely when people perceive and are completely persuaded that there is no other alternative solution for them to 
adapt. In other words, the level of restriction has an impact on the response, and self-imposed restrictions do not induce the same results in comparison to ones which are other-induced.

Brehm (1966) measured reactance as a magnitude, which denotes its dimensional flexibility. To explain this, he stated that reactance varies depending on three elements. The first relates to the significance of the free action which is removed or threatened. The second describes the extent of which this free behavior is eliminated or endangered. The third addresses cases of a mere freedom threat, in which "the greater is the threat, the greater will be the magnitude of reactance" (p. 6). Contextually, the magnitude of freedom is immediately relevant to the significance of the freedom in relationship to the importance of other existing freedoms. This explains that when people provide convincing reasons to support that a restrictive situation is exceptional, this is likely to induce less reactance, and that is because this may persuade the person that this would not necessarily have an impact on similar or other freedoms (Brehm, 1966). Prior justification or provision of additional information accompanying freedom elimination or threat plays an important role in the magnitude of reactance. However, when a freedom is gone, regardless of the justification or its legitimacy, reactance would still occur.

In general, these conditions will create restraints against direct attempts at the restoration of freedom. For this reason, these conditions will tend to give rise to attempts at indirect restoration of freedom, such as through behavioral or social implication, when that kind of restoration is possible. (p. 8)

Indirect restoration of freedom implies the effect of reactance on people, which has the potential to motivate them to restore the freedom by all possible means (Brehm, 1966). Brehm further indicated that lack of clarity, contradictory information, or lack of knowledge on what constitutes a freedom can represent a limitation for adequately analyzing the reactance. For the 
purposes of this research study, discerning the role of various social and cultural characteristics on this varying psychological phenomenon is important.

Furthermore, Brehm's (1966) PRT entails that the restriction of freedom leads to negative aversive feelings from individuals. Elimination and threats to freedom occur when individuals are refrained from acting according to a specific behavior. Krishnan and Carment (1979) found

that the existence of help participants on a given task socially pressures participants into helping back. In this scenario, perceived restriction of freedom relates to the participant's feeling about providing the presumed favor. Differently put, these individuals did not perceive that they had the autonomy to accept or deny the request and, as a result, endured a state of arousal (Krishnan \& Carment, 1979). Freedom restriction activates arousal, which leads to reactance, and Brehm (1966) explained that the extent of this arousal depends on the intensity of freedom infringement and the threat.

\section{Additional Freedom Characteristics in Reactance}

Other characteristics of freedom relate to the perceived importance of the threat. The stronger the threat, the more arousal and reactance the individual experiences. Moreover, although few studies inspect this, when people perceive a freedom as unique in its ability to satisfy a need, the restriction tends to be more arousing (Goldman \& Wallis, 1979). Heilman and Toffler (1976), as well as Rains and Turner (2007), illustrated in their applications of reactance theory that overt and intense efforts of social persuasion entice significant resisting behavior. In this sense, and since both studies are over 30 years apart, the theory's assumptions practically and consistently survive the test of time. Moreover, the explicitness of the threat would further increase the reactance (Brehm, 1966). Heller, Pallak, and Picek (1973), in their research on the interactive effects of intent and threat on reactance attitude explained that restoration tactics of 
behavioral freedom are stronger in situations where participants are subject to high-intent influence from political confederates. In this scenario, high-intent influence referred to when the confederates displayed explicit intention of influencing the participants' attitude regarding the political issue. Andreoli, Worchel, and Folger (1974) demonstrated that reactance can also occur when participants perceive a third party as subject to a threat. Andreoli et al. affirmed that this reactance occurred because participants feared losing their own freedom from observing the threat on others. In their study of reactance, Sittenthaler et al. (2016) confirmed this type of observation-induced stimulation. The existence of a unique freedom, an intense threat, persuasive intent, or social influence can all increase the likelihood for reactance to occur. Brehm (1966) defined freedom of action through a point of view of realism, which considers the prevalence of the social context and the contextual implications that come with it. Brehm asserts that it can only be a free behavior if it is practically possible to achieve. He further distinguished various ways for how people attain these freedoms. An individual could reach a freedom through a contractual agreement with another entity, through self-motivation, or out of habit (Brehm, 1966). For instance, a person may rent an apartment through a written contract outlining what the tenant can do, they may gain the freedom to play a musical instrument by acquiring the knowledge to do so, or they may believe it is their freedom to litter in a public space because they have continuously done it in the past. Brehm determined that a freedom is a freedom only when people have the bodily and psychological capabilities for it. In other words, the realistic aspect of freedom entails that the person can exercise it and knows they can, either through past occurrence, consensus, or "general custom" (p. 4). Brehm specified various references for what drives free behavior, which can come from the individual or society. Fundamentally, contextualizing freedom as a societal component can explain how individuals 
from different backgrounds react to its threat. While various people, whether from the same culture or not, might value different freedoms to various degrees, the basis of PRT is that all cultures value freedom in general.

The theory discussed control and freedoms as essential elements which people anticipate possessing with variations of certitude (Brehm \& Brehm, 1981). Individuals tend to desire having a sense of control over their environment. Brehm and Brehm described control motivation as specific to a defined outcome, or the ability to have some margin of choice. They explained that, for reactance, there is a distinction between generalized control motives and reactive ones. The first refers to the control or attempt to "master the environment" (p. 367) in a general context, while the second is rather directed toward generating a desirable outcome from a specific situation of lost or threatened freedom. However, Brehm and Brehm explained that both forms of control lead to detrimental psychological feelings, namely, frustration. Beyond the element of control, although PRT assumes the importance of freedoms in general, it also describes reactance as a magnitude (Brehm \& Brehm, 1981). Wright, Agtarap, and Mlynski (2015) discussed the implications of PRT with a focus on motivation intensity. This research used Brehm's motivational intensity theory and distinguished between the intensity of the motivation and the magnitude of the behavior. The broad suggestion of this research entails that reactance does not automatically lead to behavior. Although it increases willingness for restoration, it also requires converting this drive into behavior depending on what the person perceives as possible and needed. Brehm and Brehm established that not only is the value that individuals place on the freedom important, but also the quantity of freedoms restricted. In this respect, perceptions of freedom and control allow these complementary concepts to indicate the extent of reactance. 
Brehm and Brehm (1981) conceptualized freedom as known and possible and determined that there are variances to reactance. A persuasion effort to change someone's thought or behavior can induce more reactance when it is tied to an "attitudinal freedom" (p. 13). They explained that a threat to an attitudinal freedom is one which endangers people's position through influence. Ueno and Ogawa (1983) investigated threats to attitudinal freedom and its impact on repeated persuasion through PRT. This experiment found that people's freedom to express their initial attitudes toward a perspective impacts the effectiveness of persuasion messages around this same position. In high threat conditions and when people could express their discontent since the first communication, reactance was reduced, and it was easier to convince them of changing their attitude. In another study, Ma, Tang, and Kay (2019) manipulated reactance through cognition rather than behavior. They found that persuasion efforts aiming at controlling people's thought and attitudinal process, rather than actions, led to greater reactance. Brehm and Brehm suggested that even implied threat to freedom, as opposed to explicit, can induce reactance.

\section{Behavioral, Cognitive, and Emotional Consequences}

Reactance operates on the level of cognition, emotions, and behavior; however, it involves two types of threats and two kinds of restoration techniques. Because reactance magnitude depends on the extent of a perceived threat (Steindl \& Jonas, 2012), Brehm (1966) distinguished between two types of reactance. The first relies on internal threats to freedom, which denote that people impose a decision on themselves by opting for a certain possibility over another. The second type of reactance is external, and it emerges from restrictive societal pressure, which aims at influencing individuals. Moreover, Steindl and Jonas (2012) confirmed that, after a person is aware of a threat, the motivational state of reactance leads to emotional, 
behavioral, and/or cognitive attempts to recover lost freedom. Brehm (1966) elaborated that, when going through reactance, individuals often feel discomfort, aggression, and anger. Further behavioral consequences happen as people attempt indirectly or directly to restore the freedom. Behaviorally, explicit reinstating of freedom is when people act out the restriction, while implicit restoration is when they externalize reactance through watching others' direct reactance (Brehm $\&$ Brehm, 1981). When it comes to reactance, recent literature on behavioral change differentiates between attitudes, intentional resistance actions, and performance (Steindl et al., 2015). Whether through internal or external perceived threats (Brehm, 1966), or through direct or indirect restoration (Brehm \& Brehm, 1981), reactance can occur on the level of the thought process, on the emotional level, or the behavioral level (Brehm, 1981).

Reactance can produce a behavioral consequence that can be counter to the purpose of the restriction. Brehm and Brehm's (1981) observation of reactance behaviors includes instances of participating in the same behavior which was limited. In other words, this is what Brehm (1966) referred to as the boomerang effect, which refers to when state reactance induces behavior oppositional to the intended influence (Brehm, 1966). This reactance effect constitutes a reversed consequence to the initially posed restriction. For instance, Brehm explained that underage students who were prohibited from drinking consume alcohol significantly more than adults do. Moreover, the researchers explain that motivation occurs to reestablish the threatened freedom through engaging in related social behavior, for example, spending time with those who are engaged in a prohibited behavior (Brehm \& Brehm, 1981). The boomerang effect of reactance highlights the complexity of human behavior and can lead to unexpected outcomes during the persuasion process. 
Reactance is a perceived and felt experience. Brehm and Rozen (1971) posited further outcomes of reactance on the emotions of the people who experience it. PRT explains that restrictions cause strong sensations; people who feel behaviorally controlled may perceive the prohibited or limited action as more desirable and appealing. Further results of research on perception and emotion relate to individuals' state of unease, which can project through experiencing a state of bitterness and hostility (Nezlek \& Brehm, 1975). Moreover, individuals can attempt to minimize their reactance, but eventually not succeed (Brehm \& Brehm, 1981). This indicates that it is in people's short-term benefit not to go through this unpleasant experience. In the occurrence of reactance, people could experience emotional eruption, enragement, or submission to the threat (Wortman \& Brehm, 1975). Wortman and Brehm explained that these are different ways of recognizing the menace and admitting their incapability of surpassing the restriction. The perceptual and felt element of reactance is an intense and unpleasant experience of dissonance for those who are experiencing it.

\section{Theoretical Applications}

The implementation of PRT from social and clinical psychology provide important insights for its development. Certain studies focus on the relationship between personality traits and the likelihood of experiencing arousal. For instance, Rhodewalt and Macroft (1988) showed that high achievers as more likely to experience reactance as opposed to individuals who work steadily but with less achievement. One of PRT's applications to clinical psychology relates to its facilitation of efficient therapy (Shoham, Trost, \& Rohrbaugh, 2004). Shoham et al. observed that PRT's recommendations contribute to facilitating clients' recovery because it helps therapists understand that freedom-restricting advice can result in a boomerang effect. Certain scholarly works confirmed the efficiency of paradoxical interventions (Rohrbaugh, Tennen, 
Press, \& White, 1981). This term refers to when therapists advise clients of continuing with their actions to achieve a reversed response of behavioral change (Rohrbaugh et al., 1981). While this reversed psychology technique works in given situations, it remains that the results of this reactance-based persuasion tactic are neither consistent nor reliable (DeBord, 1989).

Although much research on reactance theory comes from the field of psychology, Quick (2013) noted its pragmatism in communication research. The theory holds implications for the communication field in several ways. For example, threatening communication is more likely to spark reactance, which is why prominent researchers in the field analyze the impact of manipulating messages on reactance (Rosenberg \& Siegel, 2018). Rosenberg and Siegel's review of PRT-related research explained that more recent studies principally inspect two kinds of communication messages: The first is what they label as "controlling language," while the other is what they refer to as "autonomy-supportive language" (p. 6). Miller, Lane, Deatrick, Young, and Potts (2007) explained that controlling language uses words like "must" and "should," while autonomy-supportive language includes messages with less certain terms, such as "perhaps" and "maybe" (p. 223). By the same token, Bensley and Wu's (1991) research investigated the effect of messages with highly threatening content and found that it is more reactance-inciting for mitigating university students' alcohol intake.

Communication-related research not only regards the content of the message, but also its structure. According to Brehm and Brehm (1981), mentioning a reminder of freedom when concluding persuasive messages is an efficient tactic for minimizing the extent of reactance. In other words, when ending a persuasive message, stating that the receiver has the freedom to choose (i.e., low-threat) allows better messaging-efficiency and leads to less reactance. 


\section{State and Trait Reactance}

Researchers have delineated that reactance can be either trait or state. Dillard and Shen (2005) defined state reactance as a situationally induced reaction of negative cognitive and affective dimensions. It is a state which causes strong disinclination to action (Wicklund, 1974) and which comes instantly after a perceived threat of freedom (Brehm, 1966; Brehm \& Brehm, 1981). The consideration of state reactance as a result of anger and negative thoughts (Dillard \& Shen, 2005) emerged from Brehm’s (1966) framing of this psychological experience as comprised of feelings of hostility and aggressiveness, while the negative thoughts come from the cognitive process of counterarguing and defying the potential or imposed restriction. In other words, state reactance is an expression of an affective and cognitive experience that emerges from external situational forces of freedom limitation (Dillard \& Shen, 2005).

Although reactance was initially defined as a situation-specific phenomenon (Brehm, 1966), it was later reconsidered as an element which can differ in terms of how prone different individuals are to experience it (Brehm \& Brehm, 1981). People who tend to be reactant across contexts experience greater state reactance in comparison to those who are low in trait reactance (Erceg-Hurn \& Steed, 2011). For instance, teenagers who experience more reactance crosssituationally are more likely to be influenced by anti-smoking messaging compared to those who are low in trait reactance (Henriksen, Dauphinee, Wang, \& Fortmann, 2006). Hyland and Birrell (1979) discussed the impact of health communication campaigns on inducing state reactance and, therefore, making the persuasive messages less effective and even increasing the target's proneness to act contrarily to the desired effect. These instances illustrate the significance of this conceptual evolution, which led to a distinction between state and trait reactance, for understanding their various outcomes on the persuasive process. 
Although Brehm (1966) conceptualized reactance as a situationally induced state, several investigators dealt with reactance as stemming from one's personality trait. As a stable characteristic of personality determining general proneness to reactance (Miller et al., 2007), trait reactance has been applied across various fields. Trait reactance is a characteristic which occurs across contexts (Yost \& Finney, 2017). Yost and Finney describe the concept through its application to a variety of organizational, educational, and medical settings. It has also been used for various purposes, such as to explain the impact of marketing practices (e.g., Wendlandt \& Shrader, 2007). It was also applied to health communication (e.g., Dillard \& Shen, 2005) to improve the shortcomings of the persuasive process in this context. Ilie (2013) investigated trait reactance to understand the healthcare environment in relationship to job time restrictions, and how people are likely to react contrary to the intended purpose of communication practitioners and their health messages. Burgoon et al. (2002) found that trait reactance is more likely to occur with people who value their independence and are less likely to abide by social influence. Their autonomy entails a strong sense of self-perceived competence and ability to make choices, which induces oppositional feelings in an attempt to protect their freedom.

\section{Boomerang Effect}

A boomerang effect is when state reactance occurs in a manner which induces oppositional behavior to the intended influence (Brehm, 1966). This concept includes instances in which perceived freedom limitation results in an increased desire to engage in the relevant behavior. Quick and Stephenson (2007) classified boomerang effects into three types: direct, related, and vicarious. Direct boomerang effects, which Brehm's initial theory addresses, involve someone exercising the very behavior that has been restricted. Related boomerang effects consist of performing a behavior related to the one that has been restricted. A vicarious boomerang 
manifests itself in observing the freedom restoration behavior of others (Quick \& Stephenson, 2007).

A boomerang effect describes situationally induced reactance of oppositional behavior. Brehm (1966) explained that cancelling individuals' behavioral freedom through "impersonal events" (p. 18) over which they have very little to no control is likely to induce reactance. As a result, this response would enhance the desirability of this same eliminated behavior. Moreover, Brehm posed that the highest reactance response occurs when the most attractive possibility is removed in contrast to those which are available. As a response, frustration occurs, resulting in even more desirability to engage in the restricted behavior.

To mitigate a boomerang effect, Brehm (1966) suggested reducing the level of frustration the person might experience through not limiting the most attractive existing option, when possible:

It is conceivable that frustration would result in increased attractiveness of the goal object. In order to make sure frustration does not occur, so as to eliminate this frustrationattraction view as an alternative explanation, the choice alternative to be restricted must not be the most attractive one. (p. 19)

The intertwined relationship between frustration and attraction determines the level of experienced reactance and the likelihood of a boomerang effect to occur. Kulkarni, Wang, and Yuan (2019) investigated the negative impact of providing shoppers with incentives which lead them to unplanned buying decisions. They found that when people are reminded to buy a product during shopping, it creates a boomerang effect, increasing their likelihood of abandoning the search for their unplanned purchase. The study described promotional reactance in light of this negative reaction from shoppers and described ways to increase product attractiveness through 
allowing shoppers to claim these incentives (Kulkarni et al., 2019). Adapting communication messages for less frustration and more attractiveness of the desired outcome reduces the chances of a countereffect.

For Brehm (1966), the important element of a reactance response which increases the liking of a restricted behavior relates less to social threat, and more to "the loss of freedom per se, for whatever reason" (p. 28). One underlying assumption of this conceptualization is that it is the freedom that is important, rather than the argument supporting it. However, this statement also accepts the significance of freedom as a universal concept.

\section{Reactance and Language}

Miller et al. (2007) investigated reactance which young adults experience through the influence of controlling language in health messages. The results of the study determined that there are negative effects of promotional health messages when they include controlling language with young adults. The research also suggested more positive reactions on the part of the young adults when the researchers used persuasion. Miller et al. indicated that a focus on concrete language gains more attention and significance, and therefore it is considered more positive. Their linguistic contributions to persuasion determined that domineering language results in a negative perception of the source of the message. This controlling language includes direct imperatives of orders instead of suggestive language (McLaughlin, Schutz, \& White, 1980). In other words, direct and authoritative language is more likely to be perceived as freedom limiting, and therefore more reactance inducing.

\section{Measuring Reactance}

Brehm (1966) initially considered reactance as an element which is relevant to the situation. Nevertheless, many studies after his conceptualization regard it as a stable trait which 
can be determined across different contexts of freedom threat. The reason for this reframing emanates from Brehm's indication that people may experience varying amounts of reactance (Brehm, 1966). Brehm and Brehm (1981) further suggested that people have different ways of assessing threat to freedom depending on personality characteristics, influencing the level of reactance. Moreover, multiple academic studies (e.g., Dowd, Milne, \& Wise, 1991; Hong \& Faedda, 1996) explained that, predominantly, reactance studies heavily rely on considering reactance as a trait. Yet, several researchers question its reliability when used alone. Current research significantly uses trait reactance, however, not as a sole concept for understanding PRT. Hong's (1992) Psychological Reactance Trait scale measures trait reactance, which is the tendency or likelihood of experiencing reactance as a personal trait. Shoham et al. (2004) contradict the validity of Hong's measure for its lack of directness. They refute Hong's consideration of reactance as a trait because of its volatility and dependence on the intensity of the situation. Despite this criticism, these same researchers still defend the usefulness of this measure for clinicians, as long as its application is for a motivational situation (Shoham et al., 2004). Hong's scale remains the most frequently used measurement for trait reactance. Other instruments measuring this trait are scarce, mostly because PRT defines reactance as "an intervening, hypothetical variable" (Brehm \& Brehm, 1981, p. 37), and this conceptualization makes it challenging to establish a direct measurement. Nevertheless, Hong's (1992) application is valid when considering Miron and Brehm's (2006) description of reactance as a subjectively experienced emotion, along with the willingness to regain freedom.

Salzburger's State Reactance Scale (SSR) by Sittenthaler, Traut-Mattausch, Steindl, and Jonas (2015) underlined Brehm's (1966) definition of reactance as a situation-driven condition. Further presumptions for this scale rely on the idea that it is a subjective reaction inciting 
negative emotions of resentment, aggressiveness, and irritability (Dowd \& Wallbrown, 1993). Furthermore, Jonas et al. incorporated new elements to the SSR through assessing behavioral intentions. Sittenthaler et al. (2015) tested this measure by looking at the experience of reactance, negative attitude, and aggressive behavioral intentions. This study is useful in testing the validity of the scale and correlating its components. SSR highly correlates with other state reactance instruments (Sittenthaler et al., 2015).

\section{Reactance and Technology}

Researchers (e.g., Eyssel \& Hegel, 2012; Ham, Cuijpers, \& Cabibihan, 2015) have investigated the interaction between humans and technology. Eyssel and Hegel (2012) suggested that technologies with basic human-like output are sufficient to trigger social responses. Results of this research demonstrated that humans apply gender stereotypes to robots in a similar way they assign these social biases to humans. Ham et al.'s (2015) research on the persuasive ability of a robot using human-like gazing and movement suggested that this influence is comparable to strategic tactics used among humans. This research showed that, similar to human interaction, an artificial agent or a robot that used gestures when making eye contact with another individual became less convincing. This finding suggested that these human-like cues from artificial agents has an influence on the perceived credibility of the message. Ham et al. also asserted that some persuasion tactics from robots are not necessarily successful as they might be with human-human communication in influencing attitudes. In this study, gazing robots were more persuasive than those which added gestures. This interest in technologically mediated persuasion acknowledges a differentiation and an overlap between these interactions, which may infer similar implications for PRT. 
Ghazali, Ham, Barakova, and Markopoulos (2018) described people's response to persuasive attempts which induce of negative affect as leading to less compliance. In their study on persuasive messages from robots, they found that communication providing more social cues, namely human-looking facial and speech characteristics, induced a higher psychological reactance compared to when these cues are minimal to non-existent for the users receiving these messages. Ghazali et al. demonstrated that video games players are more likely to experience psychological reactance when they receive advice from a software displaying human characteristics, or what the research referred to as "social agency" (p. 59). In this research, participants played low to high psychological involvement games, in which gamers received impersonal to personal advice. Players were also exposed to various degrees of social cues, which varied from the game displaying text to the players viewing a robot mimicking human movement, expression, and intonation. Results of the research suggested that robots displaying forceful speech in combination with explicit persuasion intent led to high levels of reactance. This research confirmed that perception of robots' agency with high user-involvement is likely to infer a higher reactance response. Therefore, when technology combines high social cues, the likelihood of the success of the message in inducing a user-action is lower. Nevertheless, Ghazali et al. found that average levels of social cues from the output of the video game provoked the lowest psychological reactance results. These results align with Brehm's (1966) conceptualization of reactance as a magnitude which varies depending on the perceived intensity of the threat. The present study investigated PRT through a situation in which the inability to use a previously available technology represents the freedom restriction. 


\section{Intercultural and Cross-cultural Communication}

Although Brehm (1966) does not explicitly mention the element of culture as a significant component impacting reactance (c.f., Miron \& Brehm, 2006), it can be valuable for the research scene to further explore the plausibility of its role in reactance. Culture is a fluid concept as people use it depending on the context. There has not been a single and universal conceptualization of culture, which resulted in over three hundred different definitions of it (Baldwin, Faulkner, Hecht, \& Lindsley, 2006). Scholars often proposed clashing conceptualizations of this complex term (Kroeber \& Kluckhohn, 1952). Some literature described it as a manner of doing things (Schuck, Aubusson, Buchanan, \& Russell, 2012), which differs from group to group of people. Culture can also mean a functioning structural set of patterns and a system of traditions, ideas, behaviors, ideals, artifacts, and symbols (Baldwin et al., 2006). Baldwin et al. further explain that from an anthropological perspective, culture is "the complex whole which includes knowledge, belief, art, morals, law, custom, and any other capabilities and habits" (Tylor, 1871, p. 1), which society members obtain. Brislin (1981) referred to the concept as the result of a shared history, while Hofstede, Hofstede, and Minkov (2010) compared it to a "mental software" (p. 5) which distinguishes human groups. Baldwin et al. (2006) suggested that culture is an ever-changing notion through time and space, particularly as it is the result of a continuing human interaction.

Hall (1959) defined culture as the result of communication processes. "Culture is communication and communication is culture" (p. 186). This approach determined the significance of communication in reflecting and shaping culture. Certain cultural theorists, like Hall or Bennett (1986), focused on group differences to infer cultural statements. This theoretical lens suggests a level of membership homogeneity to denote a shared cultural identity. Cultural 
similarities can exist as a result of common environmental, historical, or biological factors (Creanza, Kolodny, \& Feldman, 2017). These various contextual forces emerge to determine and construct the communicative cultural process. Moreover, Baldwin (2018) described the need for a flexible conceptualization of culture, particularly within the globalized world in which people transcend traditional geographic boundaries through recurrent digital and physical exposure and interaction. His malleable definition might provide insights which consider the particularity of this globalized world and its specific dynamics of negotiation and resistance.

Although they are interconnected, the fields of intercultural and cross-cultural interaction have differences. Intercultural communication regards instances of communication which involve interlocutors from varying cultural backgrounds (Gudykunst, 2002), whereas crosscultural communication typically infers a comparative approach between different cultural settings (Hofstede, 1997). The intercultural domain investigates people's cultural convergence and adaptation as a result of their interaction, as well identity negotiation and management (Gudykunst, 2002). Hofstede's (1997) interest in international communication through the comparison of nations according to cultural dimensions suggests a cross-cultural lens. The two domains are related and intersect, as an understanding of cross-cultural communication deepens the comprehension of motives and origins of intercultural contexts, and visa-versa.

Adjustment to cultures is important for intercultural communication. Intercultural competence requires an awareness as well as a reduction of the gap between the cultures involved in the communication through effective and appropriate interaction (Sptizberg, 2000; Wiseman, 2002). Cross cultural adaptation theories (Oberg, 1960; Ruben \& Kealey, 1979; Kim, 2001; Zimmerman, Holman, \& Sparrow, 2003) refer to the challenges foreigners face as they become accustomed to the social expectations of a new host culture. Given the socialization 
process in cross-cultural adaptation, it is through intercultural communication that this adjustment can occur. It might be that through intercultural communication competence, adaptation can occur more effectively through meeting the purpose of the communication and maintaining appropriate interaction aligned with the other's social expectations. These conceptualizations suggest that a smoother adjustment might occur with people who are interculturally competent.

\section{Implications for Reactance Research}

Since intercultural communication is complex and because psychological theories may have limitations regarding their adaptability to multiple cultures, applications of PRT must also consider culture. Patel, Li, and Sooknanan (2011) discussed intercultural communication relative to individuals' personal daily experiences and explained that perspective-taking facilitates crosscultural interactions. With an exponential rate of technological advancement that allows people to travel faster and communicate through various instantaneous channels, intercultural human contact is greater than ever (Patel et al., 2011). History plays a significant role in shaping cultures' present state and future direction. Patel et al. argued that Western influences and traditions in education can create a biased lens in intercultural research. Azuma (1984) referred to this bias in the application of psychological theories and described psychological phenomena as inherently constrained by culture.

Although there have been contributions to psychology from other civilizations tracing back to ancient Egypt (Bynum, 1992), the Western perspective dominates contemporary psychology (Azuma, 1984). Moreover, Jonas et al. (2009) suggested that, often, theories which are established by Western theorists and often applied to Westerners are restricted in their ability to capture other contextual values. Jonas et al. discussed the tendency for such theories to focus 
on individualistic notions of freedom. Psychological phenomena such as reactance arousal would inherently be constrained by culture, suggesting that when a theory is constructed in one context, it does not necessarily apply to another. Brehm's (1966) reactance theory also reflects modern psychology limitations.

The Western paradigm has made notable contributions to theories dictating social knowledge; however, some psychological theories need intercultural and cross-cultural applications to establish validity. Triandis (1996) described the theory-to-ground gap in research as limiting and stated that, "if psychology is to become a universal discipline it will need both theories and data from the majority of humans" (p. 407). Prominent non-Western researchers have produced research that makes a comprehensive framework for psychological theories and applications incrementally attainable, for instance, Hui and Triandis (1986) on individualism and collectivism, Kim and Berry (1993) on individual psychologies, and Kitayama, Markus, and Lieberman (1995) on the collectivistic perspective of self-esteem. Triandis (1996) confirmed that, because of such non-Western contributions, we know "each culture may have, at least to some extent, its own psychology" (p. 407). Moreover, Kim and Berry (1993) discussed the notion of indigenous or native psychology as distinct and simultaneously sharing characteristics with contemporary or Western psychology. To illustrate this, they explained that, when scholars compare cultures, "culture-specific characteristics" and "shared characteristics" (p. 8) emerge. Reconsidering the dominant premises of psychology to reach what Triandis referred to as "universal psychology" (p. 407), one which considers cultural variations, is both a possible and desirable aim for a holistic approach to understanding human behavior, especially crossculturally. Investigating PRT (Brehm, 1966) across various cultures, as well as within intercultural contexts can reveal developments of its methodological instruments, as well as may 
disclose new conceptual connections either further reinforcing or weakening its initially posited framework.

\section{Intercultural Interaction and Adaptation}

Interaction between cultures involves a recognition of one's and others' identity. Several scholars discuss culture as a sort of software indicating the way humans ought to do things (Hofstede, 1997; Kluckhohn, 1951; Kluckhohn, Kelly, \& Linton, 1945). Culture can be socially constructed, which entails that people's software can be updated for a more appropriate contextual compatibility during interaction. Moreover, Brislin's (1981) view on culture explains that it is relevant to group identity and connection. The view dividing cultural groups into nations suffers some limitations because it does not consider Brislin's group characteristics, such as shared experiences and history. In this instance, the definition of cross-cultural matters often varies due to fluctuating definitions of culture (Hall, 1959; Martin \& Nakayama, 2000). Moreover, intercultural interaction competence stems from understanding group differences, such as individual values and institutional structures (Spitzberg \& Changnon, 2009). In other words, increased intercultural communication difference can lead to greater difficulty in achieving competence.

While there are various approaches to intercultural communication competence, the semiotic one entails that people understand codes through their own cultural references (Beamer, 1992). In other words, people decode meaning through what they have learned from their habitat. This perspective evokes differences in how messages are viewed and rooted in societal norms, which can vary from one culture to another (Hall, 1959). The semiotic approach relies upon interpreting messages through existing cultural structures (Beamer, 1992). 
Culture shock can occur in cross-cultural settings (Jack, 2014) when individuals deal with unforeseen cues which they do not know how to handle (Gaw, 2000). Spitzberg and Changnon (2009) discussed that, in regard to cultural learning, the concept of culture shock has been employed to explain transcultural adaptation and the psychological stress which comes with it. And, although the concept regards separate cultures, there are variations for the circumstances which induce it. For instance, a transition from one social class environment to another is likely to lead to culture shock, or in other instances in which individuals move to a different country for various purposes, like working (Ruben, 1989). From a pragmatic perspective, learning cultural codes is useful for updating people's cultural software into a transcultural version in which they can find shared meaning in today's global workplaces. From national cultural differences to international business environments, boosting intercultural communication competence can allow businesses to benefit from a better communication, and therefore reduce the likelihood of error and increase return on investments.

Oberg's (1960) definition of culture shock describes it as a person's challenge to understand their environment and to determine how to act, whilst experiencing daily anxiousness. The term emerged for studies on expatriates, in which individuals move to a different geographic area for a living. There are several views on culture shock and adaptation in scholarly research: from Oberg's (1960) U-curve to Kim's (2001) spiral conceptualization of adaptation. Cross-cultural studies are often linked to adaptation (Ruben \& Kealey, 1979; Zimmerman, Holman, \& Sparrow, 2003).

Kim's (2001) cross-cultural adaptation theory refers to the continuous stress of embarking into a new confounding cultural environment, and that is over an extended time frame. It involves individuals who move from one geographic area to another; for example, 
short-term travelers, sojourners, and immigrants (Kim, 2001), as well as applies to instances of adjustment to work (Adler, 1981) or educational environments (Liu \& Gallois, 2014). This theory is highly useful but has its limitations. Cross-cultural adaptation theory first presupposes that adaptation eventually occurs for most people. It disregards instances of voluntary or involuntary resistance to the integration process. Moreover, Kim's concept of host conformity pressure further describes how foreigners go through societal expectations on foreigners to adhere to the cultural system of the host country. In comparison, reactance theory (Brehm, 1966) is an example of a framework which accounts for individuals' discomfort in what feels like a restrictive situation. Although Kim's theory particularly describes cross-cultural transitions, it does broadly assume that traveling individuals are mostly free or that they mostly feel as such. Brehm's (1966) theory explained that resistance can occur, as opposed to Kim's presumption of humans' inherent willingness to conform.

Adaptation research (Ruben \& Kealey, 1979; Zimmerman, Holman, \& Sparrow, 2003) provides insights for the complexity of the cross-cultural and intercultural communication processes. It implies that individuals who have been exposed to these contexts of interaction are distinct in their perception of the world, as well as in their levels of communication competence (Spitzberg, 2015). Such considerations infer that general conclusions which are made concerning independent cultures, such as Hofstede's (1997) work, might be relevant within the limits of those populations; however, they might not apply similarly to those who have been through intercultural or cross-cultural exposure.

Gudykunst (2003) described that the intercultural adjustment of foreigners, which is a significant component for building a global community (Patel et al., 2011), involves people’s ability to be in a culture which fulfills their human need for meaning in the midst of a 
continuously volatile and uncertain environment. Although being part of a third culture does not entail that people would have to let go of their individuality (Gudykunst, 2003), it does imply an important adaptation process (Casmir, 2013). Thus, this reveals that investigating a cross-cultural context, where various forms of negotiation are likely to occur, such as the workplace, necessarily implies considering the impact of the adaptation process. In other words, an international employee who has spent two months in a company would not have a similar experience to another employee who has worked there for five years or more. Although the time can indicate adaptation, it does not ensure it in cases in which an individual is unwilling to adapt.

Cross-Cultural Adaptation theory (Oberg, 1960) explains that an adaptation phase is likely to occur beyond the first three to six months of living in and interacting with the new cultural environment, as a challenging learning process for adjustment. He adds that, an individual who just arrived in a foreign country is likely to experience a honeymoon phase, while at a later stage, the same person can experience a crisis period or culture shock (Oberg, 1960; Kim, 1988). The spiral nature of adaptation, as explained by cross-cultural adaptation theory, denotes a two-step-forward and one-step back motion of progress (Kim, 1988). The journey of integration is gradual and generally moves forward despite minor setbacks.

\section{Intercultural Competence and Sensitivity}

Intercultural communication competence describes people's willingness, awareness, and skills to successfully and appropriately interact with those who are from other cultures (Wiseman, 2002). Intercultural communication competence comprises significant characteristics for explaining the cross-cultural experience. Moreover, communication competence emerged from a body of literature which is concerned with the enhancement of cross-cultural experiences 
through adaptation, effectiveness, and satisfaction (c.f., Guthrie \& Zektick, 1967; Ruben \& Kealey, 1979).

Ruben (1989) explained communication competence as occurring as a result of adjustment efforts to cope with the host culture. A further definition of intercultural communication competence is as follows:

Competence has been variously equated with understanding (e.g., accuracy, clarity, coorientation, overlap of meanings), relationship development (e.g., attraction, intimacy), satisfaction (e.g., communication satisfaction, relational satisfaction, relational quality), effectiveness (e.g., goal achievement, efficiency, institutional success, negotiation success), appropriateness (e.g., legitimacy, acceptance, assimilation), and adaptation. (Bok, 2009, p. 6)

Nevertheless, there are various applications to intercultural communication competence. Intercultural communication competence is a significant asset for travelers and international interpersonal encounters, especially when a business purchases another company's shares (Spitzberg, 2015). According to Koester and Lustig (2015), intercultural communication competence does not primarily revolve around the behavior, but rather around the social perception that it creates. It is thus the perceived value or advantage (Martin, 2015) of “efficiency, adequacy, and satisfaction” (Topçu \& Eroğlu, 2017, p. 49324). The utility in this conceptualization justifies the significance of such competence as a probable competitive advantage. Koester and Lustig (2015) further explained that learning elements from a foreign culture, such as the language or customs, is a cross-cultural capacity which is useful but less indepth compared to intercultural communication competence. 
Scholars approached intercultural communication competence through various ways. Gudykunst (2003) focused on who is involved in the interaction and asserted the difference between interpersonal and intergroup communication. Triandis (1995) viewed communication competence from the perspective of cultural dimensions, such as individualism-collectivism. Other approaches consider self-identity within a culture as a self-construct, rather than an otherconstruct (Collier, 1989). These various underlying frameworks shape the criteria for what constitutes effective and appropriate communication, which reaches the intended objective of interaction (Spitzberg \& Cupach, 1984). In this sense, for intercultural communication competence to be effective and appropriate, it must be targeted in a clear manner which optimizes the chances for reaching the desired communication outcome through awareness of the cultural gap in a non-judgmental manner (Sptizberg, 2000; Wiseman, 2002), as well as it should generally avoid violating socially expected rules (Spitzberg, 2000).

There has been criticism to conceptualizations of communication competence, which has led to the inclusion of sub-concepts for a better definition, such as intercultural sensitivity. Spitzberg and Changnon (2009) posited that research operationalizing intercultural competence lacked generalizability because it did was only applied within Western European and North American contexts. There are gaps in communication competence measurement, such as for the purpose of intercultural trainings (Chen \& Starosta, 2000), as well as attitudinal and behavioral elements for assessing cross-cultural skills (Chen \& Starosta, 2016; Spitzberg \& Cupach, 1984). This resulted in the integration of intercultural awareness, adroitness, and sensitivity (Fritz, Mollenberg, \& Chen, 2002). The first relates to the cognitive aspect of the process, which assesses people's ability to comprehend one's culture in contrast to another's. The second describes the behavioral element of the intercultural situation, which communicators enact while 
successfully reaching communication goals. The third refers to people's emotional desire to recognize, value, and accept cultural dissimilarity. Sensitivity revolves around psychological components applying to the individual, namely, "self-esteem, self-monitoring empathy, openmindedness, nonjudgmental, and social relaxation” (Fritz et al., 2002, p. 167).

Intercultural sensitivity, or the capability to adapt to those from other cultures, is one dimension of intercultural communication competence (Spitzberg \& Cupach, 1984). Chen and Starosta's (2000) definition of intercultural sensitivity is significant for this research. Bennett (1986) described those who enjoy intercultural sensitivity as capable of adapting through shaping themselves cognitively, affectively, and behaviorally, while Dong, Day, and Collaço (2008) described that high levels of intercultural sensitivity are negatively related to ethnocentrism. Nevertheless, Chen and Starosta's (2000) distinction between the three dimensions of awareness, adroitness, and sensitivity provided clarity for distinguishing of each one of them, to eventually evaluate intercultural communication competence. Chen and Starosta's definition of intercultural sensitivity considered that:

Interculturally sensitive persons are able to reach the level of dual identity and enjoy cultural differences by gradually overcoming the problems of denying or concealing the existence of cultural differences and attempting to defend their own world views, and moving to develop empathic ability to accept and adapt cultural differences. (p. 3)

This conceptualization denotes that acquiring intercultural sensitivity puts the communicator in an advantageous position for reaching their intended goal. Through this definition, this research speculates that a person who is interculturally sensitive might experience less reactance (Brehm, 1966) because their personal traits might favor such results. The definition of sensitivity also does not place one identity over another, but rather acknowledges the potential for both, or more, 
to coexist and define the same person. Most importantly, this definition of intercultural sensitivity discloses the key element to what makes it significant for this research, which relates to a positive and enjoyable adaptation experience.

Two aspects of intercultural sensitivity are self-monitoring and open-mindedness (Chen \& Starosta, 2000). During intercultural interaction, people who pay close attention to how they can adapt to better fit social situations, or high self-monitors, are inclined to be more alert and concerned with their culturally different interlocutor's expressions (Berger \& Douglas, 1982). Moreover, people who are open-minded are willing to engage in self-explanation and welcome the other person's explanation (Chen \& Starosta, 2000). Smith (1966) described this openmindedness as the readiness to acknowledge, accept, and enjoy different perspectives of what could constitute reality through the consideration of others' particularities. He further contends that it is not enough to have these characteristics, but also be able to convert them into actions during intercultural communication. Self-monitoring and open-mindedness are components of sensitivity which partially describe the intercultural experience.

Empathy, interaction involvement, and non-judgment are also indicators for intercultural sensitivity (Chen \& Starosta, 2000). Empathy is perspective-taking ability (Gardner, 1962), which several scholars adopted as a concept for understanding the sensitivity aspect of crosscultural interactions (e.g., Bennett, 1986, Chen \& Starosta, 1997). This concern for people’s emotions and responses through active listening and grasping of the intercultural context (Parks, 1994) translates to the idea that the more empathetic a person is, the more likely they are to be interculturally sensitive (Chen \& Starosta, 2000). Moreover, the level of interaction involvement describes a person's responsiveness, attentiveness, and perceptiveness to the interaction, which reinforces the likelihood for an appropriate intercultural conversation (Chen \& Starosta, 2000). 
Finally, non-judgment regards when individuals genuinely consider others' messages while mitigating the influence of their own predispositions (Chen \& Sarosta, 2000). Being nonjudgmental allows for intercultural sensitivity, since it serves to reduce internal communication interferences, as opposed to letting biases be the driving force of the cross-cultural process (Fiedler, Mitchell, \& Triandis, 1971). Empathy, interaction involvement, and non-judgment combined provide a better comprehension of intercultural sensitivity.

Intercultural communication sensitivity provides a solid conceptual framework for investigating people's ability to engage in intercultural contexts with ease, as well as effectively and appropriately (Chen \& Sarosta, 2000). The improvement of culturally diverse workplace environments implies the understanding of their constituents' competence with engaging in exchanging information, for instance, when implementing cross-cultural trainings (Chen \& Starosta, 2000). Communication sensitivity has the potential to reveal the impact of such human soft skills on reactance (Brehm, 1966), or intercultural reactance. This study will explore the level of individuals' emotional sensitivity for adaptation, to reach a better understanding of workplace reactance cross-culturally.

\section{Tolerance for Ambiguity}

McLain, Kefallonitis, and Armani (2015) described tolerance of ambiguity as a concept which has evolved conceptually and operationally. McLain et al. alluded to 65 years of research contributions of this concept, such as for trait research and measurements. The concept has been used through sociological (Frenkel-Brunswik, 1948), personality trait (Budner, 1962), as well as organizational and national approaches (Furnham \& Ribchester, 1995).

Frenkel-Brunswik (1948) defined tolerance for ambiguity as a personality trait which determines people's judgment of the world. She explained that those who lack tolerance for 
ambiguity tend to view the world through an either-or lens, leading to premature evaluations of the world. The motivation behind this fallacious tendency is to seek for certain and clear answers, even if at the expense of a rejection others. Nevertheless, Budner (1962) narrowed this definition and described intolerance for ambiguity as the tendency to interpret the world from the lens of a threat, straying away from undesirable contexts and stimuli. Similarly to PRT, tolerance for ambiguity can make some choices attractive and others less attractive, all for the purpose of eliminating the unpleasant experience of the unknown, which can arise from dealing with ambiguity. Einhorn and Hogarth (1986) conducted research reinforcing the relationship between tolerance for ambiguity and cognition, as a lack of perception of the various possible interpretations in a situation (Weick, Sutcliffe \& Obstfeld, 2005). Adorno, Frenkel-Brunswik, Levinson, and Sanford (1950) referred to it through the cultural lens, which determines a tendency to reject what people deem as unfamiliar to them. Similarly, Brehm and Brehm's (1981) trait reactance refers to a perceptual trigger of threat, which motivates restoration efforts to mitigate an unwanted experience.

Fearing the unknown is a human experience which societies deal with it differently (Hofstede, 1997). Hofstede's psychological approach to intercultural studies suggests that, to mitigate the psychological consequences of this unpleasant feeling, people have created coping mechanisms which vary from culture to another. He explained that ambiguity adaptation manifests through rule of law, religious faith, and technological tools. Humans have established laws to elevate uncertainty and create safe environments. For instance, Noort, Reader, Shorrock, and Kirwan (2016) used Hofstede's theoretical framework to apply a cultural dimension to safety practices. This research indicates that national cultural tendencies impact organizational safety culture, and it supports the relationship between ambiguity avoidance and safety culture in cross- 
cultural settings (Noort et al., 2016). Religion is also a way of facing natural phenomena, interacting with people's perception of free will, as it creates a framework for dealing with the uncertainties of the future (Hofstede, 1997). For instance, religion can provide comfort to individuals and societies through ideologies of determinism and beliefs about what life after death constitutes (Hofstede, 1997). Hofstede noted that, similarly, technology is a tool which helps people navigate the world while avoiding uncertainties. Technology, from its primitive to sophisticated forms, has the potential of delivering reliable results transcending the limitations of human capacity. By the same token, when technology fails to achieve this purpose, it can transform into a threat.

Hofstede (1997) considered uncertainty as an internal experience. Although it is an individual subjective feeling, he also describes it from a societal perspective: "Those feelings and the ways of coping with them belong to the cultural heritage of societies and are transferred and reinforced through basic institutions" (p. 110). These adjustment mechanisms, therefore, vary from one culture to another. Individuals do not necessarily rationalize them or enact them through logical reasoning, although they might do so in certain cases; rather the mechanisms are deeply rooted in distinct societal values, passed on from one generation to the next. Hofstede asserted that studies of personality are distinct from those investigating culture. Tolerance for ambiguity regards how people deal with perceived inadequate or lack of information or incompatible perceptions (Budner, 1962), while uncertainty avoidance deals with society’s programming of its individuals to tolerate unstructured contexts (Hofstede, 1997). Both constructs deal with ambiguity and people's effectiveness in coping with change.

Hofstede's (1997) uncertainty avoidance considered people's level of anxiety rather than fear, in which anxiety is a relatively more intense experience. Also, ambiguity regards people's 
potential for dealing with more than one interpretation of the world, Pettigrew (1958) discussed that people classify their understanding of the world into categories. He explained that people who perceive that there more ways for viewing the world are more likely to be tolerant and open to more than one approach for problem solving. For instance, a study exploring Pettigrew's category width for the adoption of new household technology illustrated the significance of cognitive definitions in relationship to decision-making processes (Eckrich \& McCall, 2009). A study relating Hofstede's (2010) uncertainty avoidance and tolerance for risk found that managers from high uncertainty avoiding countries practiced risky decisions according to their personal trait and perception of their tolerance for it (Frijns, Gilbert, Lehnert, \& Tourani-Rad, 2013).

\section{Organizational Culture}

Hofstede's (1997) interest in nations is not the only existing view on culture. Organizations can also have cultures of their own and share an internal belief system of reality. Management plays an important role for the creation of an organizational culture, and that is because this entity of the organization intentionally or unintentionally establishes it in a manner which is particular to that organization (Andriukaitienè, Cherep, Voronkova, Punchenko, \& Kyvliuk, 2019). Organizational cultures involve communicative efforts which are devoted for the purpose of achieving a certain organizational goal (Andriukaitiené et al., 2019). The microculture of an organization, or the culture which is confined to the organizational setting as opposed to the cross-national macro culture, is distinct in the way through which its hierarchical dynamics occur (Olchi, 1978). Organizational culture is designed by some, if not all, of its members, composed of multiple layers, and is generationally transmitted (Andriukaitienè et al., 2019). Zakarevičius, Kvedaravičius, and Augustauskas (2004) denoted the importance of 
understanding the managerial culture which gives birth to the holistic organizational one. O’Donnell and Boyle (2008) defined organizational culture as the combination of various observable repetitive behaviors and symbols carrying belief systems and principles. Claudia (2016) explained that organizational culture can emanate from a natural process of interaction, as well as it can be the result of human manipulation such as through organizational rules.

"Managerial practice shows that organizations resist change by force rules, habits, and rigidity structures, leading to a strong retardation to new market conditions" (p. 102). Moreover, "the development of organizational culture involves the stages of organizational culture selfevaluation and the preparation and implementation of a new plan for of organizational culture management" (Andriukaitienè et al., 2019, p. 175).

\section{Intercultural Communication in the Workplace}

\section{Intercultural Interactions in Organizations}

Global communities are the result of various environmental factors. The increased diversity of contemporary global settings today is relatively new and coincides with technological advancements in transportation and communication, revolutionizing human crosscultural interactions (Gudykunst, 2003). No longer do geographic limitations restrict human communication (Patel et al., 2011). Consequently, the contribution of geographic determinism to shaping societies' history, physical location ceases to possess the same impact as it once did. There are various reasons why humans migrate, which might include job searches, investment opportunities, or hope for a better life (Patel et al., 2011). As Patel et al. elaborated:

The goal of building a global community that can work in harmony will remain a very significant phase of our lives this century. As global communities come together to live, 
to learn and to work in all regions of the world where they become active participants in public life, building global community values will remain a challenging task. (p. 5) The term global community alludes to individuals in a certain country existing together, whether physically or virtually, with some members from other countries of origin, establishing a new culture which envelopes and intersects the existing co-cultures within it (Patel et al., 2011). Patel et al. explained, however, that this notion is limited to denoting individual members' readiness and willingness to integrate into the host culture. This approach to intercultural communication is based on reaching or maintaining harmony and dignity among people who belong to these communities as well as the common good for all humans. While Patel et al. recognized that not all people might have the willingness to integrate, they still considered that a conceptualization of a global community allows researchers to investigate the "harmonious exchange of cultural goods or wealth among participating cultures" (p. 6).

Similar to outside of the workplace, intercultural communication within organizations can involve third cultures, in which people who adapt to different cultural settings acquire a new hybrid identity (Useem, Useem, \& Donoghue, 1963), suggesting the existence of a variety of contrasting or oppositional cultural forces (Patel et al., 2011). Other perspectives, such as Hall and Hall's (1989) high and low context cultures, Hofstede's (1997) individualism and collectivism, and Kluckhohn and Strodtbeck's (1961) long-term and short-term perspectives as well as high and low power distance all further indicated the various influences that can interfere with cross-cultural exchange. There are, simultaneously, challenges to practicing intercultural communication; namely, tribalism, ethnocentrism, and isolationism (Koester \& Lustig, 2015). For a balanced intercultural setting, as within the workplace, what characterizes an efficient third culture is its negotiated complexity (Patel et al., 2011). 
Dialogue is important for cross-cultural negotiation in the workplace. Fisher (1980) discussed the usefulness of social negotiation for identity and collective meaning-making. When investigating international negotiation of professionals who work cross-culturally, he contended that people from various cultural backgrounds can construct different decision-making processes and styles, or what he denotes as national characteristics of identity. Fisher considered that the role of people's self-perception regarding their national identity can also impact negotiation since it carries underlying premises about what constitutes the norms and values of negotiation. Communication interference is an inevitable consequence for human interaction. Fisher discussed this when he alluded to cross-cultural distractions which are irrelevant to the message of a foreign persuader, for instance, their hand gestures or use of personal space.

\section{Technology in the Workplace}

Brehm's (1966) reactance theory provides insights for psychologically and socially driven human behavior, including in the workplace (Zawadzki, Danube, \& Shields, 2012). With the surge of technological implementations within organizations, there could be insightful takeaways for organizations as to how various employees might react, or not react, to changes. Technology within the workplace are not only tools to reach a pragmatic purpose, but can also be the subject of interaction in the workplace. Applying PRT to explore employees' inherent and acquired forces influencing perceptions and behavior during technological organizational change.

Technological advancement has an impact on how people function and interact. Bariff and Lusk (1977) describe the significance of cognitive and personality tests, in organizations, for the design of management information systems. They determined that there are elements contributing to "user adaptive behavior" (p. 820), including cognitive style and implementation 
apprehension. The latent includes instances of change resistance, defense mechanisms, and stress tolerance. Moreover, Bariff and Lusk argue that psychological factors influence how users interact with information systems, in which they manage databases, determine options and results, choose commands, and implement actions. At the last stage and post-assessment, users communicate their action. The final part of managing information systems, thus, requires effective communication between the system and its users.

The system analyst implementing an information system must consider the strategic and operational elements, as well as the organizational function of the users. A system analyst selects the adequate report characteristics in terms of content, format, and presentation. Psychologists (Bieri, 1971; Schroder, 1971) and management information systems professionals suggest the importance of providing users with tools which comply with their cognitive comprehension for decision-making (Poli, Valeriani, \& Cinel, 2014). Moreover, Bariff and Lusk (1977) explained that psychological profiling of potential users can help with technological adjustments. During the implementation phase, users' change resistance, defensive tendencies, and anxiety can interfere with their experience. Through understanding users' psychological patterns, system analysts can mitigate aversive reactions (Bariff \& Lusk, 1977).

Bariff and Lusk (1977) suggested using previous psychological instruments or developing situation-specific ones through considering the cost and benefit, as well as the relevance of the existing tests. To facilitate communication through information systems, system managers consider both users' cognitive and behavioral styles. Bariff and Lusk demonstrated the significance of adopting a compound cognitive method, which investigates users' thought process, classifies their input into low to high analytical skills, and explores their various solution-searching approaches (systematic vs. heuristic). Next, user adaptability is what Bariff 
and Lusk measured through, for example, "implementation apprehension" (p. 823), in other words, resistance to change, defensiveness, and anxiety. Throughout the design and implementation phases, resistance to change tests use the dogmatism scale (Rokeach, 1960) or the boarder estimation of authoritarianism. This scale further indicates open-mindedness, which determines design implementations for each category of users. Bariff and Lusk denoted that according to these categorizations, users might require various product positioning messaging or trainings across organizational departments and hierarchies. Moreover, Dickson and Simmons (1970) discussed apprehension, which can contribute to dysfunctional user actions. They used the defense mechanism inventory (Gleser \& Ilhilevich, 1969) as a tool to comprehend user attitudes toward the system or its developers, such as hostility, blaming, suspicion, masochism, and denial (Bariff \& Lusk, 1977). The literature suggests that such negative perceptions originating from ego defenses can potentially affect the experience with another system or the opinion of other individuals. Finally, understanding stress levels specific to individuals or organizational departments allows to comprehend reactions to information systems and their usage through manifest anxiety and tolerance of ambiguity tests (Taylor, 1953). Before, during, or after the implementation of information systems into an organization, high stress levels and resistance to change increase the likelihood of dysfunctional user behavior (Bariff \& Lusk, 1977). Some cross-cultural psychology research (i.e., Bieri, 1971; Pettigrew, 1058) suggested that people's cognitive ability denotes that individuals who view a variety of ways as acceptable for solving a problem. Psychological reactance can also be a defense mechanism which technology users can experience cross-culturally.

The type of technological tool which an organization tries to change or implement influences the intercultural interaction and defines the response of reactance. A study 
investigating cultures' electronic interaction and looking at the influence of email and social norms on negotiation (Rosette, Brett, Barsness, \& Lytle, 2012) distinguished between Hong Kong and American negotiators and records the first as more aggressive when using email. This finding denotes the substantial role of using various communication media for intercultural negotiation. Rosette et al. explained the significance of considering the intercultural aspect of communication before introducing a medium to an organization. The authors suggested that, beyond high speed, easy usage, and financially convenient choices for media, the decision of implementation should also consider behavioral factors, particularly in the existence of cultural variations.

\section{Research Questions}

Intercultural reactance, or in other words, state reactance experienced during intercultural communication, is yet to be explored, particularly in the workplace. This study investigates the prominence of people's intercultural sensitivity and tolerance for ambiguity for trait and state reactance in the workplace. Applying this theoretical framework to a context of technological change can help better comprehend these dimensions for organizational change management. There has not been enough research on the intercultural variations of reactance. Trait reactance is a magnitude which derives from people's character, as opposed to the situation (Brehm, 1966) and adding the dimension of country of origin to this concept might challenge advances suggesting the universality of PRT. The current study expects a potential cultural difference under the premise that the need for freedom is universal (Brehm, 1966), however, freedom experiences are not. This suggests a potential cross-cultural variation in reactance results, which the present study investigated through clusters of distinct national cultures.

$\mathrm{RQ}_{1}$ : Do people experience trait reactance differently based on their cultural background? 
This question particularly tests both the cross-cultural difference of the reactance experience, as opposed to the intercultural aspect, since it is investigating reactance throughout different cultural groups. However, this research applied intercultural and cross-cultural lenses on Brehm's (1966) state reactance. The intercultural element was embedded in the survey, which inferred in its plot that the communication is from an intercultural-distinct manager who comes from a different country from the participant. The cross-cultural element of this research appeared in the comparison of the recorded results from three groups of participants; those who originate from the United States, Morocco, and other Western and Non-Western countries. In other words, state reactance in this research is by default labeled Intercultural State Reactance. The hierarchal aspect is also embedded in the scenario through implying that the participant is receiving a communication from their superior. Given that organizational cultures can be distinct in their hierarchical structure (Olchi, 1978), it is noteworthy to investigate how they influence intercultural reactance in the context of organizational change, across cultures:

$\mathrm{RQ}_{2}$ : Do people experience state reactance to technological organizational change in an intercultural workplace interaction differently based on their cultural background?

This research presumes that there might be a relationship between tolerance for ambiguity and trait reactance as well as a potential relationship between intercultural sensitivity and trait reactance. The theoretical reasoning behind these assumptions considers that tolerance for ambiguity might motivate freedom restoration and that the trait characteristics which lead to intercultural sensitivity might overlap with the ones in trait reactance. Particularly, the aspects of intercultural sensitivity which motivate an understanding and enjoyment toward an unknown other might be relevant to people's comfortability with ambiguity in a general sense. Also, trait reactance reflects the personality characteristic of proneness to reacting to a perceived threat or 
restriction to freedom (Brehm, 1966), including organizational change (Nesterkin, 2013). In contrast, intercultural sensitivity helps with adaptability to change management practices. Therefore, I advanced the following research questions:

$\mathrm{RQ}_{3}$ : Does a high tolerance of ambiguity relate to trait reactance?

$\mathrm{RQ}_{4}$ : Does intercultural sensitivity relate to trait reactance?

Moreover, the study will determine the combined impact of tolerance for ambiguity and intercultural sensitivity on state reactance. Tolerance for ambiguity and intercultural sensitivity both regard instances of open immersion to a different and ambiguous experience. The present study assumes that there might be common driving forces between tolerance for ambiguity and intercultural sensitivity in the workplace. The following question further suspects a relationship between fearing the unknown, through tolerance for ambiguity, and freedom restoration in a given situation:

RQ5: Does the linear combination of tolerance of ambiguity and intercultural sensitivity predict state reactance in an intercultural workplace interaction?

Finally, although trait reactance is a constant personality characteristic, while state reactance varies depending on the situation; there are strong conceptual links between the two. This study will also test the relationship between state and trait reactance for an intercultural situation through the following hypothesis

$\mathrm{H}$ : Trait reactance will predict state reactance in an intercultural workplace interaction.

\section{Conclusion}

Intercultural reactance describes reactance within an intercultural situation of interaction. This study will investigate reactance through an intercultural lens of communication dynamics in a workplace situation of organizational change. Understanding the role of intercultural sensitivity 
and tolerance for ambiguity as intercultural dimensions will help investigate their impact on state reactance. This research will also consider the hierarchical structure of organizations as a potentially reactance-inducing component. Because trait reactance is not situationally induced or measured as opposed to state reactance (Brehm, 1966), this research will measure state reactance independently and will investigate its relationship to other non-situationally induced dimensions of intercultural sensitivity and tolerance for ambiguity. 


\section{CHAPTER II: METHODS}

This chapter will describe the research methodology and design used in the present study. An electronic survey asked participants for their background information, details about an organization in which they worked, and frequency of intercultural interaction. The survey also collected information on the participants' tolerance for ambiguity, trait reactance, and intercultural sensitivity. Then, participants read a hypothetical situation of software change in the workplace, which a manager who was from a different country communicated to them. Finally, respondents answered questions measuring their state reactance.

\section{Participants}

The sample consisted of a total of 242 participants, out of which six individuals (2.5\%) did not answer the demographic questions. The participants were 53.9\% female and $46.3 \%$ male, with $0.4 \%$ who self-identified gender as other and another $0.4 \%$ who preferred not to disclose this information. The participants' age ranged from 18 to 71 years old, with an average age of $28.9(S D=9.68)$. In terms of country of origin, $40.1 \%$ of the sample identified as originally from Morocco and $32.6 \%$ from the United States. Due to the diversity of the remaining countries in the sample and for the purpose of creating quantifiable clusters, this research classified the remaining participants' countries into other non-Western and other Western. These categories respectively represented $17.4 \%$ and $9.9 \%$ for participants' country of origin. Regarding the country in which participants spent most of their life in, $34.2 \%$ indicated that it was the United States and 38.8\% indicated that it was Morocco. This demographic question further found 16.7\% of participants spent most of their life in other non-Western countries and $10.4 \%$ in other Western countries in which participants spent most their life. At the time they responded to the survey, 57\% of the participants indicated that they lived in the United States and 23\% in 
Morocco, while $8.3 \%$ of the countries classified as other non-Western countries and $11.6 \%$ as other Western countries. See Table 1 for a summary of the participants' background for country of origin, country most life spent in, and country currently living in.

Among the participants who identified as being from the United States, $0.6 \%$ selfidentified as Native Hawaiian or other Pacific Islander, 3.5\% as Hispanic or Latino/Latina, 4.1\% as biracial/mixed, 7.6\% as Asian, 9.3\% as Black/African American, 50.6\% as White/Caucasian, and $24.4 \%$ as other for ethnicity. The survey instructed people from countries other than the United States to skip this question on ethnicity. Furthermore, most of the respondents' highest completed educational level is a bachelor's degree $(n=126,52.3 \%)$, followed by a master's degree $(n=76,31.5 \%)$, associate degree $(n=14,5.8 \%)$, high school graduate diploma or equivalent $(n=11,4.6 \%)$, doctoral degree $(n=8,3.3 \%)$, and other $(n=6,2.5 \%)$.

Table 1

Descriptive Statistics for Demographic Items

\section{Country}

Of Origin $\quad$ Spent Most of Life In Currently Living In

\begin{tabular}{lccc}
\hline United States & $79(32.6 \%)$ & $82(34.2 \%)$ & $138(57 \%)$ \\
Morocco & $97(40.1 \%)$ & $93(38.8 \%)$ & $56(23.1 \%)$ \\
Other (non-Western) & $42(17.4 \%)$ & $40(16.7 \%)$ & $20(8.3 \%)$ \\
Other (Western) & $24(9.9 \%)$ & $25(10.4 \%)$ & $28(11.6 \%)$
\end{tabular}

Note. Total participants were $N=242$ for origin and current residence, but $N=240$ for longest residence. 
Next, survey respondents selected the frequency of intercultural interaction at their place of work based on the definition stating that frequent intercultural interaction represents daily or weekly task-oriented communication between people from different countries. From the respondents to this question, 37\% $(n=85)$ determined that it was very often, $24.1 \%(n=55)$ often, $19.3 \%(n=44)$ occasionally, $13.6 \%(n=31)$ rarely, and $5.7 \%(n=13)$ never. The survey instructed respondents to answer this section's remaining questions for the organization for which they previously identified intercultural interaction frequency. For the size respondents' organization, 17 participants did not respond. Of the remaining 225 individuals, $25.8 \%$ indicated that the number of employees in their organization is 3 to $35,14.7 \%$ for 251 to 500 employees, $12 \%$ for 26 to 50 employees, $12 \%$ for 1,001 to 10,000 employees, $0.3 \%$ for 51 to 100 employees, $7.1 \%$ for 101 to 250 , and $6.7 \%$ for 501 to 1,000 employees.

Most employees spent 24 to 60 months in the same organization (33.9\%), following 6 to 12 months (26.5\%), 3 to 6 months (13.9\%), 1 to 3 months (11.3\%), 60 to 120 months (5.7\%), less than a month (4.3\%), 120 to 240 months (2.6\%), and over 20 years (1.7\%). Most of the respondents were employees (68.7\%), followed by managers/ supervisors and executives (17.4\%), and staff (13.9\%). The survey answers identified a representation of $72.4 \%$ of full-time workers, $26.6 \%$ part time, and $1 \%$ both full and part time. Moreover, $3.7 \%$ self-identified as freelancers and $2.5 \%$ as self-employed. In terms of work contract, $59.1 \%$ had a temporary contract, $34.1 \%$ had indefinite contract, and $6.8 \%$ had a long-term contract.

\section{Procedures}

The study was distributed via an electronic survey, through Qualtrics survey software, to various employees by the researcher contacting companies who have culturally diverse employees. Specifically, multinational companies as well as national ones were targeted. The 
survey link was distributed through emails and social media platforms, including the researcher's personal Facebook, Instagram, and LinkedIn accounts. In some cases, there was prior contact, through mediated or face-to-face communication, to establish connections with employees who were interested in distributing the survey link to their coworkers.

Following a consent form outlining the social risks for contributing to this study and stipulating that participants must be over 18 years old and have had in the past at least weekly intercultural interactions in the workplace, respondents filled out the survey. The survey instrument consisted of a series of Likert scales and few open-ended questions reflecting the main concepts which this study investigated. Demographic questions collected information about the participants' age, gender, country of origin, ethnicity, and social status. The purpose of this part of the survey instrument was to determine the background of the participants.

The survey asked about the frequency of intercultural interaction at their place of work. This frequency of intercultural interaction within the workplace was defined as daily or weekly task-oriented communication between individuals from different cultural backgrounds, specifically in terms of country of belonging. This section also included a question on the size of the same organization and how long participants have worked there. Next, the survey measured the participants' tolerance for ambiguity in a general manner which was not confined to a particular context of scenario. Using a 5-point scale, the purpose of this section was to test the participants' likelihood to view ambiguous contexts as desirable (McLain, 2009). Next, the survey used Hong's and Faedda (1996) conceptualization of trait reactance, while the following section adapted Fritz et al.'s (2002) review of Chen and Starosta's (2000) scale for intercultural sensitivity. Tolerance for ambiguity and trait reactance scales came prior to the scenario since they measured aspects of the participants' personality, as opposed to a contextual situation. 
After that, the instrument described a hypothetical scenario and invited participants' perspective on it. The imaginary situation in the survey described an organizational setting in which the boss of the participant, who comes from a different culture, informed the employee of an abrupt software introduction into the entire organization. The narrative was designed to evoke a reactance response, and the Likert-type questions which follow it tested the extent of experienced state reactance. See the Appendix for the full survey instrument.

\section{Scenario}

The survey posed a hypothetical situation to the respondents. The scenario presented a context to test intercultural state reactance. Because this research posed and tested for a reactance-inducing situation, it considered recommendations to employ direct and authoritative language (McLaughlin et al., 1980; Miller et al., 2007) thereby strategizing language choices in the survey scenario to induce reactance (see Appendix). The scenario asked the participant to imagine they worked at an organization in which their manager comes from a different culture from theirs and who is not from the United States. Early in the morning, their manager called them about a software implementation. The manager informed the employee of a technological organizational change situation about which he or she had no prior information. The manager also did not provide enough information and rather kept it ambiguous, besides informing them that it is a software which everybody would have across the organization and that everybody would be receiving a training session. The manager acknowledged that he or she did not have information about the software and added that the employee must attend a training, a controlling language which was likely to induce reactance through a boomerang effect (Miller et al., 2007). Finally, in order to induce more ambiguity and reactance to the situation, the manager did not provide the employee with a determined date. Ghazali et al. (2018) found that "as the level of 
social agency and psychological involvement increased, psychological reactance would increase as well" (p. 62). Miller et al. (2007) described controlling or commanding language as more likely to be reactance inducing: "Highly explicit, directive language is often viewed as controlling and may contribute to a sense of helpless dependence" (p. 223). The purpose of not specifying the national identity of the manager was to minimize respondents' specific biases or perceptions about a certain culture. This study concerned intercultural communication; however, it focused on the cultural difference in general, rather than individuals of specific cultures.

For the last section of the survey, respondents indicated the number of times they encountered a similar scenario. Out of all the survey respondents, 182 participants answered this question indicating that, for a range of 0 to 100 , the average number of times respondents encountered a similar scenario to the one in the survey was 11.39 times $(S D=20.42)$. This indicates the relevance of the presented experimental design of the study to the respondents' lived experience and, therefore, further solidifies the applicability of their answers.

\section{Measures}

\section{Non-Scaled Items}

The first set of items on the survey included demographic and screening questions. Beyond age, gender, and social status, this part of the survey determined the participants' general cultural background through measures of country of origin, country in which they have spent most of their lifetime, the country in which they live in at the time of taking the survey, and their ethnicity. The second element which this section tried to determine regarded some aspects of the organizational culture and the participants' positioning within it. Further questions were on the organization's size, time spent working there, and participant's job position. 
At the end of the survey, three final questions appeared. The first of these questions regarded whether or not the person has been through a similar experience before. Brehm (1966) explained that people usually experience less reactance when a situation is redundant. This question addressed possible redundancy of the reactance stimuli as it impacted the results. The final two questions were open-ended items asking participants to describe their experiences travelling abroad and interacting with different cultures through work experiences.

\section{Tolerance for Ambiguity}

The Multiple Stimulus Types Ambiguity Tolerance II (MSTAT-II) is a 13-item measure of ambiguity tolerance as "an orientation, ranging from aversion to attraction, toward stimuli that are complex, unfamiliar, and insoluble" (McLain, 2009, p. 977). This study uses 12 out of the 13 items from the MSTAT-II scale (McLain, 2009). The item which was not included in this study was removed to avoid redundancy with another item in the scale. Response options were arranged on a 5-point Likert scale, ranging from 1 (strongly disagree) to 5 (strongly agree). Examples of items from the scale include: "I try to avoid problems that seem to have more than a single 'best' answer," and "I find it hard to make a choice when the outcome is uncertain." After reverse coding some items (see Appendix), the scale was summed and averaged to create a composite score for the scale. Higher mean scores indicate a higher tolerance for ambiguity.

The scale has previously shown an alpha reliability coefficient of .83 (McLain, 2009). In this study, tolerance for ambiguity scale $(\alpha=.76)$ produced good Cronbach's alpha coefficient reliability. Although an exploratory factor analysis (EFA) was conducted on the tolerance for ambiguity scale in this study, it did not provide interpretable results. Thus, 12 items were retained based on the reliability results alone and treated as a unidimensional scale. 


\section{Trait Reactance}

The scale measuring individual proneness to trait reactance consisted 11 items (Hong, 1992; Hong \& Faedda, 1996). Participants responded to the 5-point Likert scale, from 1 (strongly disagree) to 5 (strongly agree). Example items include "When something is prohibited, I usually think, 'That's exactly what I am going to do,"” "I become frustrated when I am unable to make free and independent decisions," and "I resist the attempts of others to influence me." Prior studies indicate that the 11-item scale is unidimensional and recommend analyzing the scale in its' entirety (Dillard \& Shen, 2005; Shen \& Dillard, 2005). Thus, none of the items were removed and the entire measure was analyzed as a unidimensional scale in the present study. Hong and Faedda's (1996) found $(\alpha=.77)$ good reliability for the scale. Dillard and Shen (2005) reported also good reliability for this scale, ranging from .79 to .83 , in their studies. In the present study, Trait Reactance scale $(\alpha=.76)$ produced good reliability.

\section{Intercultural Sensitivity}

Questions from the intercultural sensitivity section of the survey used Fritz et al.’s (2002) intercultural sensitivity scale, which confirmed Chen and Starosta's (2000) exploratory analysis. Although Chen and Starosta's scale is an acceptable measure, Fritz et al. determined that the factor loading for item 11 was below .40. While Fritz et al. acknowledge that two of the four factors had lower reliability results, they still confirmed the overall validity of Chen and Starosta's scale as a whole for measuring intercultural sensitivity. Thus, the present study maintained all 22 items of Fritz et al.'s scale and subjected it to further factor analysis.

In the present study, the initial EFA led to the iterative elimination of 15 items that failed to meet a 60/40 factor loading criteria. The final EFA procedure produced an acceptable threefactor solution. Both the KMO measure (.695) and Bartlett's test $\left[\chi^{2}=504.024(21), p<.001\right]$ 
were acceptable. Three factors had eigenvalues greater than 1.00 , which was confirmed by the scree plot. The three-factor solution collectively explained $61.64 \%$ of the variance. See Table 2 for the factor loadings.

Table 2

Factor Loadings for the Intercultural Sensitivity Scale

\begin{tabular}{|c|c|c|c|}
\hline Survey Item & $\begin{array}{l}\text { Emotional } \\
\text { Sensitivity }\end{array}$ & $\begin{array}{c}\text { Cultural } \\
\text { Sensitivity }\end{array}$ & $\begin{array}{l}\text { Interactional } \\
\text { Sensitivity }\end{array}$ \\
\hline $\begin{array}{l}\text { 53. I often get discouraged when I am } \\
\text { with people from different cultures. } \\
\text { [Recoded] }\end{array}$ & .923 & .108 & .064 \\
\hline $\begin{array}{l}\text { 54. I often feel useless when } \\
\text { interacting with people from different } \\
\text { cultures. [Recoded] }\end{array}$ & .741 & .167 & .065 \\
\hline $\begin{array}{l}\text { 52. I get upset easily when interacting } \\
\text { with people from different cultures. } \\
\text { [Recoded] }\end{array}$ & .672 & .177 & .154 \\
\hline $\begin{array}{l}\text { 46. I respect the ways people from } \\
\text { different cultures behave. }\end{array}$ & .153 & .771 & .093 \\
\hline $\begin{array}{l}\text { 45. I respect the values of people } \\
\text { from different cultures. }\end{array}$ & .209 & .719 & .273 \\
\hline $\begin{array}{l}\text { 38. I have a feeling of enjoyment } \\
\text { towards differences between my } \\
\text { culturally distinct counterpart and I. }\end{array}$ & .124 & .150 & .823 \\
\hline $\begin{array}{l}\text { 37. I often show my culturally- } \\
\text { distinct counterpart my understanding } \\
\text { through verbal or nonverbal cues. }\end{array}$ & .063 & .127 & .603 \\
\hline Eigenvalue & 2.94 & 1.44 & 1.04 \\
\hline$\%$ of Variance & $27.69 \%$ & $17.43 \%$ & $16.52 \%$ \\
\hline Cronbach's Alpha & .83 & .75 & .68 \\
\hline
\end{tabular}

Note. Underlined factor coefficients show acceptable factor loadings. Items that are not underlined did not load on the corresponding factor.

The first factor explained $27.69 \%$ of the variance with a 2.94 eigenvalue, while the second factor explained $17.43 \%$ of the variance with a 1.44 eigenvalue, and the third factor 
explained $16.55 \%$ of the variance with a 1.04 eigenvalue. The first factor, which was labeled the Emotional Sensitivity subscale, consisted of three items related to the emotions and feelings as respondents communicate with people from other cultures. The second factor, which was labeled the Cultural Sensitivity subscale, consisted of two items related to the perception of the group of people or the culture's values, customs, and traditions. The third factor, which was labeled the Interactional Sensitivity subscale, consisted of two items are other-oriented focusing on the individual respondents' rapport and relationship to the other person. The final three-factor solution produced an overall alpha coefficient reliability of .76 for the Intercultural Sensitivity scale. The three items that comprised the emotional sensitivity subscale $(\alpha=.83)$ while the two items that comprised the cultural sensitivity subscale $(\alpha=.75)$ and the two items that comprised the interactional sensitivity subscale $(\alpha=.68)$ produced reliabilities that are respectively very good, respectable, and minimally acceptable.

\section{State Reactance}

State reactance was measured by adapting Salzburger's State Reactance Scale (Sittenthaler et al., 2015). The 10-item Likert-type scale asked participants about the relevance of the presented statements after being on the phone with their manager. For each statement, respondents could choose whether it was least 1 (not at all) to most relevant 5 (very much). The items describe freedom, frustration, disturbance, prejudice, discrimination, advantages, Internet, complain, and advice against. Sittenthaler et al. adapted these survey statements to a reactancearousing scenario, similar to the scenario employed in the present study. Sittenthaler et al. validated the scale through a three-factor model on experience of reactance $(\alpha=.91)$, negative attitudes $(\alpha=.67)$, and aggressive behavioral intentions $(\alpha=.70)$. Due to specific differences 
between the scenario employed in the present study and the one used by Sittenthaler, several items were reworded or adapted. Thus, the state reactance scale was subjected to factor analysis.

In the present study, all items met the 60/40 factor loading criteria. The EFA procedure produced an acceptable two-factor solution. Both the KMO measure (.882) and Bartlett's test $\left[\chi^{2}\right.$ $=1303.871(45), p<.001]$ were acceptable. Two factors had eigenvalues greater than 1.00, which was confirmed by the scree plot. The two-factor solution collectively explained $63.86 \%$ of the variance. See Table 3 for the factor loadings.

The first factor explained $33.96 \%$ of the variance with a 3.39 eigenvalue, while the second factor explained $29.88 \%$ of the variance with a 2.98 eigenvalue. The first factor, which was labeled the State Retaliation subscale, consisted of six items related to participants' external behavioral akin to non-confrontational vengeful reaction. The second factor, which was labeled the State Arousal subscale, consisted of four items related to participants' state internal cognitive and sensational reaction. The final two-factor solution produced an overall alpha coefficient reliability of .90 for the full scale. The state retaliation subscale $(\alpha=.89)$ and the state arousal subscale $(\alpha=.88)$ each demonstrated very good reliability.

\section{Data Analysis}

Data were analyzed in SPSS to address each research question and hypothesis posed in the study. One-way analysis of variance (ANOVA) tests were conducted to answer research questions one and two. Given the small numbers of participants in the other non-Western and other Western groups, these were combined into a single category prior to running statistical tests. Research questions three and four were addressed through calculating bivariate correlations. A series of multiple linear regression procedures were conducted to address RQ5. A 
series of simple linear regression tests were run to answer the hypothesis. Alpha was set to .05 to determine statistical significance for all tests.

Table 3

Factor Loadings for the Intercultural State Reactance Scale

\begin{tabular}{|c|c|c|}
\hline Survey Item & Retaliation & Arousal \\
\hline $\begin{array}{l}\text { 63. Would you think that the boss also shows } \\
\text { discriminatory behavior in other areas? }\end{array}$ & .882 & .140 \\
\hline $\begin{array}{l}\text { 62. Would you think that this boss could have } \\
\text { prejudices against foreigners? }\end{array}$ & .811 & .085 \\
\hline $\begin{array}{l}\text { 64. How likely would you think it is that this man } \\
\text { takes advantage of other people? }\end{array}$ & .703 & .307 \\
\hline $\begin{array}{l}\text { 66. How strong would your wish to complain } \\
\text { about this reaction to Human Resources? }\end{array}$ & .687 & .363 \\
\hline $\begin{array}{l}\text { 67. How much would you advise other } \\
\text { employees against this boss? }\end{array}$ & .619 & .433 \\
\hline $\begin{array}{l}\text { 65. Would you like to ruin his reputation by } \\
\text { spreading negative word of mouth about this } \\
\text { boss? }\end{array}$ & .613 & .230 \\
\hline 60. How much does his approach annoy you? & .186 & .895 \\
\hline $\begin{array}{l}59 \text {. Would you be frustrated about your boss's } \\
\text { approach? }\end{array}$ & .166 & .839 \\
\hline $\begin{array}{l}\text { 61. To what extent would you be } \\
\text { offended/disturbed by this approach? }\end{array}$ & .254 & .786 \\
\hline $\begin{array}{l}\text { 58. To what extent would you perceive the } \\
\text { manager's call as a restriction of freedom? }\end{array}$ & .330 & .611 \\
\hline Eigenvalue & 3.39 & 2.98 \\
\hline$\%$ of Variance & $33.96 \%$ & $29.88 \%$ \\
\hline Cronbach's Alpha & 0.89 & 0.88 \\
\hline
\end{tabular}

Note. Underlined factor coefficients show acceptable factor loadings. Items that are not underlined did not load on the corresponding factor. 


\section{Conclusion}

The present study collected information from a sample of adult workers which is mostly highly educated and from various backgrounds (Morocco, United States, other Western, and other non-Western countries). Data collected explored the cross-cultural and intercultural stakes of these concepts in a change management situation. The next chapter will report the results of the survey and participants' tolerance for ambiguity, trait reactance, intercultural sensitivity, as well as their state reactance levels in reaction to a hypothetical scenario of software change. 


\section{CHAPTER III: RESULTS}

The five RQs and hypothesis in this research were subject to quantitative analysis. The first two RQs were answered through ANOVAs to determine the statistical differences between the means of three independent groups. The first RQ investigated trait reactance across the groups (United States, Morocco, and Other) while the second RQ explored intercultural state reactance across these same groups. RQs three and four were answered through bivariate correlations determining the relationship between the variables in each question. RQ3 answered how much trait reactance varies when tolerance for ambiguity changes, while RQ4 speculated on the existence of a relationship between trait reactance and tolerance for ambiguity. To answer RQ5, two multiple regression tests were run to predict the value of intercultural state reactance, across two subscales, on the basis of the linear combination of tolerance for ambiguity and intercultural sensitivity. Two simple regressions answered the hypothesis, which explored whether trait reactance predicts intercultural state reactance across its two subscales. Overall, the quantitative analysis and tests revealed findings which were significant for some research questions and non-significant for others.

\section{Oneway ANOVAs}

\section{Research Question One}

RQ1 asked whether people experience Trait Reactance differently based on their

Cultural Background. A oneway ANOVA was conducted to compare the effect of trait reactance on respondents' cultural background. The oneway ANOVA showed that trait reactance differed significantly based on participants' cultural background, $F(2,208)=5.60, p=.004, \eta^{2}=.05$. A post hoc Bonferroni test revealed that the only significant difference between groups was found between participants from the United States $(M=2.80, S D=.50)$ and Morocco $(M=3.08, S D=$ 
.55), with participants indicating they are from the United States experiencing less trait reactance compared to those who indicated that they are from Morocco, $p=.003,95 \%$ CI [-.48, -.07]. The group representing participants coded Other $(M=2.92, S D=.49)$, from both Western and nonWestern countries, were not significantly different from either the United States or Moroccan groups. Thus, the present research partially confirmed that people experience Trait Reactance differently based on their Cultural Background. Trait reactance does differ among people with different cultural backgrounds. More specifically, those from the United States reported less trait reactance than those from Morocco.

\section{Research Question Two}

RQ2 asked whether people experience State Reactance differently based on their Cultural Background. Three separate oneway ANOVAs, for each subscale of state reactance, as well as one for the full scale, were calculated to answer RQ2. An oneway ANOVA was conducted to compare the effect of full state reactance scale on respondents' cultural background. The oneway ANOVA showed that the effect of state reactance on participants' cultural background was not significant, $F(2,202)=.23, p=.78, \eta^{2}=.002$. A post hoc Bonferroni test revealed that participants from the United States $(M=2.24, S D=.81)$, Morocco $(M=2.14, S D=.83)$, and Other $(M=2.20, S D=.79)$ did not report significantly different levels of state reactance.

A second oneway ANOVA was conducted to compare the effect of the State Retaliation subscale on respondents' cultural background. The oneway ANOVA showed that the effect of the state retaliation subscale on participants' cultural background was not significant, $F(2,202)=$ $.13, p=.87, \eta^{2}=.001$. A post hoc Bonferroni test revealed that participants from the United 
States $(M=1.88, S D=.78)$, Morocco $(M=1.82, S D=.88)$, and Other $(M=1.88, S D=.82)$

experienced relatively equal levels of state retaliation.

A third one-way analysis of variance (ANOVA) was conducted to compare the effect of the state arousal subscale on respondents' cultural background. The oneway ANOVA showed that the effect of the state arousal subscale on participants' cultural background was not significant, $F(2,207)=.40, p=.66, \eta^{2}=.003$. A post hoc Bonferroni test revealed that participants from the United States $(M=2.78, S D=1.07)$, Morocco $(M=2.62, S D=1.10)$, and Other $(M=2.70, S D=1.01)$ experienced relatively equal levels of state arousal. Thus, this study did not confirm that people experience State Reactance differently based on their Cultural Background. More specifically, whether measured by the full state reactance scale or the individual subscales, none of the three groups experienced state reactance differently.

\section{Bivariate Correlations}

RQ3 asked whether Trait Reactance and Tolerance for Ambiguity were related. A bivariate correlation was run to assess the relationship between trait reactance and tolerance for ambiguity. Trait reactance demonstrated a statistically significant negative linear association with tolerance for ambiguity, $r(202)=-.19, p=.005$. Thus, RQ3 determined that Trait Reactance and Tolerance for Ambiguity were related. Trait reactance is negatively related to tolerance for ambiguity.

RQ4 asked whether Trait Reactance and Intercultural Sensitivity were related. A bivariate correlation was run to assess the relationship between trait reactance and intercultural sensitivity. Trait reactance did not demonstrate an association with the emotional sensitivity subscale, $r(207)=-.03, p=.59$, the cultural sensitivity subscale, $r(206)=-.04, p=.52$, or the interactional sensitivity subscale, $r(207)=.07, p=.25$. Overall, there was no statically 
significant relationship between trait reactance and intercultural sensitivity. Thus, the present study did not confirm that Trait Reactance and Tolerance for Ambiguity were related.

Correlations among all the scales and subscales are represented in Table 4. In addition to the bivariate correlations that address RQ3 and RQ4, several other bivariate correlations of note are presented in Table 4. For instance, tolerance for ambiguity demonstrated statistically significant negative linear associations with the full intercultural state reactance scale, $r(195)=$ $.24, p<.001$, state retaliation subscale, $r(195)=-.23, p=.001$, and state arousal subscale, $r(200)$ $=-.19, p=.005$. In addition, the full intercultural sensitivity scale demonstrated a statistically significant negative linear association with the full intercultural state reactance scale, $r(201)=$ $.22, p=.001$. Finally, the state retaliation subscale demonstrated significant negative associations with the emotional sensitivity subscale, $r(203)=-.27, p<.001$, and the cultural sensitivity subscale, $r(202)=-.16, p=.01$. 
Table 4

Bivariate Correlations among Scales and Subscales for All Variables

\begin{tabular}{|c|c|c|c|c|c|c|c|c|c|c|c|}
\hline & $M$ & $S D$ & $\alpha$ & TFA & TR & SR & $\mathrm{SA}$ & RET & ICS & $\mathrm{ES}$ & $\mathrm{CS}$ \\
\hline TFA & 3.37 & .51 & .76 & - & & & & & & & \\
\hline $\mathrm{TR}$ & 2.94 & .53 & .76 & $-.19 * *$ & - & & & & & & \\
\hline SR & 2.19 & .81 & .90 & $-.24 * * *$ & $.18^{*}$ & - & & & & & \\
\hline SA & 2.70 & 1.07 & .88 & $-.19 * *$ & $.15^{*}$ & $.85 * * *$ & - & & & & \\
\hline RET & 1.86 & .83 & .89 & $-.23 * * *$ & $.16^{*}$ & $.89 * * *$ & $.53 * * *$ & - & & & \\
\hline ICS & 4.18 & .50 & .76 & $.30 * * *$ & .008 & $-.22 * * *$ & $-.14^{*}$ & $-.23 * * *$ & - & & \\
\hline $\mathrm{ES}$ & 4.28 & .70 & .83 & $.28 * * *$ & -.03 & $-.23 * * *$ & -.12 & $-.27 * * *$ & $.80 * * *$ & - & \\
\hline $\mathrm{CS}$ & 4.32 & .65 & .75 & $.17^{*}$ & -.04 & $-.16^{*}$ & -.12 & $-.16^{*}$ & $.70 * * *$ & $.34 * * *$ & - \\
\hline IS & 3.89 & .71 & .68 & $.16^{*}$ & .07 & -.05 & -.08 & -.01 & $.64 * * *$ & $.21 * *$ & $.31 * * *$ \\
\hline
\end{tabular}

Note. TFA = Tolerance for Ambiguity, $\mathrm{TR}=$ Trait Reactance, $\mathrm{SR}=$ State Reactance, $\mathrm{SA}=$ State Arousal Subscale, $\mathrm{RET}=$ State Retaliation Subscale, ICS = Intercultural Sensitivity, ES = Emotional Sensitivity Subscale, CS = Cultural Sensitivity Subscale, IS = Interactional Sensitivity Subscale. ${ }^{*} p<.05 .{ }^{*} p<.01 .{ }^{* * *} p<.001$ 


\section{State Reactance Regression Models}

\section{Research Question Five}

RQ5 asked whether a linear combination of Tolerance for Ambiguity and Intercultural Sensitivity predicts Intercultural State Reactance. Two multiple regression procedures were calculated for the two subscales of Intercultural State Reactance.

A multiple linear regression procedure investigated if the State Retaliation subscale could be predicted by the linear combination of Tolerance for Ambiguity and Intercultural Sensitivity (Emotional Sensitivity subscale, Cultural Sensitivity subscale, and Interactional Sensitivity subscale). Missing cases were excluded pairwise. Variance accounted for is determined by the $R^{2}$ statistic while the more conservative $R^{2}$ adj reflects shrinkage and tends to be a lower estimate of the variance. Thus, as is common practice, the $R^{2}$ statistic is reported as the variance accounted for, but the $R^{2}$ adj is also reported. Results of the regression analysis indicated that $11.3 \%$ of the variance in the state retaliation subscale could be predicted by tolerance for ambiguity and intercultural sensitivity, $R_{a d j}^{2}=.09, F(4,192)=6.12, p<.001$. Results of the regression indicated that predictor variables were able to account for a significant amount of variance in the outcome variable. Regression coefficients indicated that tolerance for ambiguity, $\beta=-.176, t=-2.46, p=$ $.01,95 \%$ CI [-.51, -.05], emotional sensitivity subscale, $\beta=-.212, t=-2.82, p=.005,95 \%$ CI [$.42,-.07]$, cultural sensitivity subscale, $\beta=-.087, t=-1.16, p=.24,95 \%$ CI $[-.30, .07]$, interactional sensitivity subscale, $\beta=.088, t=1.22, p=.22,95 \%$ CI $[-.06, .26]$, were significant individual predictors of the state retaliation subscale. Squared part correlations revealed that tolerance for ambiguity uniquely predicted $2.82 \%$ of the variance and intercultural sensitivity predicted $5 \%$ of the variance (emotional, 3.69\%; cultural, $0.62 \%$; interactional, $0.69 \%$ ). None of the variables produced Tolerance or Variance Inflation Factor (VIF) statistics indicating 
collinearity. Beta weights for tolerance for ambiguity and intercultural sensitivity are located in Table 5. Thus, the results confirmed that a linear combination of Tolerance for Ambiguity and Intercultural Sensitivity predicts Intercultural State Reactance. The linear combination of tolerance for ambiguity and intercultural sensitivity predicted a significant amount of variance in state retaliation, though emotional sensitivity and tolerance for ambiguity were the only significant unique predictors of state retaliation.

Table 5

Beta Weights for State Retaliation Regression Model

\begin{tabular}{|c|c|c|c|}
\hline \multirow[b]{2}{*}{ Variables } & \multicolumn{3}{|c|}{ Intercultural State Reactance (State Retaliation subscale) } \\
\hline & B & SE B & $\beta$ \\
\hline Tolerance for Ambiguity & -.286 & .116 & $-.176^{*}$ \\
\hline Emotional Sensitivity & -.249 & .088 & $-.212 *$ \\
\hline Cultural Sensitivity & -.111 & .096 & -.087 \\
\hline Interactional Sensitivity & .103 & .084 & .088 \\
\hline$R^{2}$ & & & \\
\hline$F$ & & & \\
\hline
\end{tabular}

Note. An * indicates a unique significant predictor variable at $p<.01 .(n=196)$

A multiple linear regression procedure investigated if Intercultural State Reactance (State Arousal subscale) could be predicted by the linear combination of Tolerance for Ambiguity and Intercultural Sensitivity (Emotional Sensitivity subscale, Cultural Sensitivity subscale, and Interactional Sensitivity subscale). Missing cases were excluded pairwise. Results of the regression analysis indicated that $5.1 \%$ of the variance in the state arousal subscale could be 
predicted by tolerance for ambiguity and intercultural sensitivity, $R_{a d j}^{2}=.031, F(4,197)=2.63, p$ $=.03$. Results of the regression indicated that predictor variables were not able to account for a significant amount of variance in the outcome variable. Regression coefficients indicated that tolerance for ambiguity, $\beta=-.168, t=-2.30, p=.02,95 \% \mathrm{CI}[-.65,-.05]$, emotional sensitivity subscale, $\beta=-.041, t=-.53, p=.59,95 \% \mathrm{CI}[-.29, .16]$, cultural sensitivity subscale, $\beta=-.077, t$ $=-1.00, p=.31,95 \% \mathrm{CI}[-.37, .12]$, interactional sensitivity subscale, $\beta=-.028, t=-.37, p=.71$, $95 \%$ CI [-.26, .17], were significant individual predictors of the state arousal subscale. Squared part correlations revealed that tolerance for ambiguity uniquely predicted $2.56 \%$ of the variance and intercultural sensitivity predicted $0.7 \%$ of the variance (emotional, $0.14 \%$; cultural, $0.49 \%$; interactional, $0.07 \%)$. None of the variables produced Tolerance or VIF statistics indicating collinearity. Beta weights for tolerance for ambiguity and intercultural sensitivity are in Table 6 . Thus, these findings further confirmed that the linear combination of tolerance for ambiguity and intercultural sensitivity predicted a significant amount of variance in state arousal, though tolerance for ambiguity was the only significant unique predictor of state arousal.

\section{Hypothesis}

The hypothesis posits that Trait Reactance predicts Intercultural State Reactance. Two simple regression procedures were run to address the hypothesis since intercultural state reactance consisted of two subscales. 
Table 6

Beta Weights for State Arousal Regression Model

\begin{tabular}{|c|c|c|c|}
\hline \multirow[b]{2}{*}{ Variables } & \multicolumn{3}{|c|}{ Intercultural State Reactance (State Arousal subscale) } \\
\hline & B & SE B & $\beta$ \\
\hline Tolerance for Ambiguity & -.352 & .153 & $-.168 *$ \\
\hline Emotional Sensitivity & -.062 & .116 & -.041 \\
\hline Cultural Sensitivity & -.127 & .126 & -.077 \\
\hline Interactional Sensitivity & -.041 & .111 & -.028 \\
\hline$R^{2}$ & \multicolumn{3}{|c|}{.51} \\
\hline$F$ & \multicolumn{3}{|c|}{2.63} \\
\hline
\end{tabular}

Note. An * indicates a unique significant predictor variable at $p<.05 .(n=201)$

A simple regression procedure investigated whether trait reactance could predict the state retaliation subscale. Missing cases were excluded pairwise. Results of the regression analysis indicated that $2.8 \%$ of the variance in the state retaliation subscale was predicted by trait reactance, $R_{a d j}^{2}=.02, F(1,196)=5.62, p=.01$. More specifically, the significant results of the regression procedure indicated that trait reactance positively predicted a significant amount of variance in the state retaliation subscale. Analysis of regression coefficient indicated that trait reactance, $\beta=.167, t=2.37, p=.01,95 \% \mathrm{CI}[.04, .47]$ was a significant predictor. Thus, the hypothesis was confirmed. Trait reactance predicted a significant amount of variance in state retaliation. Beta weights for trait reactance are reported in Table 7. 
Table 7

Beta Weights for Trait Reactance Predicting Intercultural State Retaliation

\begin{tabular}{|c|c|c|c|c|}
\hline & \multicolumn{3}{|c|}{ Intercultural State Reactance (State Retaliation subscale) } \\
\hline & & B & SE B & $\beta$ \\
\hline Trait Reactance & & .261 & .110 & $.167 *$ \\
\hline & $R^{2}$ & \multicolumn{3}{|c|}{.028} \\
\hline & $F$ & \multicolumn{3}{|c|}{5.62} \\
\hline
\end{tabular}

Note. An * indicates a unique significant predictor variable at $p<.05 .(n=198)$

A simple regression procedure investigated if Trait Reactance could predict the State Arousal subscale. Missing cases were excluded pairwise. Results of the regression analysis indicated that $2.5 \%$ of the variance in the state arousal subscale was predicted by trait reactance, $R_{a d j}^{2}=.02, F(1,201)=5.21, p=.02$. More specifically, the significant results of the regression procedure indicated that trait reactance positively predicted a moderately significant amount of variance in the state arousal subscale. Analysis of regression coefficient indicated that trait reactance, $\beta=.159, t=2.28, p=.02,95 \% \mathrm{CI}[.04, .59]$ was a significant predictor. Beta weights for trait reactance are reported in Table 8. Thus, these results further confirmed the hypothesis. Specifically, trait reactance predicted a significant amount of variance in state arousal. 
Table 8

Beta Weights for Trait Reactance Predicting Intercultural State Arousal

\begin{tabular}{|c|c|c|c|c|}
\hline & \multicolumn{3}{|c|}{ Intercultural State Reactance (State Arousal subscale) } \\
\hline & & B & SE B & $\beta$ \\
\hline Trait Reactance & & .321 & .140 & $.159 *$ \\
\hline & $R^{2}$ & \multicolumn{3}{|c|}{.025} \\
\hline & $F$ & \multicolumn{3}{|c|}{5.21} \\
\hline
\end{tabular}

Note. An * indicates a unique significant predictor variable at $p<.05 .(n=203)$

\section{Summary}

Overall, the data revealed significant findings for some research questions and nonsignificant findings for others. More specifically, RQ1 indicated that trait reactance differs among people with different cultural backgrounds. Participants from Morocco reported significantly more trait reactance compared to those from the United States, while trait reactance for participants from other countries, both from Western and non-Western, was not significantly different compared to Morocco or United States. Results of RQ2 found that the three samples of Morocco, United States, and other countries experienced similar levels of intercultural state reactance. This finding was consistent, whether measured using the full state reactance scale and its two subscales of state retaliation and state arousal. RQ3 demonstrated that there is a significant negative relationship between trait reactance and tolerance for ambiguity. In other words, participants with higher trait reactance reported less tolerance for ambiguity. However, results of RQ4 did not find a significant relationship between trait reactance and intercultural sensitivity emerged. RQ5 demonstrated that the combination of tolerance for ambiguity and 
intercultural sensitivity predicts intercultural state reactance. This finding applied to both subscales of intercultural state reactance and across the three subscales of intercultural sensitivity. Finally, the hypothesis positing that trait reactance predicts intercultural state reactance was confirmed with both subscales of intercultural state reactance. 


\section{CHAPTER IV: DISCUSSION}

As technological advancement continues to be a part of our daily lives, organizational changes involving technology can be perceived as threats to, or restrictions of, our freedom behaviors. Investigating how psychological reactance operates in a multicultural organization can have important implications for our work lives. Brehm's (1966) psychological reactance has proven to be a solid theoretical framework for understanding human behavior in persuasive communication. The universality of PRT was tested in this study through examining its crosscultural and intercultural applicability. This study used adult employee participants from the United States, Morocco, and other Western and non-Western countries to explore how technological changes impact psychological reactance in multicultural, organizational settings. The present study measured their trait reactance, intercultural sensitivity, and tolerance for ambiguity, before providing participants with a scenario on technological change to test state reactance.

\section{Summary of Findings}

The present study was driven by five research questions as well as a hypothesis. The results of the quantitative data analysis indicate support for some of the research questions and the hypothesis, but not all. The results offer insight into how trait reactance, intercultural sensitivity, tolerance for ambiguity, and the cross-cultural characteristics of the participants affect their state reactance, given a situation involving a software change in their organization which their manager announces.

\section{Research Question One}

RQ1 explored whether trait reactance differs among people with different cultural backgrounds. Brehm (1966) did not initially discuss psychological reactance as a trait variable; 
however, he alluded to the idea that people potentially have varying reactions to freedom threat or restrictions. Brehm and Brehm (1981) elaborated on this conceptualization, since it aligned with how reactance was initially theorized. The premise is that individuals have various desires for autonomy and self-determination (Brehm, 1966; Wicklund, 1974). Autonomy is described as related to seeking independence and freedom, as well as characterized by resistance to forceful control or external influence (Hmel \& Pincus, 2002; Murray, 1938). This latter definition corresponds with Brehm's PRT. Pavey and Sparks (2009) argue that "autonomy and reactance are both associated with greater freedom from external constraints" (p. 289). Leander et al. (2016) found that reactance functions as part of a self-regulatory system for the pursuit of autonomy. They also suggested that self-regulation is the motivation to determine one's own destiny, which, in light of reactance, may trigger an experience of sensitivity inflating the reactant's assessment of the threat. Leander et al. argued that this leads to a delusional perception of the menace, triggering a reactance response. Thus, reactance is a means of restoring autonomy.

If trait reactance is fueled by the need for autonomy and self-determination, then it might be the case that participants from Morocco tend to have a greater desire for autonomy and selfdetermination, compared to Americans as well as participants from other countries. RQ1 answered that trait reactance differs among people with different cultural backgrounds. Specifically, participants from Morocco reported significantly more trait reactance compared to Americans. Meanwhile, trait reactance for participants from other countries, both from Western and non-Western, was not significantly different compared to those from Morocco or the United States. 
There are historical, social, political, and economic reasons why variations in trait reactance may exist between Moroccans and Americans. Morocco and the United States have contrasting historical and sociopolitical backgrounds. The kingdom of Morocco has been ruled by the same dynastic family of Alaouites since 1666 (Meyers, 1983), an "unbroken political tradition" that traces back to the ninth century Idrisid dynasty (Joffe, 1988, p. 201). After Morocco's independence from colonial powers in 1956 (Pennell, 2009) and particularly after King Mohamed VI ascended the throne in 1999 (Maghraoui, 2001), the country transitioned into an era of reconciliation of its ancient heritage with hegemonic international interests in democracy and human rights. Morocco's transition created a system maintaining the guardianship and decisive role of the monarchy (Joffe, 1988), which reigns over a parliament, government, and constitution (Guilain \& Helen, 2007). This hybrid model is a representation of Moroccans' deeply rooted cultural value of loyalty, accompanied with a desire for freedom and self-determination. This transition or blend of cultural values appears across various Moroccan societal institutions, such as in the media (Hidass, 1993) and the workplace (Ali \& Wahabi, 2016), suggesting that Moroccans may have very different experience of freedom than Americans.

Although the current study does not contend that one country or culture values freedom more than another, which is in line with Brehm's (1966) conceptualization of PRT, this research argues for various past experiences of what represents freedom, shaping its experience. Americans value independence and self-determination, which places a significance on individuals' ability to take control of their own destiny. Cultural characteristics of independence, individualism, equality, democracy, meritocracy, and consumerism (Littler, 2013) are prevalent values among others in the United States. Carl (2011) explained the liberalism in the United 
States as a political and social philosophy and reality of the American people. He explained that liberalism considers the freedom of the individual as essential for the greater societal good, in a context where the state's role is to maintain social order through the coexistence of a multitude of individual freedoms. Carl further explained that 20th century liberalism in the United States moved from the "laissez-faire liberalism" in which individuals interact in a merit-based free market, to "reform liberalism" in which the masses need to protect themselves from corporate hegemony, and finally towards a "right-based liberalism" (p. 8) in which people clustered into social groups to assert their rights. Competitive capitalism further suggests people's freedom to choose what to purchase or produce as a necessary condition for retaining other forms of freedom, as well as reinforces the role of the government in guaranteeing individual freedoms (Friedman, 2002). These historical and present-day characteristics of the American cultural landscape reinforce that it is one which values individuals' freedom of choice.

If people experience trait reactance differently depending on their nation, this aligns with previous literature which suggests that what is distinctive about these nations, or what constitutes culture, is indeed what shapes perceptions of freedom (Franck, 1997). Consequently, one conclusion is that when views on freedom differ, reactance differs. However, perceptions of freedom might not be the only cultural element which determines the extent of trait reactance.

\section{Research Question Two}

RQ2 found that the groups of participants from Morocco, the United States, and other countries experienced similar levels of intercultural state reactance. The mean scores showed that participants experienced state reactance differently, but the differences were not statistically significant. Those from the United States reported to experiencing higher state reactance when responding to the scenario, though they reported lower trait reactance. Overall, state reactance 
mean scores were low for all three groups, while they were moderate or low for trait reactance. Since trait reactance tends to predict state reactance (Brehm \& Brehm, 1981; Quick \& Stephenson, 2008), it could be that state reactance scores were low because participants only reported moderate levels of trait reactance.

Although most participants indicated that the scenario was familiar and realistic, the results indicated that the scenario did not trigger high levels of state reactance. This scenario may not have provoked as much state reactance as anticipated. Another possible reason nonsignificant findings could be that participants might have been too familiar with similar situations, and this familiarity might be what led them to not perceive it as a threat. Brehm and Brehm (1981) alluded to the significance of previous experiences on how people perceive threats. Even though the scenario used controlling language, reinforced the element of organizational hierarchy, and attempted to trigger ambiguity, the familiarity of this situation of technological change in organizations, particularly from managers, might have dampened state reactance. Nevertheless, these results do not necessarily mean that technological change in organizations fails to potentially trigger a reactance response.

Overall, since trait reactance varies cross-culturally, therefore remaining relatively static for course of an individual's life, some state reactance may vary greatly across cultures, depending on the particular freedom or choice behavior that has been restricted or threatened. Furthermore, some state reactance may not vary across cultures. With respect to the specific state reactance subscales, it is interesting to note that mean scores for the retaliation subscale were nearly identical across cultural groups and were extremely low. In contrast, mean scores for the arousal subscale varied more and were nearly a full point higher. While no significant differences among the cultural groups were found on either subscale, a closer inspection of the 
mean scores suggests that arousal was stronger than retaliation and that arousal may differ more among cultural groups than retaliation.

The technological organizational change described in the scenario presented to participants is also a distinct situation for reactance. Most respondents indicated that this scenario was familiar to them, aligning with how technological change is a phenomenon which impacted most people in the world. This familiarity further suggests that this software change does not violate their expectancy of their work culture. Although people from Morocco and the United State might vary on trait reactance, perhaps due to their cultural backgrounds or nationality, they may converge on their vision of work culture, in terms of expectations and values. This might be a result of globalization as well as the Westernization of the Moroccan sample included in this study.

\section{Research Question Three}

RQ3 demonstrated that participants with higher trait reactance reported less tolerance for ambiguity. In other words, those who report greater intolerance for ambiguity also report higher levels of trait reactance. Hofstede (1997) referred to tolerance for ambiguity as a psychological defense mechanism to mitigate the consequences of unpleasant experiences which come from fearing the unknown. Hofstede's definition of tolerance for ambiguity aligns with the findings suggesting that people who are less comfortable with vague and non-specific circumstances are more likely to resist to situations which they do not comprehend. A perceived threat is likely to emerge from lack of understanding (Jones \& Brehm, 1970); thus, an intolerance for ambiguity is likely to be interpreted as an attack on one's freedom. Both trait reactance and tolerance for ambiguity are psychological defense mechanisms to preserve or protect one's self from what is convenient and desirable to the person. 
Budner (1962) defined intolerance for ambiguity as an interpretation of the world which tends to stray away from undesirable situations of threats. Similar to PRT (Brehm, 1966), tolerance for ambiguity can influence the desirability of choices for the purpose of eliminating dealing with the unpleasant unknown (Budner, 1962). Brehm and Brehm's (1981) trait reactance also referred to a perceived trigger of threat, which motivates restoration efforts to mitigate an unwanted experience. Trait reactance and tolerance for ambiguity converge in their conceptual definition, which explains the confirmation of RQ3.

\section{Research Question Four}

RQ4 results did not find a significant relationship between trait reactance and intercultural sensitivity emerged. This finding seems consistent with the conceptual definitions of both concepts. Because trait reactance represents a personality characteristic which people internalize and live with, and intercultural sensitivity might occur at a later stage in life, the results are coherent with the previously posited conceptual definitions. Furthermore, intercultural sensitivity happens through interaction with those who are from different cultures and those who have acquired intercultural sensitivity have learned to exercise perspective-taking, which requires seeing how the interlocutor might have in common with them. Since this aspect of openness does not play a role in trait reactance, which revolves around freedom, the results are conceptually coherent.

Taken together, the results of research questions three and four suggested that trait reactance is related to tolerance for ambiguity, but not to intercultural sensitivity. This might hint at a conceptual alignment between trait reactance and tolerance for ambiguity, as both may be fairly stable psychological personality traits (Budner, 1962; Miller et al., 2007), which people carry with them from an early age. Intercultural sensitivity, however, is more of a competence or 
skill which evolves and develops over time. Thus, it may not be surprising that intercultural sensitivity and trait reactance were weakly connected. Since tolerance for ambiguity and trait reactance are both relatively constant throughout the lifetime of the individual, the results of the study are coherent with conceptual definitions of the research variables.

\section{Research Question Five}

The results of RQ5 suggest that intercultural sensitivity and tolerance for ambiguity predict state reactance, except in the case of the cultural and interactional subscales of intercultural sensitivity. In RQ3 tolerance for ambiguity and trait reactance were related, and through the results of RQ5, tolerance for ambiguity and state reactance were also shown to be related. This illustrates an association between tolerance for ambiguity and trait reactance. Additionally, tolerance for ambiguity negatively predicts state reactance, making it an important variable in terms of the findings for this study.

Although intercultural sensitivity was not significantly related to trait reactance in RQ4, the results of RQ5 showed that intercultural sensitivity is a significant negative predictor of state reactance. It is logical to consider that individuals with high intercultural sensitivity would react less to the intercultural manager imposing a technological change on them. More particularly, the beta weights were also stronger for emotional sensitivity, compared to tolerance for ambiguity, for the state retaliation subscale. Thus, the lower tolerance for ambiguity scores are, the more state reactance; and, the lower intercultural sensitivity is, the higher state reactance. Overall, the regression model was significant, meaning that the linear combination of all four variables significantly predicted state reactance. However, only tolerance for ambiguity and emotional sensitivity subscale were significant unique negative predictors of state reactance. Although the cultural and interactional subscales of sensitivity were not significant unique predictors, they 
contribute to the overall variance explained in the state retaliation regression model. In comparison, on the state arousal subscale, the linear combination of predictor variables is still significant; however, this time, only tolerance for ambiguity emerged as a significant unique negative predictor while the three intercultural sensitivity subscales were not significant unique predictors.

Participants with low intercultural sensitivity have higher state reactance to the scenario. This suggests that, although the scenario was not successful at triggering high state reactance responses, it was able to depict an intercultural interaction between an employee and their manager from a different culture. Moreover, the arousal subscale measures whether or not the participants' reactance is likely to be triggered, while the state retaliation subscale measures outward behavior. This suggests that when it comes to predicting whether or not participants are likely to act (i.e., retaliate), intercultural sensitivity—and emotional sensitivity in particularmatters more. In the scenario, intercultural sensitivity does not play a role since it would not interfere with participants' state reactance arousal. However, emotional sensitivity is the more important predictor in whether or not participants would retaliate, and tolerance for ambiguity plays a role, too. Intercultural sensitivity is not only an indicator of one's ability to deal with intercultural encounters. Intercultural emotional sensitivity may reflect maturity, which would allow the participant to refrain from retaliating against their manager's change.

Intercultural sensitivity and tolerance for ambiguity take the same direction when it comes to being negative predictors of state reactance. Adorno et al. (1981) referred to intolerance for ambiguity as a tendency to reject what is other than one's familiar cultural setting. The findings of the present study align with the cultural perception of ambiguity. It could be that those with high intercultural sensitivity are less likely to perceive a culturally distinct counterpart 
as an ambiguous threat. Put differently, those who have a low tolerance for ambiguity might be more likely to navigate the world from the perspective of threat elimination. In other words, people who prefer not to deal with situations in which there is very little or inconsistent information might be perceiving them as threatening to their perception of order and would therefore trigger a need to restore it. These findings are inconsistent with Brehm's (1966) PRT which addresses perceived threat to freedom restrictions specifically.

\section{Hypothesis}

The results indicated that trait reactance predicts state reactance. The results were significant, but trait reactance only predicted a small percent of the variance explained (2.8\%) in state reactance for the scenario tested in this study. In comparison to previous research, which suggests that trait reactance does predict state reactance (Brehm \& Brehm, 1981; Quick \& Stephenson, 2008), the present results concur. While trait reactance predicted state reactance, the results indicated a cross-cultural variation for trait reactance and not for state reactance. Although people with high trait reactance tend to have higher state reactance results, when classified according to country of origin, the comparison between these cultures varied for trait reactance. The hypothesis, in combination with some previous results, raise important considerations on the role of cross-cultural and intercultural elements in reactance.

The cross-cultural convergence in state reactance, as opposed to trait reactance, might allude to a convergence of workplace culture and organizational expectations. In other words, it might be that most cultural groups in the sample have similar expectations about organizational change and particularly software change. Researchers like Jensen and Bjørn (2015) explained that when it comes to the global workplace and information technology development of software across nations, employees face instances of convergence in concepts and divergence in meaning. 
In other words, they might be using the same terms to while referring to nuanced interpretations. However, the present findings of this study only depicted this variation in trait reactance rather than state, which suggests a potential convergence in how participants made sense of the scenario that was presented.

\section{Implications}

\section{Practical Implications}

Four practical implications emerged from the data analysis that have applications for employees, managers, and scholars concerned with organizational change. First, the findings of the present study suggest that technology users' perception of change depends on how the change is introduced or implemented, the level of interaction with the technology, and which technology was changed. In the case of the present study, it may be that the choice in the survey scenario of describing a software change is a particularly frequent practice in organizations. Although previous research demonstrated that there is a difference between people's responses to the change and to the technology itself (Ghazali et al., 2018), the choice of persuasive approach for implementation within an organization can influence people's attitude. Organizational technological change triggers social reactions (e.g., Eyssel \& Hegel, 2012; Ham et al., 2015), which are yet to be further investigated. Ghazali et al. (2018) suggested that video games which communicated fewer social cues led to low user reactance, suggesting that the interaction with the technology can indicate the extent of reactance. This finding further suggests that lack of detail about the technological change in the scenario is also related to low state reactance results. In addition to the low amount of information presented in the scenario on the change, individuals may also view technologies (e.g., software, hardware, artificial technology) differently and internalize varying perceptions of threat. Mohan, $\mathrm{Xu}, \mathrm{Cao}$, and Ramesh (2008) explained that, in 
organizations, software development is a frequent practice in change management practices. It might be that people's familiarity with software changes, and particularly as participants of this study indicated their familiarity with such a change, justifies their low reactance to it. Lack of detail or higher ambiguity in the supervisor's statement about the change might have also contributed to these reactance results. Furthermore, Brehm (1966) denoted that people react to previously experienced situations differently from new ones. The present study suggests that people may experience more reactance for less familiar types of technological change, such as with artificial intelligence implementations. Brehm and Brehm (1981) also suggested that personal threats to freedom are more likely to trigger reactance. Organizations' striving for efficiency and optimization of their operations has led to implementations of artificial intelligence, such as driverless cars, which can be either autonomous or require cooperation with humans. Artificial intelligence, automation, and robotization technologies provide a unique selling point of mitigating human error, particularly for industries and organizations which have a stake in growth and continuous improvement values and practices (Hedelind \& Jackson, 2011; Lawless \& Sofge, 2017; Kolberg \& Zühlke, 2015). This kind of technological organizational change is likely to be perceived as a threat for people's jobs and as a replacement for human labor (Lawless \& Sofge, 2017). More studies on PRT are needed in this direction to evaluate the amount of perceived threat and its impact on implementation, depending on the type of technology as well as level of interaction with the technology.

Second, the findings further suggest that human characteristics, such as intercultural sensitivity and tolerance for ambiguity, impact intercultural state reactance. The competence of intercultural sensitivity involves open-mindedness and self-monitoring, as well as suggests the ability to interact during intercultural contexts with ease (Chen \& Starosta, 2000). In the present 
study, participants' low emotional sensitivity predicted high state reactance. In this investigation, cases of high tolerance for ambiguity, which is characterized as the high likelihood for the ability to endure unknown contexts (Chen \& Starosta, 2000), predicted lower intercultural state reactance. Both emotional sensitivity and tolerance for ambiguity were significant predictors of state reactance. Previous research (Merrotsy, 2013; Tegano, 1990) has demonstrated that tolerance for ambiguity was positively correlated with creativity trait characteristics. Since both intercultural sensitivity and tolerance for ambiguity are characterized with the personality trait of openness, and given that organizations with larger structures tend to promote a dominant culture of compliance with rules and rigidity, while smaller ones are more likely to endorse creativity (Perry, 1995), it may be that larger organizations, such as multinational companies, face a bigger challenge for intercultural emotional sensitivity as well as more resistance when it comes to change. Ironically, the findings suggest that although multinational organizations are the most likely to engage intercultural and cross-cultural communication, as well as have a greater stake in technological evolutions; however, the very culture which needs these aspects to sustain itself does not reflect it. "Developing organizational culture that stimulates and promotes creativity and innovation is an imperative for organizations seeking a competitive advantage" (Ali Taha, Sirkova, \& Ferencova, 2016, p. 7). Thus, a recommendation is for larger scale companies to create systems which not only hire, but also retain through creating contexts for employees with creative and open-minded traits, in order to avoid reactance.

Third, the findings suggest that scholars ought to investigate reactance across various cultural groups. Although trait reactance is distinguished within the results as significant crossculturally, the scenario in this study was not able to produce a similar variation, perhaps because of how the two largest national categories in the sample, of Morocco and the United States, 
converge in their view of organizational culture and diverge in their lived experiences which contributed to their education. Trait reactant individuals routinely rebel against authority figures (Dowd et al., 1991), which might suggest that Moroccans are, in general, more likely to rebel against authority figures, including within organizations. However, because of the Westernized Moroccan sample, this specific sample of the study is representative of a niche group of Moroccans, not allowing general conclusions on nations like with Hofstede's work. Overall, the current study was able to detect some cross-cultural variation, regarding trait reactance, but not when it comes to state reactance. Perhaps that other cultural groups that are more different than the ones in the present study, aside from Morocco and the United States, would show more state reactance differences.

Fourth, previous research explained that introducing and reinforcing intercultural sensitivity training programs within organizations could play an important role in helping to develop employees' intercultural competency (Bennett, 1986; Chen \& Starosta, 1997). Intercultural sensitivity is necessary for effective and appropriate interaction in a globalized context of increased interdependence (Bennett, 1986; Chen \& Starosta, 1997). Bennett suggested that strengthening intercultural sensitivity components of self-esteem, self-monitoring, openmindedness, empathy, interaction involvement, and non-judgment through training has promising results on intercultural cooperation for reaching organizational goals. For instance, Bennett described a developmental training model of affective, cognitive, and behavioral evolution through stages of denial, defense, minimization, acceptance, adaptation, and integration. Intercultural communication training can provide organizations with a competitive edge in the global market, as well as help with employee attraction and retention. 


\section{Theoretical Implications}

Three theoretical implications emerged from this study. First, the results suggest implications for research concerning PRT (Brehm, 1961), cross-cultural communication, intercultural communication, as well as perceptions of freedom in relationship to selfdetermination and autonomy (Deci, 1971). Overall, the results have important conceptual implications for PRT. There was a strong association between tolerance for ambiguity and trait reactance, which further reinforces their conceptual proximity. The current study suggests that concepts such as tolerance for ambiguity and intercultural sensitivity have an impact on state reactance. Thus, it is reasonable to conclude that there are both inherent and learned forces which determine state reactance. Conceptually, tolerance for ambiguity involves mitigating an unwanted situation of threat, similarly to how trait reactance occurs. This further aligns with how the intercultural emotional sensitivity subscale is the one which, negatively, predicts state reactance. One explanation is that the emotional maturity is what orchestrates how people deal with tolerance for ambiguity and state reactance, in terms of whether they enact it into a retaliation or behavior. Further theoretical implications might consider the relevance of the retaliation subscale of state reactance, in this study to the boomerang effect.

The cross-cultural aspect of this study represents a step forward, toward a more universal approach to psychology (Triandis, 1986). The current research used PRT as a valid theoretical framework, in order to test its cross-cultural validity. There is a lack of non-Western samples in theories like PRT, which might have led to a lack of non-Western considerations in the development of its scales and measurements. Although the current study found some crosscultural variation, more research in this direction would be further revealing about the need to revisit the scales. This is particularly true in cases when researchers translate existing scales, 
allowing them to be loyal to Brehm's (1966) theoretical framework, while adjusting to culturespecific meaning making and connotations.

The findings of the study did not demonstrate a cross-cultural difference in state reactance, while it was significant for trait reactance. The current study speculates that this nonsignificant finding as revealing and worthy of further investigation, as well as suggests that the intercultural communication aspect may have dampened state reactance results. In other words, because the respondents were dealing with a situation emphasizing that the interlocutor is from a different culture, this might have led them to report less state reactance. Although there was not enough data from participants for the open-ended questions, a preliminary analysis reveals that people were emphasizing their enjoyment of intercultural interaction and did not want to report signs of insensitivity. In addition, even though state reactance was not significantly different across cultures, the results illustrated that mean scores for the arousal subscale were relatively higher compared to the ones for the retaliation subscale. This alludes to people's self-suppression of enacting reactance behavior. In other words, participants might have been trying to appear tolerant, particularly as they felt triggered but did not express intentions for behavioral retaliation. Based on the findings reported in the present study, it is reasonable to speculate that organizational settings do not encourage people to enact psychological reactance as a face-saving approach, which also infers intercultural implications (Ting-Toomey, 1994). However, findings in this study suggest the prevalence of the intercultural aspect. In addition to the scenario's accentuation on the intercultural difference between the manager and employee, intercultural sensitivity was also shown to have a negative relationship with state reactance. Perhaps that the intercultural aspect of communication adds a suppressor effect, clouding differences that PRT would tell us to expect. The present study infers that there is a lack of knowledge on how PRT 
operates within different cultural groups, as it assumes that interactants are from the same culture.

The cross-cultural difference in trait reactance, but not in state reactance, carries theoretical considerations for Brehm's (1966) PRT. It could be that the specifics of the present study scenario in terms of the little information it presents about the software change and the manager's background, as well as the prevalence of the software change as a recurrent practice in the workplace all contributed to a convergence in state reactance. Specific situations determine how people make meaning of potential restrictions and that the amount of information presented and familiarity of the situation can influence reactance arousal and retaliation. These are aspects which Brehm already discussed through reactance theory; however, there is a lack of clarity in previous research on how that interplays in the existence of an intercultural other. The crosscultural difference in trait reactance, but not in state reactance, reinforces criticism toward Hofstede's research (1977) suggesting that across countries, there are co-cultures which could converge despite their national belonging (McSweeney, 2002).

Second, self-determination theory (Deci, 1971) suggests that the psychological need for regulating one's sense of autonomy is universal. This theory of motivation and personality defined autonomy as behaving consistently with one's values, independently from external pressure (Deci, 1971). Chirkov, Ryan, Kim, and Kaplan (2003) suggested that autonomy does not necessitate behaving independently from external influence, but rather requires acting upon what one perceives as personal conviction. Wichmann (2011) investigated autonomy through self-determination theory and found that it was relevant to well-being across cultures. In the same direction, Deci and Ryan (2012) described human needs for competence and selfdetermination, such as autonomy, as intrinsic motivation: 
Intrinsic motivation was considered an inherent characteristic of human beings and was viewed as the prototype of psychological freedom or self-determination. It could be either undermined or enhanced depending on whether the social environment supported or thwarted the needs for competence and self-determination. (p. 3)

This conceptualization is consistent with PRT's (Brehm, 1966) motivation and freedom-driven characteristics. This acknowledgment of the social factors which shape individuals' selfdetermination (Deci \& Ryan, 2012) might allude to a possible cross-cultural variety of motivation for autonomy. In other words, although it is a universal psychological trait, it can be debated that different environments shape distinct variations of the need for autonomy.

The motivation to restore freedom is compatible with the quest for autonomy, as they are both intrinsic and universal, moreover, people's sense of autonomy is socially constructed (Deci, Koestner, \& Ryan, 1999). In a meta-analysis on intrinsic motivation in education and the effects of reward, Deci et al. (1999) found that positive verbal feedback enhanced intrinsic motivation, while tangible or nonverbal rewards undermined it, when people expect it. The meta-analysis found that both task and performance related rewards decreased this intrinsic motivation when expected and increased it when unexpected. Deci et al. (1999) explained that the influence of extrinsic reward on intrinsic motivation is relevant to the element of perceived control. These findings suggested that innate motivation, or the intuitive psychological need for competence and self-determination (Deci et al., 1999), is influenced through social learning. Reactance is triggered through the need to restore a perceived freedom threat (Brehm, 1966), which stems from a higher need for self-determination and autonomy (Pavey \& Sparks, 2009). Through the findings of RQ1, the present research findings aligned with some of the principles in selfdetermination theory (Deci, 1971) suggesting the prominence of environmental forces in shaping 
the intrinsic motivation of autonomy, which fuels the restorative mechanism of trait reactance (Brehm, 1966).

Triandis (1995) suggested that people from different cultures acquire characteristics which become part of their nature through learning or unconscious assimilation, and thus internalize behavioral and attitudinal practices accordingly. Chirkov et al. (2003) provided a criticism to previous research and distinguished between autonomy and individualism. Although some researchers (i.e., Oishi, 2000; Rudy, Sheldon, Awong, \& Tan, 2007) argued that certain Asian cultures did not view autonomy as desirable, others like Chirkov et al. (2003) considered that this misconception confused autonomy with individualistic values. Oishi's (2000) description of autonomy as an exclusively Western value does not distinguish between people's internalization of social expectations and their ability to genuinely choose for themselves. Although the need for autonomy as a motivation can vary from culture to another (Deci et al., 1999), it remains distinct from the constructs of individualism and collectivism (Chirkov et al., 2003). Similarly, trait reactance implies that the need for freedom is universal. However, people internalize different visions of what represents a threat to freedom through socialization and previous experiences.

The third theoretical implication concerns Hofstede's (1997) work on cultures. According to Hofstede's model, Morocco was found to be a hierarchical nation with a power distance score of 70 , on a scale from 0 to 100 , in which authority is not justified and domination and control of those in charge of an organization is expected (Al-Alawi \& Alkhodari, 2016). Comparatively, the United States showed a close score to Morocco's on power distance of 72 (Wu, 2006). Morocco scored a 46 in individualism, out of 100, according to Hofstede's model, making it highly collectivistic (Al-Alawi \& Alkhodari, 2016) aligning with the idea that "Moroccans value loyalty 
and it is the most important value in the society" (p. 20860). The two countries diverged on this dimension, with a score of 64 for the United States, suggesting it is highly individualistic $(\mathrm{Wu}$, 2006). When it comes to uncertainty avoidance, according to the Hofstede model, Morocco stood at a 68 , out of 100 , which translates to a tendency for avoiding uncertainty (Al-Alawi \& Alkhodari, 2016). Because of rigid societal expectations, most Moroccans were found to be less likely to tolerate behavior interfering with the norms (Al-Alawi \& Alkhodari, 2016). For the United States, uncertainty avoidance was 77 (Wu, 2006), scoring a slightly higher but close score to Morocco's. These results align with the results of this study in the sense where there are, overall, some variations between Morocco and the United States; however, the variation was not major. Research using Hofstede provides an idea on overall national tendencies; however, is does not consider co-cultural variations, like with the niche sample of the current study which represents an adult educated population. Using Hofstede's dimensions can be useful in determining how wide or close the gap is between countries. Perhaps future research should investigate reactance by employing Hofstede's dimensions to compare and contrast cultures that vary greatly from one another.

\section{Limitations}

Like any research study, this investigation had limitations. First, although the participants sampled in the study were adult workers from various cultures, the sample had shortcomings. For instance, the sample only consisted of English-literate Moroccans, the majority of whom indicated that they had at least a master's degree. Historically, Morocco's multilinguistic landscape of Tamazight, Moroccan Arabic, Classical Arabic, French, and Spanish, as commonly spoken languages, goes back to its colonization and proximity to Europe (Errihani, 2017). In 2013, Morocco's King Mohammed VI gave a speech on education stating that the return to 
bilingualism helps assure the country's place in the global village (Errihani, 2017). Errihani further explained that the promotion of English, which only emerged in the past two decades, at the expense of French language instruction, in Moroccan education is because English is not perceived to be as imperialistically charged, provides wider employment prospects, and has a global reach. In addition, most of the Moroccan participants in the present study also reported having spent the majority of their lives in other countries, mostly in Europe and the Unites States. Thus, it is reasonable to speculate that Moroccan participants in the present study are globally minded and interculturally experienced, some of which might even represent a third culture (Patel et al., 2011) who adapted (Kim, 2001) to the social cues and expectations of these Western countries. Therefore, this sample might not be representative of the average Moroccan, which also could explain their reported high levels of intercultural sensitivity.

Second, while this study employed commonly used scales, the measurement instruments for certain variables were less than ideal. Some scales did not factor well after running an EFAs for the current sample, while others were not optimal with factoring or not entirely consistent with prior reporting of those scales. Further measurement limitations spring from two of three subscales for intercultural sensitivity consisting of only two items each, which is less than desirable for scale development. Although the scales have been widely used and provide satisfactory reporting with certain samples, further scale development is needed in the future for these scales. For the intercultural sensitivity scale, the means were high, suggesting that there was not much variance across cultural groupings of Morocco, United States, and other Western and non-Western countries. Some items of the intercultural sensitivity scale may also be prone to social desirability bias. Paulhus (2002) described social desirability as the tendency for respondents to provide answers which are likely to make them perceived favorably by the social 
ideal. Although the survey explicitly informed the participants of its anonymity and confidentiality, further scale development might be warranted when it comes to the wording.

Third, the scenario employed in this study raised issues. Even though most participants said the scenario was familiar and similar to events they experienced in the past. Participants only read a hypothetical scenario and did not experience a real situation of intercultural communication. Plus, participants were not asked to report about a technological organizational change and any prior reactance to that change. Other forms of investigation, such as through ethnographies, might be able to address this limitation. The scenario instrument may not have triggered as much state reactance as predicted for this study. It may be that the language used in the was not enough to trigger reactance, or that employees perceive this scenario of technological organizational change as an impersonal freedom (Brehm \& Brehm, 1981). Particularly because this change is more relevant to the organization, rather than the employee personally (i.e., changing the employees' salaries, the geographic location of work, or replacing some of their daily tasks with robotization). The survey instrument could have collected further information on the respondents' relationship with their manager as well as well-being in the organization. Also, the scenario did not define the culture of the manager, other than stating that they come from another country. This depiction of a generalized cultural other might have represented a limitation which omitted perceptual nuances, potentially influencing reactance levels. Further efforts could also use two scenarios and randomly assigned participants to detect the elements of the scenario which either reduce or induce intercultural state reactance.

Fourth, the survey questions were able to track participants by country. However, countries are not necessarily cultures. Tracking participants by cultural groups may be a better means of distinguishing differences in reactance. Cross-cultural adaptation plays a role in 
detecting intercultural state reactance variation. For instance, foreign workers who already adapted to a certain host culture might not experience reactance differently from those who are from the host culture organization, as less adapted foreign workers might.

Fifth, this research did not gather data from a complementary qualitative approach to further understand the underlying reasons behind respondents' answers. The last two open-ended questions in the survey attempted to further comprehend their perception of travelling and intercultural interaction with individuals from other countries. However, the responses collected were not sufficient to make broader conclusions or connections with previous research results. For future research, it would be insightful to explore the concepts of this study under different methods for a better grasp of the underlying motivations of the respondents, namely through focus groups or ethnographies.

\section{Suggestions for Future Research}

One of the most promising aspects of the current study lies in the attempt to test PRT across cultural groups. However, more scholarly work needs to be conducted in this area. Specifically, seven suggestions for future research emerged from this investigation. First, the previous scales on PRT might not have been developed across diverse samples for a tailored design. Therefore, more scholarship is needed in this area in the future to reach Pepitone and Triandis' (1987) universal psychology, which acknowledges the prominence of distinct ecological factors as varying forces for meaning-making and social behavior across cultures. Results suggesting more variation in state arousal in comparison to state retaliation suggests that future research might explore how these two subscales of intercultural state reactance interact as well as vary across cultures, particularly in comparison to when the intercultural aspect is

omitted. The present study suggests that the intercultural aspect of interaction might act as a 
repressive element for this sample, which was found to be high in intercultural sensitivity. Further research could expand toward various populations as well as explore further crosscultural or intercultural variables, other than the ones in the present research, to Brehm's (1966) PRT.

Second, future scholars need to compare other cultures, not just Morocco and the United States. Previous research using Hofstede's cultural dimensions on these Morocco (Al-Alawi \& Alkhodari, 2016) and the United States (Wu, 2006) suggested that the two have differences; however, there are other comparisons which divulge farther dimensional gaps. Future research considering countries with wider cultural differences might reveal further cross-cultural factors contributing to reactance. It might be noteworthy to consider the impact of globalization and intensified international interaction, influenced by sociopolitical and technological forces, on creating cultural convergence between certain countries (Bergiel, Bergiel, \& Upson, 2012) in relationship to reactance theory.

Third, additional theories, such as adaptation theory, need to be addressed when dealing with measuring reactance in an interculturally diverse environment. The current study attempted to gather data on the participants' living history in terms of what country they were born, country in which they spent most of their life, as well as where they lived while taking the survey. Most of the respondents in this study, particularly those who were of Moroccan origin and who belonged to the category of other Western and non-Western countries, recorded various answers for these questions. However, the design of the present study was not able to establish a relationship between this data and other variables or derive any conclusions from it. Future research might consider the relationship between individuals with various levels of adaptation with reactance, intercultural sensitivity, and tolerance for ambiguity. 
Although the present study alluded to Hofstede's cross-cultural dimensions, the interest was in reviewing uncertainty avoidance, as conceptually related to tolerance for ambiguity (Furnham \& Marks, 2013) and which the present study investigated. Hofstede's uncertainty avoidance has been widely studied cross-culturally; however, tolerance for ambiguity's conceptual relevance to intercultural sensitivity as well as the need to investigate it crossculturally made it more appealing. Future research might consider incorporating Hofstede's six dimensions and their relationship with reactance.

Fourth, researchers need to collect data in multiple ways. Experimental and longitudinal research would enrich our understanding of the quantitative data which this study collected. It would also provide a more controlled testing of the variables as well as a better understanding for the causal process. For instance, the current study could have randomly assigned participants with one of two scenarios; the first mentioning that the manager is from another culture while the other would not include this aspect. Future research can hold a quasi-experiment through focus groups or employees and subjecting them to a freedom threat which would then further investigate it in a social context of interaction. Further qualitative data such as organizational ethnographies and interviews would help with explore the cultural layer of reactance behavior as well as the group members' interpretation of themselves as well as others.

Fifth, COVID-19 lockdown responses in various countries might provide insights for researchers interested in the potential cross-cultural variation in dealing with health-related freedom restrictions. Comprehending COVID-19 perceived threat of freedom might involve a content analysis of mass media as well as social media to discern users' reactions to the phenomenon in terms of whether or not different people perceive it as a freedom restriction or not, as well as the role of technology in health communication and persuasive messages for the 
mobilization of masses. Future studies might also consider the impact of various communication strategies in mitigating or reinforcing reactance responses cross-culturally, as well as how contexts of intercultural communication on COVID-related freedom restrictions interplay.

Sixth, other types of technology implementations might reveal stronger or weaker reactance depending on the perceived threat which these technologies might trigger. For instance, privacy threats are predicted to be elevated with the emerging fifth generation technology for cellular networks (Kaska, Beckvard, \& Minárik, 2019). The cybersecurity debate around this technology has created international tensions between countries. It could be interesting to investigate, from an international and political communication perspective, how these implementations could lead to reactance responses among nation leaders and big corporations, through rhetoric and action.

Finally, future research could investigate how people's view on their own selfdetermination can impact their reactance. For instance, if people believe that they have agency in the world, does that mean they would be more likely to experience reactance? If the core of the cross-cultural variation question resides in the various perceptions of freedom, it could also be revealing to explore how perceptions on large scale freedoms, such as human rights' freedoms, impact perceptions on common daily freedoms.

\section{Conclusion}

The present study emphasized the importance of continuing to test the relationship between PRT and relevant cultural concepts. The constructs of tolerance for ambiguity as well as intercultural emotional sensitivity appear to be promising for the prediction of intercultural state reactance, particularly in situations of organizational technological change. Future research needs to continue testing trait and state reactance, along with other variables to strengthen its prediction 
models. Operationally, investigating PRT through cross-cultural and intercultural lenses can provide promising insights for the further development of measurement instruments and offer practical, applied solutions for organizations and managers to implement.

PRT is a valid theoretical framework but might not be as universal as Brehm (1966) described it. The present study critiques PRT's lack of application across non-Western populations, which could potentially provide wider applicability of its dimensions and scales. This critique of PRT as a theory rooted in Western assumptions suggests that it may be incomplete and monolithic. Subjecting it to further cross-cultural and intercultural testing in technological organizational settings of change would advance it toward universality. 


\section{REFERENCES}

Adler, N. (1981). Re-entry: Managing cross-cultural transitions. Group and Organization Studies, 6(3), 341-356. doi:10.1177/105960118100600310

Adorno T. W., Frenkel-Brunswik E., Levinson D. J., Sanford R. N. (1950). The authoritarian personality. New York, NY: Oxford.

Al-Alawi, A. A., \& Alkhodari, J. H. (2016). Cross-cultural differences in managing businesses: Applying Hofstede cultural analysis in Germany, Canada, South Korea and Morocco. Elixir International Business Management, 95(2016), 40855-40861. Retrieved from: https://www.elixirpublishers.com/

Ali, A. J., \& Wahabi, R. (1995). Managerial value systems in Morocco. International Studies of Management \& Organization, 25(3), 87-96. doi:10.1080/00208825.1995.11656661

Ali Taha, V., Sirkova, M., \& Ferencova, M. (2016). The impact of organizational culture on creativity and innovation. Polish Journal of Management Studies, 14(1), 7-17. doi:10.17512/pjms.2016.14.1.01

Andreoli, V. A., Worchel, S., \& Folger, R. (1974). Implied threat to behavioral freedom. Journal of Personality and Social Psychology, 30(6), 765-771. doi:10.1037/h0037529

Andriukaitienė, R., Cherep, A., Voronkova, V., Punchenko, O., \& Kyvliuk, O. (2019). Managing organizational culture as a factor in organizational change. Humanities Bulletin of Zaporizhzhe State Engineering Academy, 0, 169-179. doi:10.26661/20727941.2018 .155562

Azuma, H. (1984). Psychology in a non-Western country. International Journal of Psychology, 19(1-4), 45-55. doi:10.1080/00207598408247514 
Baldwin, J. R., Faulkner, S. L., Hecht, M. L., \& Lindsley, S. L. (Eds.). (2006). Redefining Culture: Perspectives across the disciplines. Mahwah, NJ: Lawrence Erlbaum Associates.

Baldwin, J. R. (2018). Evolving definitions of culture and intercultural communication for emerging global realities. In W. Jia (Ed.), Intercultural communication: Adapting to emerging global realities: A reader (2nd ed., pp. 27-43). San Diego, CA: Cognella.

Bariff, M. L., \& Lusk, E. J. (1977). Cognitive and personality tests for the design of management information systems. Management Science, 23(8), 820-829. Retrieved from https://pubsonline.informs.org/journal/mnsc

Beamer, L. (1992). Learning intercultural communication competence. The Journal of Business Communication, 29(3), 285-303. doi:10.1177/002194369202900306

Benjamin, A. J., Riggio, R. E., \& Mayes, B. T. (1996). Reliability and factor structure of Budner's tolerance for ambiguity scale. Journal of Social Behavior and Personality, 11(3), 625-632. Retrieved from https://lib.ugent.be/catalog/ejn01:954925552376

Bennett, M. (1986). A developmental approach to training for intercultural sensitivity. International Journal of Intercultural Relations, 10(2), 179-196. doi:10.1016/01471767(86)90005-2

Bennett, R., Aston, A., \& Colquhoun, T. (2000). Cross-cultural training: A critical step in ensuring the success of international assignments. Human Resource Management, 39(23), 239-250. doi:10.1002/1099-050x(200022/23)39:2/3<239::aid-hrm12>3.0.co;2-j

Bensley, L. S., \& Wu, R. (1991). The role of psychological reactance in drinking following alcohol prevention messages. Journal of Applied Social Psychology, 21(13), 1111-1124. doi:10.1111/j.1559-1816.1991.tb00461.x 
Berger, C. R, \& Douglas, W. (1982). Thought and talk: "Excuse me, but have I been talking to myself?” In F. E. X. Dance (Ed.), Human communication theory: Comparative essays (pp. 42-60). New York, NY: Harper \& Row.

Bergiel, E. B., Bergiel, B. J., \& Upson, J. W. (2012). Revisiting Hofstede's dimensions: Examining the cultural convergence of the United States and Japan. American Journal of Management, 12(1), 69-79. Retrieved from: http://www.na-businesspress.com/

Bieri, J. (1971). Cognitive structures in personality. In H. M. Schroder \& P. Suedfeld (Eds.), Personality theory and information processing (pp. 178-208). New York, NY: The Ronald Press.

Bok, D. (2009). The Sage handbook of intercultural competence. Los Angeles, CA: Sage.

Brehm, J. W. (1966). A theory of psychological reactance. New York, NY: Academic Press.

Brehm, J. W., \& Rozen, E. (1971). Attractiveness of old alternatives when a new attractive alternative is introduced. Journal of Personality and Social Psychology, 20(3), 261-266. doi:10.1037/h0031909

Brehm, S. S., \& Brehm, J. W. (1981). Psychological reactance: A theory of freedom and control. New York, NY: Academic Press.

Brislin, R. W. (1981). Cross-cultural encounters: Face-to-face interaction. New York, NY: Pergamon Press.

Budner, S. (1962). Intolerance of ambiguity as a personality variable. Journal of Personality, 30, 29-50. doi:10.1111/j.1467-6494.1962.tb02303.x 
Burgoon, M., Alvaro, E. M., Broneck, K., Miller, C., Grandpre, J. R., Hall, J. R., \& Frank, C. A. (2002). Using interactive media tools to test substance abuse prevention messages. In W. D. Crano \& M. Burgoon (Eds.), Mass media and drug prevention: Classic and contemporary theories and research (pp. 67-87). New Jersey, NY: Lawrence Erlbaum Associates.

Bynum, E. B. (1992). A brief overview of transpersonal psychology. The Humanistic Psychologist, 20(2-3), 301-306. doi:10.1080/08873267.1992.9986797

Carl, J. (2011). Freedom of choice: Vouchers in American education. Santa Barbara, CA: ABCCLIO.

Casmir, F. L. (2013). Ethics in intercultural and international communication. New York, NY: Routledge.

Chen, G. M., \& Starosta, W. J. (1997). Foundations of intercultural communication. Boston, MA: Allyn \& Bacon.

Chen, G. M., \& Starosta, W. J. (2000). The development and validation of the intercultural sensitivity scale. Human Communication, 3, 3-14. Retrieved from https://digitalcommons.uri.edu/com_facpubs

Chen, G. M., \& Starosta, W. J. (2016). Intercultural communication competence: A synthesis. Communication Yearbook, 19(1), 353-383. doi:10.1080/23808985.1996.11678935

Chirkov, V., Ryan, R. M., Kim, Y., \& Kaplan, U. (2003). Differentiating autonomy from individualism and independence: A self-determination theory perspective on internalization of cultural orientations and well-being. Journal of Personality and Social Psychology, 84(1), 97-110. doi:10.1037/0022-3514.84.1.97 
Claudia, M. P. M. (2016). The role of organizational culture in organization management. Annals of' Constantin Brancusi' University of Targu-Jiu. Economy Series, 2, 102-105. Retrieved from https://ideas.repec.org/s/cbu/jrnlec.html

Collier, M. J. (1989). Cultural and intercultural communication competence: Current approaches and directions for future research. International Journal of Intercultural Relations, 13(3), 287-302. doi:10.1016/0147-1767(89)90014-X

Creanza, N., Kolodny, O., \& Feldman, M. W. (2017). Cultural evolutionary theory: How culture evolves and why it matters. Proceedings of the National Academy of Sciences, 114(30), 7782-7789. doi:10.1073/pnas.1620732114

DeBord, J. B. (1989). Paradoxical interventions: A review of the recent literature. Journal of Counseling and Development, 67(7), 394-398. doi:10.1002/j.1556-6676.1989.tb02099.x

Deci, E. L. (1971). Effects of externally mediated rewards on intrinsic motivation. Journal of Personality and Social Psychology, 18(1), 105-115. doi:10.1037/h0030644

Deci, E. L., Koestner, R., \& Ryan, R. M. (1999). A meta-analytic review of experiments examining the effects of extrinsic rewards on intrinsic motivation. Psychological Bulletin, 125(6), 627-668. doi:10.1037/0033-2909.125.6.627

Deci, E. L., \& Ryan, R. M. (2012). Self-determination theory. In P. M. Van Lange, A. W. Kruglanski, \& E. T. Higgins (Eds.), Handbook of theories of social psychology (Vol. 1, pp. 416-437). London, UK: Sage.

Dickson, G. W., \& Simmons, J. K. (1970). The behavioral side of MIS: Some aspects of the “people problem.” Business Horizons, 13(4), 59-71. doi:10.1016/0007-6813(70)90159-x 
Dillard, J. P., \& Shen, L. (2005). On the nature of reactance and its role in persuasive health communication. Communication Monographs, 72(2), 144-168. doi:10.1080/03637750500111815

Dong, Q., Day, K. D., \& Collaço, C. M. (2008). Overcoming ethnocentrism through developing intercultural communication sensitivity and multiculturalism. Human Communication, 11(1), 27-38. doi:10.1.1.494.1553

Dowd, E. T., Milne, C. R., \& Wise, S. L. (1991). The therapeutic reactance scale: A measure of psychological reactance. Journal of Counseling \& Development, 69(6), 541-545. doi:10.1002/j.1556-6676.1991.tb02638.x

Dowd, E. T., \& Wallbrown, F. (1993). Motivational components of client reactance. Journal of Counseling \& Development, 71(5), 533-538. doi:10.1002/j.1556-6676.1993.tb02237.x

Eckrich, D. W., \& McCall, M. (2009). Category width and new household technology adoption: Developments of the measures. Journal of Management and Marketing Research, 2, 110. Retrieved from https://www.aabri.com/jmmr.html

Einhorn, H., \& Hogarth, R. (1986). Decision making under ambiguity. The Journal of Business, 59(4), S225-S250. doi:10.1086/296364

Erceg-Hurn, D. M., \& Steed, L. G. (2011). Does exposure to cigarette health warnings elicit psychological reactance in smokers? Journal of Applied Social Psychology, 41(1), 219237. doi:10.1111/j.1559-1816.2010.00710.x

Errihani, M. (2016). English education policy and practice in Morocco. English language education policy in the Middle East and North Africa. Hammond: IN, Springer.

Eyssel, F., \& Hegel, F. (2012). (S)he's got the look: Gender stereotyping of robots. Journal of Applied Social Psychology, 42(9), 2213-2230. doi:10.1111/j.1559-1816.2012.00937.x 
Fiedler, F., Mitchell, T., \& Triandis, H. (1971). The culture assimilator: An approach to crosscultural training. Journal of Applied Psychology, 55(2), 95-102. doi:10.1037/h0030704

Fisher, G. (1980). International negotiation: A cross-cultural perspective. Yarmouth, ME: Intercultural Press.

Franck, T. (1997). Is personal freedom a Western value? The American Journal of International Law, 91(4), 593-627. doi:10.2307/2998096

Frenkel-Brunswik, E. (1948). Intolerance of ambiguity as an emotional perceptual personality variable. Journal of Personality, 18(1), 108-143. doi:10.1111/j.14676494.1949.tb01236.x

Friedman, M. (2002). Capitalism and freedom. Chicago, IL: The University of Chicago.

Frijns, B., Gilbert, A., Lehnert, T., \& Tourani-Rad, A. (2013). Uncertainty avoidance, risk tolerance and corporate takeover decisions. Journal of Banking \& Finance, 37(7), 24572471. doi:10.1016/j.jbankfin.2013.02.010

Fritz, W., Mollenberg, A., \& Chen, G. M. (2002). Measuring intercultural sensitivity in different cultural context. Intercultural Communication Studies, 11(2), 165-176. Retreived from https://digitalcommons.uri.edu/com_facpubs

Furnham, A., \& Marks, J. (2013). Tolerance of ambiguity: A review of the recent literature. Psychology, 4(9), 717-728. doi:10.4236/psych.2013.49102

Furnham, A., \& Ribchester, T. (1995). Tolerance of ambiguity: A review of the concept, its measurement and applications. Current Psychology, 14(3), 179-199. doi:10.1007/bf02686907

Gardner, G. H. (1962). Cross cultural communication. The Journal of Social Psychology, 58(2), 241-256. doi:10.1080/00224545.1962.9712373 
Gaw, K. F. (2000). Reverse culture shock in students returning from overseas. International Journal of Intercultural Relations, 24(1), 83-104. doi:10.1016/s0147-1767(99)00024-3

Ghazali, A. S., Ham, J., Barakova, E., \& Markopoulos, P. (2018). The influence of social cues in persuasive social robots on psychological reactance and compliance. Computers in Human Behavior, 87, 58-65. doi:10.1016/j.chb.2018.05.016

Gleser, G. C., \& Ihilevich, D. (1969). An objective instrument for measuring defense mechanisms. Journal of Consulting and Clinical Psychology, 33(1), 51-60. doi:10.1037/h0027381

Goldman, M., \& Wallis, D. (1979). Restoring freedom when pressured not to select alternatives. Psychological Reports, 44(2), 563-566. doi:10.2466/pr0.1979.44.2.563

Gudykunst, W. B. (2003). Cross-cultural and intercultural communication. Thousand Oaks, CA: Sage.

Denoeux, P., \& Desfosses, R. (2007). Rethinking the Moroccan parliament: The kingdom's legislative development imperative. The Journal of North African Studies, 12(1), 78-108. doi:10.1080/13629380601099526

Guthrie, G. M., \& Zektick, I. N. (1967). Predicting performance in the Peace Corps. The Journal of Social Psychology, 71(1), 11-21. doi:10.1080/00224545.1967.9919761

Graves, D. (1972). Research: Cultural determinism. Organizational Dynamics, 1(2), 46-59. doi:10.1016/0090-2616(72)90011-3

Hall, E. T. (1959). The silent language. New York, NY: Doubleday.

Hall, E. T., \& Hall, M. R. (1989). Understanding cultural differences. Yarmouth, ME: Intercultural Press. 
Ham, J., Cuijpers, R. H., \& Cabibihan, J.-J. (2015). Combining robotic persuasive strategies: The persuasive power of a storytelling robot that uses gazing and gestures. International Journal of Social Robotics, 7(4), 479-487. doi:10.1007/s12369-015-0280-4

Hass, R. G., \& Linder, D. E. (1972). Counterargument availability and the effects of message structure on persuasion. Journal of Personality and Social Psychology, 23(2), 219-233. doi:10.1037/h0033032

Hedelind, M., \& Jackson, M. (2011). How to improve the use of industrial robots in lean manufacturing systems. Journal of Manufacturing Technology Management, 22(7), 891905. doi:10.1108/17410381111160951

Heilman, M. E., \& Toffler, B. L. (1976). Reacting to reactance: An interpersonal interpretation of the need for freedom. Journal of Experimental Social Psychology, 12(6), 519-529. doi:10.1016/0022-1031(76)90031-7

Heller, J. F., Pallak, M. S., \& Picek, J. M. (1973). The interactive effects of intent and threat on boomerang attitude change. Journal of Personality and Social Psychology, 26(2), 273279. doi:10.1037/h0034461

Henriksen, L., Dauphinee, A. L., Wang, Y., \& Fortmann, S. P. (2006). Industry sponsored antismoking ads and adolescent reactance: Test of a boomerang effect. Tobacco Control, 15(1), 13-18. doi:10.1136/tc.2003.006361

Hmel, B. A., \& Pincus, A. L. (2002). The meaning of autonomy: On and beyond the interpersonal circumplex. Journal of Personality, 70(3), 277-310. doi:10.1111/14676494.05006

Hidass, A. (1993). Freedom and communication in Morocco. Communication, 14(2), 78-99. doi:10.3406/comin.1993.1641 
Hofstede, G. (1997). Cultures and organizations: Software of the mind. New York, NY: McGraw-Hill.

Hofstede, G., Hofstede, G. J., \& Minkov, M. (2010). Cultures and organizations: Software of the mind (Rev. Ed.). New York, NY: McGraw-Hill.

Hong, S.-M. (1992). Hong's psychological reactance scale: A further factor analytic validation. Psychological Reports, 70(2), 512-514. doi:10.2466/pr0.1992.70.2.512

Hong, S.-M., \& Faedda, S. (1996). Refinement of the Hong psychological reactance scale. Educational and Psychological Measurement, 56(1), 173-182. doi:10.1177/0013164496056001014

Hui, C. H., \& Triandis, H. C. (1986). Individualism-collectivism. Journal of Cross-Cultural Psychology, 17(2), 225-248. doi:10.1177/0022002186017002006

Hyland, M., \& Birrell, J. (1979). Government health warnings and the "boomerang" effect. Psychological Reports, 44(2), 643-647. doi:10.2466/pr0.1979.44.2.643

Ilie, V. (2013). Psychological reactance and user workarounds. A study in the context of electronic medical records implementations. Proceedings of the 21st European Conference on Information Systems. Retrieved from https://aisel.aisnet.org/ecis2013_rip/24

Jack, A. A. (2014). Culture shock revisited: The social and cultural contingencies to class marginality. Sociological Forum, 29(2), 453-475. doi:10.1111/socf.12092

Jensen R., \& Bjørn P. (2012). Divergence and convergence in global software development: Cultural complexities as social worlds. In J. Dugdale, C. Masclet, M. Grasso, J. F. Boujut, \& P. Hassanaly (Eds.), From research to practice in the design of cooperative systems: Results and open challenges (pp. 123-136). London, England: Springer. 
Joffe, G. (1988). Morocco: Monarchy, legitimacy and succession. Third World Quarterly, 10(1), 201-228. doi:10.1080/01436598808420052

Jonas, E., Graupmann, V., Kayser, D. N., Zanna, M., Traut-Mattausch, E., \& Frey, D. (2009). Culture, self, and the emergence of reactance: Is there a "universal" freedom? Journal of Experimental Social Psychology, 45, 1068-1080. doi:10.1016/j.jesp.2009.06.005

Jones, R. A., \& Brehm, J. W. (1970). Persuasiveness of one- and two-sided communications as a function of awareness there are two sides. Journal of Experimental Social Psychology, 6(1), 47-56. doi:10.1016/0022-1031(70)90075-2

Kaska, K., Beckvard, H., \& Minárik, T. (2019). Huawei, 5G and China as a security threat. NATO Cooperative Cyber Defence Center of Excellence (pp. 1-26). Retrieved from https://www.ccdcoe.org/

Kim, U., \& Berry, J. W. (1993). Introduction. In U. Kim \& J. W. Berry (Eds.), Indigenous psychologies: Research and experience in cultural context (pp. 1-29). Newbury Park, CA: Sage.

Kim, Y. Y. (1988). Communication and cross-cultural adaptation: An integrative theory. Clevedon, England: Multilingual Matters.

Kim, Y. Y. (2001). Becoming intercultural: An integrative theory of communication and crosscultural adaptation. Thousand Oaks, CA: Sage.

Kitayama, S., Markus, H. R., \& Lieberman, C. (1995). The collective construction of self esteem: Implications for culture, self, and emotion. In J. A. Russell, J.-M. FernandexDols, A. S. R. Manstead, \& J. C. Wellenkamp (Eds.), Everyday conceptions of emotion: An introduction to the psychology, anthropology and linguistics of emotion (pp. 523550). Dordrecht, The Netherlands: Kluwer Academic. 
Kluckhohn, C. (1951). Values and value-orientations in the theory of action: An exploration in definition and classification. Toward a general theory of action. Cambridge, MA: Harvard University Press.

Kluckhohn, C., Kelly, W. H., \& Linton, R. (1945). The science of man in the world crisis. New York, NY: Columbia University Press.

Kluckhohn, F. R., \& Strodtbeck, F. L. (1961). Variations in value orientations. Evanston, IL: Row, Peterson.

Koester, J., \& Lustig, M. W. (2015). Intercultural communication competence: Theory, measurement, and application. International Journal of Intercultural Relations, 48, 2021. doi:10.1016/j.ijintrel.2015.03.006

Kolberg, D., \& Zühlke, D. (2015). Lean automation enabled by industry 4.0 technologies. IFACPapersOnLine, 48(3), 1870-1875. doi:10.1016/j.ifacol.2015.06.359

Krishnan, L., \& Carment, D. W. (1979). Reactions to help: Reciprocity, responsibility and reactance. European Journal of Social Psychology, 9(4), 435-439. doi:10.1002/ejsp.2420090409

Kroeber, A. L., \& Kluckhohn, C. (1952). Culture: A critical review of concepts and definitions. Papers. Cambridge, MA: Peabody Museum of American Archaeology and Ethnology.

Kulkarni, A., Wang, X. C., \& Yuan, H. (2019). Boomerang effect of incentive reminders during shopping trips. Journal of Consumer Marketing, 36(5), 592-599. doi:10.1108/jcm-072018-2783

Lawless, W. F., \& Sofge, D. (2017). Evaluations: Autonomy and artificial intelligence: A threat or savior? In W. F. Lawless, R. Mittu, D. Sofge, \& S. Russell (Eds.), Autonomy and artificial intelligence: A threat or savior? (pp. 295-316). New York, NY: Springer. 
Leander, N. P., vanDellen, M. R., Rachl-Willberger, J., Shah, J. Y., Fitzsimons, G. J., \& Chartrand, T. L. (2016). Is freedom contagious? A self-regulatory model of reactance and sensitivity to deviant peers. Motivation Science, 2(4), 256-267. doi:10.1037/mot0000042

Lewis, R. D. (1999). Cross cultural communication: A visual approach. Southampton, England: Transcreen Publications.

Liu, S., \& Gallois, C. (2014). Integrating intercultural communication and cross-cultural psychology: Theoretical and pedagogical implications. Online Readings in Psychology and Culture, 2(1), 1-20. doi:10.9707/2307-0919.1129

Littler, J. (2013). Meritocracy as plutocracy: The marketising of "Equality" under neoliberalism. New Formations, 80(80), 52-72. doi: 10.3898/newf.80/81.03.2013

Ma, A., Tang, S., \& Kay, A. C. (2019). Psychological reactance as a function of thought versus behavioral control. Journal of Experimental Social Psychology, 84, 103825. doi:10.1016/j.jesp.2019.103825

Machery, E., Mallon, R., Nichols, S., \& Stich, S. P. (2004). Semantics, cross-cultural style. Cognition, 92(3), B1-B12. doi:10.1016/j.cognition.2003.10.003

Maghraoui, A. (2001). Political authority in crisis: Mohammed VI's Morocco. Middle East Report, 218, 12-17. doi:10.2307/1559304

Martin, J. N. (2015). Revisiting intercultural communication competence: Where to go from here. International Journal of Intercultural Relations, 48, 6-8. doi:10.1016/j.ijintrel.2015.03.008

Martin, J. N., \& Nakayama, T. K. (2000). Intercultural communication in contexts. New York, NY: Mayfield. 
McLain, D. L. (2009). Evidence of the properties of an ambiguity tolerance measure: The Multiple Stimulus Types Ambiguity Tolerance Scale II (MSTAT-II). Psychological Reports, 105, 975-988. doi:10.2466/PR0.105.3.975-988

McLain, D. L., Kefallonitis, E., \& Armani, K. (2015). Ambiguity tolerance in organizations: definitional clarification and perspectives on future research. Frontiers in Psychology, 6, 344. doi:10.3389/fpsyg.2015.00344

McLaughlin, B., Schutz, C., \& White, D. (1980). Parental speech to five-year-old children in a game-playing situation. Child Development, 51, 580-582. doi:10.1111/j.14678624.1980.tb02584.x

McSweeney, B. (2002). Hofstede's model of national cultural differences and their consequences: A triumph of faith—a failure of analysis. Human Relations, 55(1), 89118. doi:10.1177/0018726702551004

Merrotsy, P. (2013). Tolerance of ambiguity: A trait of the creative personality? Creativity Research Journal, 25(2), 232-237. doi:10.1080/10400419.2013.783762

Meyers, A. (1983). Slave soldiers and state politics in early 'Alawi Morocco, 1668-1727. The International Journal of African Historical Studies, 16(1), 39-48. doi:10.2307/217910

Miller, C. H., Lane, L. T., Deatrick, L. M., Young, A. M., \& Potts, K. A. (2007). Psychological reactance and promotional health messages: The effects of controlling language, lexical concreteness, and the restoration of freedom. Human Communication Research, 33, 219240. doi:10.1111/j.1468-2958.2007.00297.x

Miron, A. M., \& Brehm, J. W. (2006). Reactance theory-40 years later. Journal of Social Psychology, 37(1), 9-18. doi:10.1024/0044-3514.37.1.9. 
Mohan, K., Xu, P., Cao, L., \& Ramesh, B. (2008). Improving change management in software development: Integrating traceability and software configuration management. Decision Support Systems, 45(4), 922-936. doi:10.1016/j.dss.2008.03.003

Murray, H. A. (1938). Explorations in personality. New York, NY: Oxford University Press. Nesterkin, D. A. (2013). Organizational change and psychological reactance. Journal of Organizational Change Management, 26(3), 573-594. doi:10.1108/09534811311328588

Nezlek, J., \& Brehm, J. W. (1975). Hostility as a function of the opportunity to counteraggress. Journal of Personality, 43(3), 421-433. doi:10.1111/j.1467-6494.1975.tb00714.x

Noort, M. C., Reader, T. W., Shorrock, S., \& Kirwan, B. (2016). The relationship between national culture and safety culture: Implications for international safety culture assessments. Journal of Occupational and Organizational Psychology, 89(3), 515-538. doi:10.1111/joop.12139

Oberg, K. (1960). Culture shock: Adjustment to new cultural environments. Practical Anthropology, 7(4), 177-182. doi:10.1177/009182966000700405

O’Donnell, O., \& Boyle, R. (2008). Understanding and managing organisational culture. Dublin, Ireland: Institute of Public Administration.

Oishi, S. (2000). Goals as cornerstones of subjective well-being. In E. Diener \& E. M. Suh (Eds.), Culture and subjective well-being (pp. 87-112). Cambridge, MA: MIT Press.

Olchi, W. G. (1978). The transmission of control through organizational hierarchy. Academy of Management Journal, 21(2), 173-192. doi:10.5465/255753

Parks, M. R. (1994). Communicative competence and interpersonal control. In M. L. Knapp \& G. R. Miller (Eds.), Handbook of interpersonal communication (2 ${ }^{\text {nd }}$ ed., pp. 589-618). Thousand Oaks, CA: Sage. 
Paulhus, D. L. (2002). Socially desirable responding: The evolution of a construct. In H. I. Braun, D. N. Jackson, \& D. E. Wiley (Eds.), The role of constructs in psychological and educational measurement (pp. 49-69). Mahwah, NJ: Lawrence.

Patel, F., Li, M., \& Sooknanan, P. (2011). Intercultural communication: Building a global community. Los Angeles, CA: Sage.

Pavey, L. \& Sparks, P. (2009). Reactance, autonomy and paths to persuasion: Examining perceptions of threats to freedom and informational value. Motivation and Emotion, 33(3), 277-290. doi:10.1007/s11031-009-9137-1

Pennel, C. R. (2009). Morocco: From empire to independence. London, UK: One World.

Pepitone, A., \& Triandis, H. C. (1987). On the universality of social psychological theories. Journal of Cross-Cultural Psychology, 18(4), 471-498. doi:10.1177/0022002187018004003

Perry, T. S. (1995). How small firms innovate: Designing a culture for creativity. ResearchTechnology Management, 38(2), 14-17. doi:10.1080/08956308.1995.11671678

Pettigrew, T. F. (1958). The measurement and correlates of category width as a cognitive variable. Journal of Personality, 26(4), 532-544. doi:10.1111/j.14676494.1958.tb02350.x

Poli, R., Valeriani D., \& Cinel, C. (2014). Collaborative brain-computer interface for aiding decision-making. Plos One, 9(7), e102693-e102693. doi:10.1371/journal.pone.0102693

Quick, B. L. (2013). Perceived message sensation value and psychological reactance: A test of the dominant thought disruption hypothesis. Journal of Health Communication, 18(9), 1024-1038. doi:10.1080/10810730.2013.768728 
Quick, B. L., \& Stephenson, M. T. (2007). The reactance restoration scale (RSS): A measure of direct and indirect restoration. Communication Research Reports, 24, 131-138. doi:10.1080/08824090701304840

Quick, B. L., \& Stephenson, M. T. (2008). Examining the role of trait reactance and sensation seeking on perceived threat, state reactance, and reactance restoration. Human Communication Research, 34(3), 448-476. doi:10.1111/j.1468-2958.2008.00328.x

Rains, S. A., \& Turner, M. M. (2007). Psychological reactance and persuasive health communication: A test and extension of the intertwined model. Human Communication Research, 33(2), 241-269. doi:10.1111/j.1468-2958.2007.00298.x

Rhodewalt, F., \& Marcroft, M. (1988). Type A behavior and diabetic control: Implications of psychological reactance for health outcomes. Journal of Applied Social Psychology, 18(2), 139-159. doi:10.1111/j.1559-1816.1988.tb00011.x

Rohrbaugh, M., Tennen, H., Press, S., \& White, L. (1981). Compliance, defiance, and therapeutic paradox: Guidelines for strategic use of paradoxical interventions. American Journal of Orthopsychiatry, 51(3), 454-467. doi:10.1111/j.1939-0025.1981.tb01393.x

Rokeach, M. (1960). The open and closed mind: Investigations into the nature of belief systems and personality systems. Oxford, England: Basic Books.

Rosenberg, B. D., \& Siegel, J. T. (2018). A 50-year review of psychological reactance theory: Do not read this article. Motivation Science, 4, 281-300. doi:10.1037/mot0000091

Rosette, A. S., Brett, J. M., Barsness, Z., \& Lytle, A. L. (2012). When cultures clash electronically: The impact of email and social norms on negotiation behavior and outcomes. Journal of Cross-Cultural Psychology, 43, 628-643.

doi:10.1177/0022022111407190 
Ruben, B. D., \& Kealey, D. J. (1979). Behavioral assessment of communication competency and the prediction of cross-cultural adaptation. International Journal of Intercultural Relations, 3(1), 15-47. doi:10.1016/0147-1767(79)90045-2

Ruben, B. D. (1989). The study of cross-cultural competence: Traditions and contemporary issues. International Journal of Intercultural Relations, 13(3), 229-240. doi:10.1016/0147-1767(89)90011-4

Rudy, D., Sheldon, K. M., Awong, T., \& Tan, H. H. (2007). Autonomy, culture, and well-being: The benefits of inclusive autonomy. Journal of Research in Personality, 41(5), 9831007. doi:10.1016/j.jrp.2006.11.004

Sarkissian, H., Chatterjee, A., De Brigard, F., Knobe, J., Nichols, S., \& Sirker, S. (2010). Is belief in free will a cultural universal? Mind \& Language, 25(3), 346-358. doi:10.1111/j.1468-0017.2010.01393.x

Scherr, S., \& Müller, P. (2017). How perceived persuasive intent and reactance contribute to third-person perceptions: Evidence from two experiments. Mass Communication \& Society, 20(3), 315-335. doi:10.1080/15205436.2016.1250911

Schuck, S., Aubusson, P., Buchanan, J., \& Russell, T. (2012). Beginning teaching: Stories from the classroom. New York, NY: Springer Netherlands.

Schroder, H. M. (1971). Conceptual complexity and personality organization. New York, NY: Ronald Press.

Sittenthaler, S., \& Jonas, E. (2012). "No Ivan, it's not your turn!" Cultural differences experiencing (vicarious) reactance. Psychology in Austria, 32(1), 64-72. Retrieved from: https://www.psychologie-studieren.de 
Sittenthaler, S., Traut-Mattausch, E., Steindl, C., \& Jonas, E. (2015). Salzburger state reactance scale (SSR scale): Validation of a scale measuring state reactance. Journal of Psychology. 223(4), 257-266. doi:10.1027/2151-2604/a000227

Sittenthaler, S., Jonas, E., \& Traut-Mattausch, E. (2016). Explaining self and vicarious reactance: A process model approach. Personality and Social Psychology Bulletin, 42(4), 458-470. doi:10.1177/0146167216634055

Shen, L., \& Dillard, J. P. (2005). Psychometric properties of the Hong psychological reactance scale. Journal of Personality Assessment, 85(1), 74-81. doi:10.1207/s15327752jpa8501_07

Shoham, V., Trost, S. E., \& Rohrbaugh, M. J. (2004). From state to trait and back again: Reactance theory goes clinical. In R. A. Wright, J. Greenberg, \& S. S. Brehm (Eds.), Motivational analyses of social behavior: Building on Jack Brehm's contributions to psychology (pp. 167-185). Mahwah, NJ: Lawrence Erlbaum Associates.

Smith, H. (1966). Sensitivity to people. New York, NY: McGraw-Hill.

Spitzberg, B. H., \& Cupach, W. R. (1984). Interpersonal communication competence. Beverly Hills, CA: Sage.

Spitzberg, B. H. (2015). A model of intercultural communication competence. In L. A. Samovar, R. E. Porter, E. R. McDaniel, \& C. S. Roy (Eds.), Intercultural communication: A reader (14 ${ }^{\text {th }}$ ed., pp. 343-354). Boston, MA: Cengage.

Spitzberg, B. H., \& Changnon, G. (2009). Conceptualizing intercultural competence. In D. K. Deardorff (Ed.), The Sage handbook of intercultural competence (pp. 2-52). Thousand Oaks, CA: Sage. 
Steindl, C., \& Jonas, E. (2012). What reasons might the other one have? Perspective taking to reduce psychological reactance in individualists and collectivists. Psychology, 3(12), 1153-1160. doi:10.4236/psych.2012.312a170

Taylor, J. A. (1953). A personality scale of manifest anxiety. The Journal of Abnormal and Social Psychology, 48, 285-290. doi:10.1037/h0056264

Tegano, D. W. (1990). Relationship of tolerance of ambiguity and playfulness to creativity. Psychological Reports, 66(3), 1047-1056. doi:10.2466/pr0.1990.66.3.1047

Ting-Toomey, S. (1994). The challenge of facework: Cross-cultural and interpersonal issues. New York, NY: State University of New York Press.

Topçu, U. C., \& Eroğlu, U. (2017). A review on intercultural communication competence for business research. International Business Management, 113 (2017), 49323-49327. Retrieved from https://www.elixirpublishers.com/

Triandis, H. C. (1995). Individualism and collectivism. Boulder, CO: Westview Press.

Triandis, H. C. (1996). The psychological measurement of cultural syndromes. American Psychologist, 51(4), 407-415. doi:10.1037/0003-066X.51.4.407

Tylor, E. B. (1871). Primitive culture: Researches into the development of mythology, philosophy, religion, art, and custom. London, UK: Murray.

Ueno, T., \& Ogawa, K. (1983). The effects of threats to attitudinal freedom and the expression of opinion on resistance to persuasion: Reactance effects in the repeated persuasion situations. Japanese Journal of Psychology, 54(5), 300-306. doi:10.4992/jjpsy.54.300

Useem, J., Useem, R., \& Donoghue, J. (1963). Men in the middle of the third culture: The roles of American and non-Western people in cross-cultural administration. Human Organization, 22(3), 169-179. doi:10.17730/humo.22.3.5470n44338kk6733 
Weick, K. E., Sutcliffe, K. M., \& Obstfeld, D. (2005). Organizing and the process of sensemaking. Organization Science, 16(4), 409-421. doi:10.1287/orsc.1050.0133

Weinberg, J. M., Nichols, S., \& Stich, S. (2001). Normativity and epistemic intuitions. Philosophical Topics, 29(1/2), 429-460. doi:10.5840/philtopics2001291/217

Wendlandt, M., \& Schrader, U. (2007). Consumer reactance against loyalty programs. Journal of Consumer Marketing, 24(5), 293-304. doi:10.1108/07363760710773111

Wichmann, S. S. (2011). Self-determination theory: The importance of autonomy to well-being across cultures. The Journal of Humanistic Counseling, 50(1), 16-26. doi:10.1002/j.2161-1939.2011.tb00103.x

Wicklund, R. A., \& Brehm, J. W. (1968). Attitude change as a function of felt competence and threat to attitudinal freedom. Journal of Experimental Social Psychology, 4(1), 64-75. doi:10.1016/0022-1031(68)90050-4

Wicklund, R. A. (1974). Freedom and reactance. New York, NY: John Wiley \& Sons.

Wiseman, R. L. (2002). Intercultural communication competence. In W. B. Gudykunst \& B. Mody (Eds.), Handbook of international and intercultural communication $\left(2^{\text {nd }}\right.$ ed., pp. 207-224). Thousand Oaks, CA: Sage.

Wortman, C. B., \& Brehm, J. W. (1975). Responses to uncontrollable outcomes: An integration of reactance theory and the learned helplessness model. Advances in Experimental Social Psychology, 8, 277-336. doi:10.1016/s0065-2601(08)60253-1

Wright, R. A., Agtarap, S. D., \& Mlynski, C. (2015). Conversion of reactance motives into effortful goal pursuit: Implications of Brehm's theory of motivation intensity. Journal of Psychology, 223(4), 267-276. doi:10.1027/2151-2604/a000228 
Wu, M. (2006). Hofstede's cultural dimensions 30 years later: A study of Taiwan and the United States. Intercultural Communication Studies, 15(1), 33-42. Retrieved from https://www.kent.edu/stark/iaics-journals

$\mathrm{Xu}, \mathrm{J}$. (2019). The impact of self-construal and message frame valence on reactance: A crosscultural study in charity advertising. International Journal of Advertising, 38(3), 405427. doi:10.1080/02650487.2018.1536506

Yost, A. B., \& Finney, S. J. (2017). Assessing the unidimensionality of trait reactance using a multifaceted model assessment approach. Journal of Personality Assessment, 100(2), 186-196. doi:10.1080/00223891.2017.1280044

Zakarevičius, P., Kvedaravičius, J., \& Augustauskas, T. (2004). Organizational development paradigm. Retrieved from https://hdl.handle.net/20.500.12259/41001

Zawadzki, M. J., Danube, C. L., \& Shields, S. A. (2012). How to talk about gender inequity in the workplace: Using WAGES as an experiential learning tool to reduce reactance and promote self-efficacy. Sex Roles, 67(11-12), 605-616. doi:10.1007/s11199-012-0181-z Zimmerman, A., Holman, D., \& Sparrow, P. (2003). Unraveling adjustment mechanisms: Adjustment of German expatriates to intercultural interactions, work, and living conditions in the People's Republic of China. International Journal of Cross Cultural Management, 3(1), 45-66. doi:10.1177/1470595803003001849 


\section{APPENDIX: SURVEY INSTRUMENT}

\section{Demographic Items}

Directions: Your answers to these questions will help me better understand the opinions you expressed in other sections of this survey and to compare your responses to other groups of participants. Please be assured that your responses will remain anonymous since no information is being collected that can be traced back to particular individuals.

1. What is your age? (number slider)

2. What is your gender? (Male, Female, Other, prefer not to disclose)

3. What is your country of origin? (text box)

4. What country have you spent most of your life in? (text box)

5. What country do you live in currently? (text box)

6. What is your ethnicity? [If not from U.S., please skip this question]

\begin{tabular}{|l|l|l|}
\hline $\begin{array}{l}\text { American Indian or Alaska } \\
\text { Native }\end{array}$ & Asian & Black/African American \\
\hline Hispanic or Latino/Latino & $\begin{array}{l}\text { Native Hawaiian or Other } \\
\text { Pacific Islander }\end{array}$ & White/Caucasian \\
\hline Biracial/Mixed & Other: & \\
\hline
\end{tabular}

7. What is the highest level of education you completed?

\begin{tabular}{|l|l|}
\hline No schooling beyond $8^{\text {th }}$ grade & $\begin{array}{l}\text { High school graduate, diploma or the } \\
\text { equivalent (for example: GED) }\end{array}$ \\
\hline Associate degree & Bachelor's degree \\
\hline Master's degree & Doctorate degree \\
\hline & Other \\
\hline
\end{tabular}

Directions: The following questions all deal with the organization that you work for currently (or that you worked for in the past). Please respond to these questions keeping that same organization in mind.

8. How frequently do you have, or have you had, intercultural interactions at your place of work? (In this context, frequent intercultural interaction within the workplace would be daily or weekly task-oriented communication between individuals from different cultural backgrounds, specifically in terms of country of belonging)

\begin{tabular}{|l|l|l|l|l|}
\hline Never & Rarely & Occasionally & Often & Very Often \\
\hline 1 & 2 & 3 & 4 & 5 \\
\hline
\end{tabular}


9. Which of the following most closely approximates the number of employees within this same organization?

\begin{tabular}{|l|l|l|l|}
\hline $3-25$ & $26-50$ & $51-100$ & $101-250$ \\
\hline $251-500$ & $501-1,000$ & $1,001-10,000$ & Over 10,000 \\
\hline
\end{tabular}

10. Which of the following best describe your time with this same organization?

\begin{tabular}{|l|l|l|l|}
\hline Less than a month & 1 month -3 months & 3 months -6 months & $\begin{array}{l}6 \text { months }-12 \\
\text { months }\end{array}$ \\
\hline $\begin{array}{l}24 \text { months }-60 \\
\text { months (5 years } \\
\text { approximately) }\end{array}$ & $\begin{array}{l}60 \text { months }-120 \\
\text { months }(10 \text { years })\end{array}$ & $\begin{array}{l}120 \text { months }-240 \\
\text { months }(20 \text { years })\end{array}$ & Over 20 years \\
\hline
\end{tabular}

11. Which of the following best describe your position with this same organization?

\begin{tabular}{|l|l|l|l|}
\hline Staff & Employee & Manager/Supervisor & Executive \\
\hline
\end{tabular}

12. In this organization, do you work: (Check all that apply)

\begin{tabular}{|l|l|l|l|}
\hline Full-time & As a freelancer & $\begin{array}{l}\text { Trough a contract of } \\
\text { indefinite duration }\end{array}$ & $\begin{array}{l}\text { Long-term } \\
\text { contract (More } \\
\text { than five years) }\end{array}$ \\
\hline Part time & As self-employed & $\begin{array}{l}\text { Through a temporary } \\
\text { contract (Less than five } \\
\text { years) }\end{array}$ & \\
\hline
\end{tabular}

\section{Tolerance for Ambiguity Scale}

Directions: Please indicate the extent to which you agree or disagree with the following statements. There are no right or wrong answers; simply record your first impression by clicking the applicable response. [This scale uses McLain's (2009) Multiple Stimulus Types Ambiguity Tolerance - II scale on Tolerance of Ambiguity.]

\begin{tabular}{|l|l|l|l|l|}
\hline Strongly Disagree & Disagree & Neutral & Agree & Strongly Agree \\
\hline 1 & 2 & 3 & 4 & 5 \\
\hline
\end{tabular}

13. I don't tolerate ambiguous situations well.

14. I would rather avoid solving a problem that must be viewed from several different perspectives.

15. I prefer familiar situations to new ones.

16. Problems that cannot be considered from just one point of view are a little threatening.

17. I avoid situations that are too complicated for me to easily understand.

18. I am tolerant of ambiguous situations.

19. I enjoy tackling problems that are complex enough to be ambiguous.

20. I try to avoid problems that seem to have more than a single "best" answer.

21. I generally prefer novelty over familiarity. 
22. I dislike ambiguous situations.

23. I find it hard to make a choice when the outcome is uncertain.

24. I prefer a situation in which there is some ambiguity

\section{Trait Reactance Scale}

Directions: Please indicate the extent to which you agree or disagree with the following statements. [This scale applies Hong's and Faedda (1996) conceptualization of trait reactance.]

\begin{tabular}{|l|l|l|l|l|}
\hline Strongly Disagree & Disagree & Neutral & Agree & Strongly Agree \\
\hline 1 & 2 & 3 & 4 & 5 \\
\hline
\end{tabular}

25. Regulations trigger a sense of resistance in me.

26. I find contradicting others stimulating.

27. When something is prohibited, I usually think, "This is exactly what I'm going to do."

28. I become frustrated when I am unable to make free and independent decisions.

29. It irritates me when someone points out things which are obvious to me.

30. I become angry when my freedom of choice is restricted.

31. When I sense that someone is trying to influence me, I resist.

32. It makes me angry when another person is held up as a role model for me to follow.

33. When someone forces me to do something, I feel like doing the opposite.

34. I consider advice from others to be an intrusion.

35. Advice and recommendations usually induce me to do just the opposite.

\section{Intercultural Sensitivity Scale}

Directions: Please indicate the extent to which you agree or disagree with the following statements. [Taken from Fritz et al. (2002) intercultural sensitivity scale, reviewing Chen and Starosta's (2000) scale.]

\begin{tabular}{|l|l|l|l|l|}
\hline Strongly Disagree & Disagree & Neutral & Agree & Strongly Agree \\
\hline 1 & 2 & 3 & 4 & 5 \\
\hline
\end{tabular}

36. I am open-minded to people from different cultures

37. I often show my culturally-distinct counterpart my understanding through verbal or nonverbal cues

38. I have a feeling of enjoyment towards differences between my culturally-distinct counterpart and me

39. I enjoy interacting with people from different cultures

40. I avoid those situations where I will have to deal with culturally-distinct persons

41. I tend to wait before forming an impression of culturally-distinct counterparts

42. I don't like to be with people from different cultures

43. I think my culture is better than other cultures

44. I think people from other cultures are narrow-minded

45. I respect the values of people from different cultures

46. I respect the ways people from different cultures behave

47. I would not accept the opinions of people from different cultures

48. I am pretty sure of myself in interacting with people from different cultures

49. I find it very hard to talk in front of people from different cultures

50. I always know what to say when interacting with people from different cultures 
51. I can be as sociable as I want to be when interacting with people from different cultures 52. I get upset easily when interacting with people from different cultures

53. I often get discouraged when I am with people from different cultures

54. I often feel useless when interacting with people from different cultures

55. I try to obtain as much information as I can when interacting with people from different cultures

56. I am sensitive to my culturally-distinct counterpart's subtle meanings during our interaction 57. I am very observant when interacting with people from different cultures

\section{Scenario}

Directions: Please read the following scenario carefully. You will be asked to respond to subsequent questions keeping this scenario in mind.

Imagine that you are an employee at an organization, in which your manager comes from a different culture and who is not from the United States. You go to work at 8 a.m. and intend to start your routinely tasks. After five minutes of being in your office, you are about to log into your computer, and you receive a phone call from your boss.

You pick up the phone and your boss says to you:

"Good morning, Information Technology (IT) people came in and installed a new software last night. This means that the software you like and you are currently using for your daily tasks can no longer be used. The new software will impact everybody's daily tasks in the organization. I don't have more information now. You must attend a training session soon. I will send out an invite for everyone when I get the chance to."

\section{State Reactance Scale}

Directions: Describe how you would feel after this hypothetical situation according to the following scale. There are no right or wrong answers; simply record your first impression by clicking the applicable response. [Experience of Reactance subscale from the SSR Scale (Sittenthaler, Traut-Mattausch, Steindl, Jonas, 2015)].

\begin{tabular}{|l|l|l|l|l|}
\hline Not at all & Not much & Neutral & Somewhat & Very much \\
\hline 1 & 2 & 3 & 4 & 5 \\
\hline
\end{tabular}

58. To what extent would you perceive the manager's call as a restriction of freedom? (freedom)

59. Would you be frustrated about your boss's approach? (frustrated)

60. How much does his approach annoy you? (annoyed)

61. To what extent would you be offended/disturbed by this approach? (disturbed)

62. Would you think that this boss could have prejudices against foreigners? (prejudices)

63. Would you think that the boss also shows discriminatory behavior in other areas? (discriminate)

64. How likely would you think it is that this man takes advantage of other people? (advantages)

65 . Would you like to ruin his reputation by spreading negative word of mouth about this boss through an online review? (Internet) 
66. How strong would your wish to complain about his reaction to Human Resources (HR)? (complain)

67. How much would you advise other employees against this boss? (advise against)

\section{Final Questions}

Finally, please answer the following questions...

68. How many times have you ever encountered a scenario similar to the one you read in this survey? (number slider from 0 to 100 )

69. Please briefly describe any experiences you have had travelling or living abroad. (text box)

70. Please briefly describe any work experiences you have had with colleagues from countries or cultures other than your own. (text box) 